\title{
WestVirginiaUniversity
}

THE RESEARCH REPOSITORY @ WVU

Graduate Theses, Dissertations, and Problem Reports

2018

\section{Respiratory Flow Characterization of Workers in Healthcare Environment}

Jintuo Zhu

Follow this and additional works at: https://researchrepository.wvu.edu/etd

\section{Recommended Citation}

Zhu, Jintuo, "Respiratory Flow Characterization of Workers in Healthcare Environment" (2018). Graduate Theses, Dissertations, and Problem Reports. 7287.

https://researchrepository.wvu.edu/etd/7287

This Dissertation is protected by copyright and/or related rights. It has been brought to you by the The Research Repository @ WVU with permission from the rights-holder(s). You are free to use this Dissertation in any way that is permitted by the copyright and related rights legislation that applies to your use. For other uses you must obtain permission from the rights-holder(s) directly, unless additional rights are indicated by a Creative Commons license in the record and/ or on the work itself. This Dissertation has been accepted for inclusion in WVU Graduate Theses, Dissertations, and Problem Reports collection by an authorized administrator of The Research Repository @ WVU.

For more information, please contact researchrepository@mail.wvu.edu. 


\title{
Respiratory Flow Characterization of Workers in Healthcare Environment
}

\author{
Jintuo Zhu \\ Dissertation submitted to the \\ Statler College of Engineering and Mineral Resources \\ at West Virginia University \\ in partial fulfillment of the requirements for the degree of \\ Doctor of Philosophy in \\ Industrial Engineering
}

Committee Members:

Xinjian He, Ph.D., Chair

Steve Guffey, Ph.D.

Ashish Nimbarte, Ph.D.

Feng Yang, Ph.D.

Ziqing Zhuang, Ph.D.

Department of Industrial and Management Systems Engineering

Morgantown, West Virginia

2018

Keywords: healthcare workers, respiratory flow, powered air-purifying respirators, minimum operational airflow, minute volume, peak inhalation flow

\section{Copyright 2018 Jintuo Zhu}




\section{ABSTRACT \\ Respiratory Flow Characterization of Workers in Healthcare Environment \\ Jintuo Zhu}

Powered air-purifying respirators (PAPRs) are preferred personal protective equipment for healthcare workers (HCWs) when there is an outbreak of highly contagious pathogens (e.g., SARS, H1N1, Ebola, etc.). Current minimum operational flow rates for National Institute for Occupational Safety and Health (NIOSH)-approved PAPRs were mainly obtained in industrial settings 50 years ago, and by today's standards is obsolete. Currently, no national or international standards are available regarding the minimum operational flow for PAPRs used by HCWs. The objective of this research was to investigate the breathing characteristics of HCWs utilizing an innovative wearable breathing recording device, and to determine the minimum operational flow for using loose-fitting PAPRs in healthcare environment.

Firstly, the performance of two portable breathing recording devices from manufactures "A" and "B" was assessed using 15 human subjects while performing a series of simulated healthcare work activities. The results suggest that both manufacturers' devices are suitable for characterizing breathing flows for HCWs. However, the device from Manufacturer A produced less variability.

Then, a laboratory experiment was set up to test the accuracy and compatibility of the devices "A" and "B". The device " $A$ " was identified with high accuracy and better compatibility, thus was chosen for the following field study of respiratory flow characterization of workers in a real healthcare environment.

Finally, the device " $\mathrm{A}$ " was worn by nine HCWs in a hospital to investigate their respiratory flow when performing the "isolation unit work" (a more physical demanding work exposed to possible contiguous diseases). The final conclusion was that NIOSH may consider lowering the $170 \mathrm{~L} / \mathrm{min}$ minimum operational flow for loose-fitting PAPRs used in healthcare environment when updating the future PAPR standards. 


\section{Table of Contents}

Table of Contents .....................................................................................................iii

Acknowledgements ....................................................................................................... vii

List of Peer-reviewed Publications.................................................................... ix

List of Conference Posters ..................................................................................... $\mathrm{x}$

List of Figures................................................................................................................ $\mathrm{xi}$

List of Tables .......................................................................................................... xii

INTRODUCTION ...................................................................................................... 1

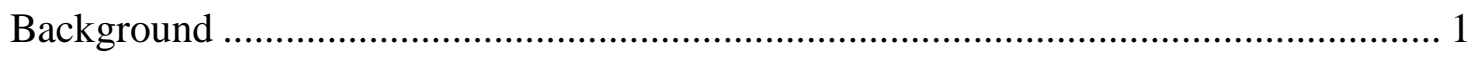

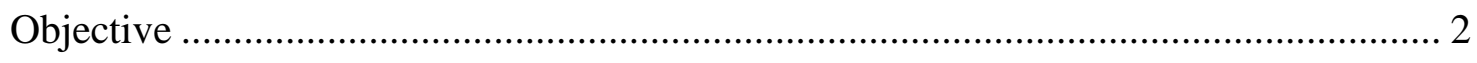

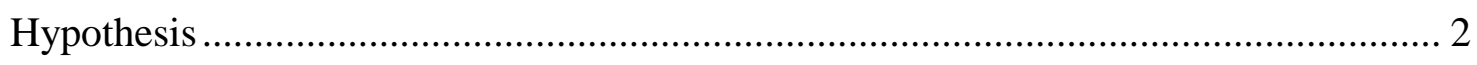

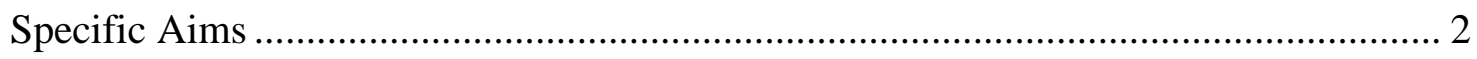

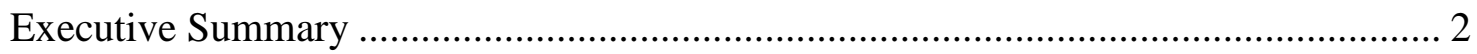

\section{CHAPTER 1}

Assessment of Two Personal Breathing Recording Devices in a Simulated Healthcare Environment (Specific Aim 1) .................................. 7

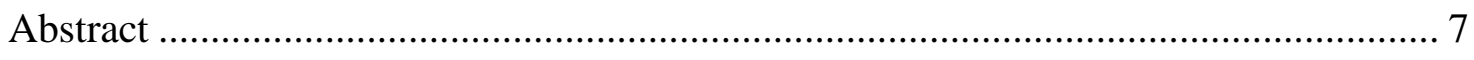

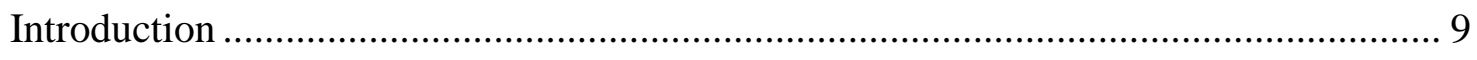

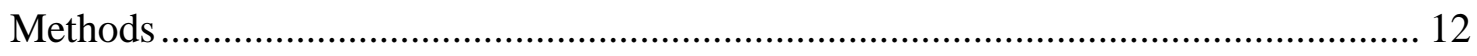

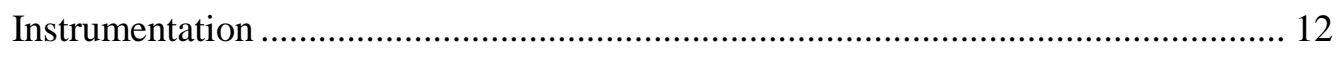

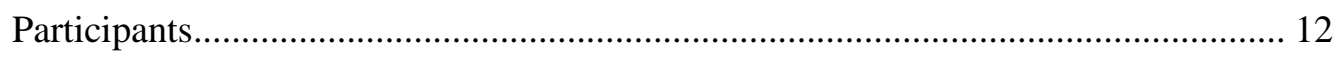

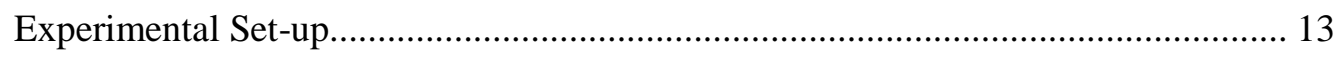

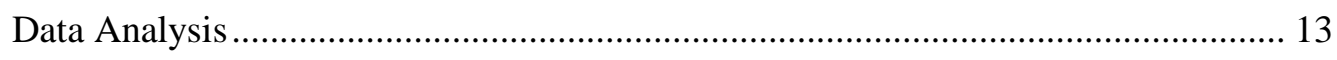

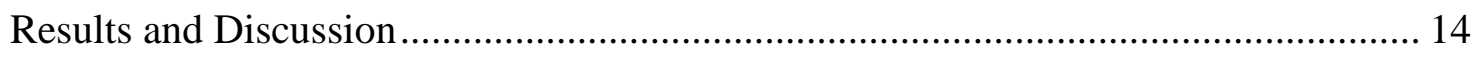

Performance Evaluation of Device A ………………………………………….... 14 


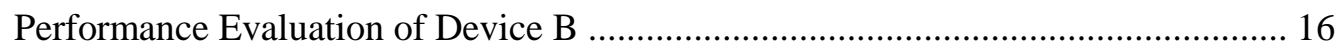

Performance Comparison of Devices A and B ....................................................... 19

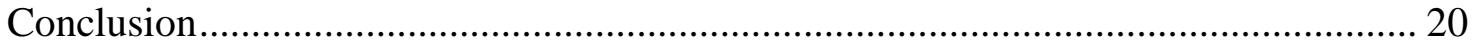

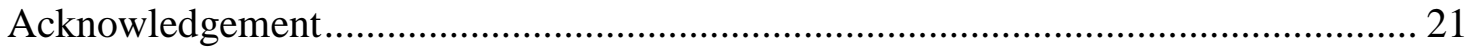

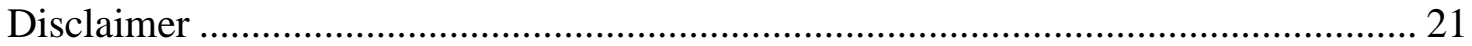

\section{CHAPTER 2}

\section{Exploring Two Novel Personal Respiratory Flow Recording Systems for Utilization in Respiratory Protection Studies (Specific Aim 2) ............... 22}

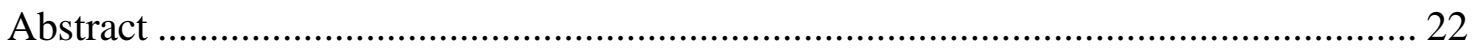

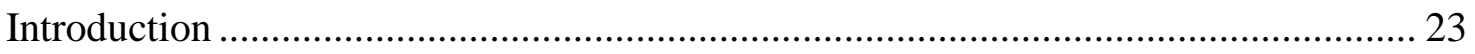

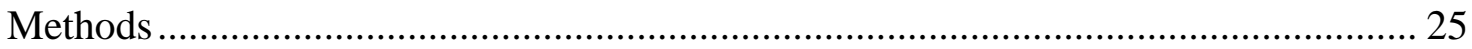

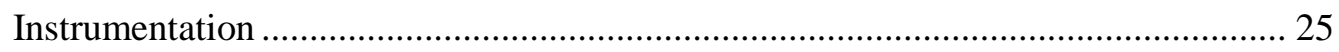

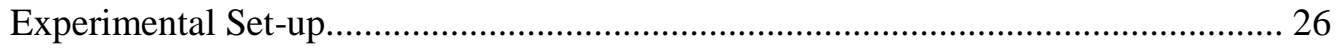

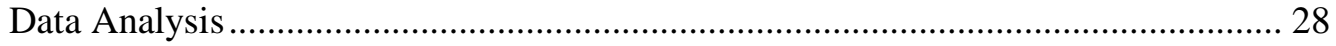

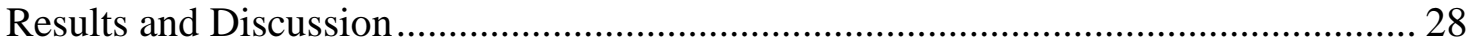

Accuracy of Respiratory Flow Recording System A ….......................................... 28

Accuracy of Respiratory Flow Recording System B …............................................. 30

Compatibility of Respiratory Flow Recording System A ......................................... 30

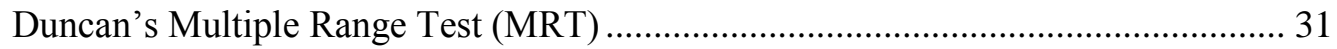

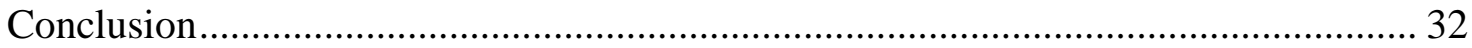

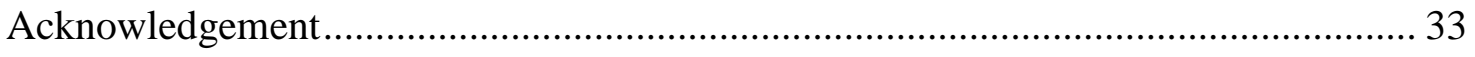

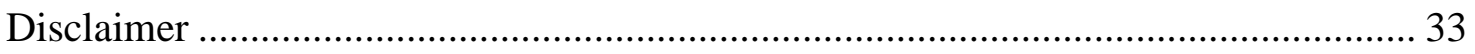

\section{CHAPTER 3}

\section{A Hospital Study of Respiratory Flow Characteristics of Healthcare Workers Using a Portable Flow Recording Device (Specific Aim 3)..... 34}

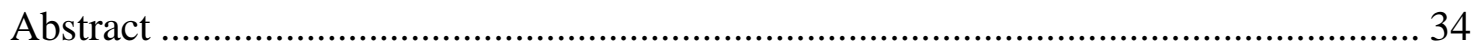

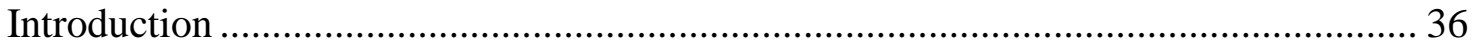




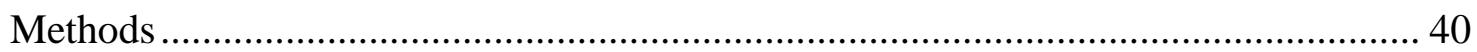

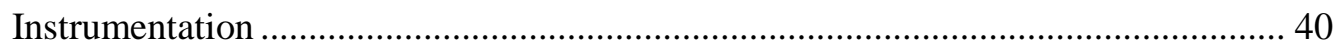

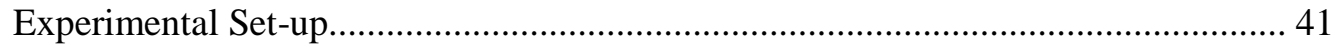

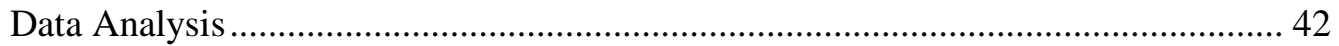

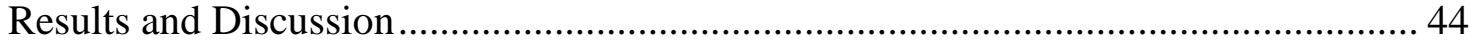

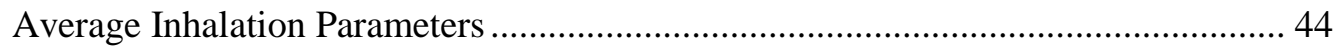

Per Minute Inhalation Parameters ................................................................................ 49

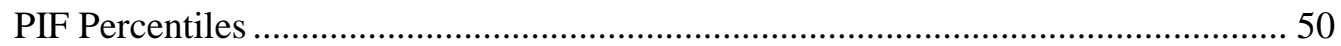

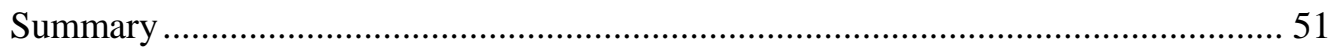

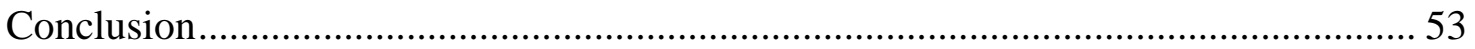

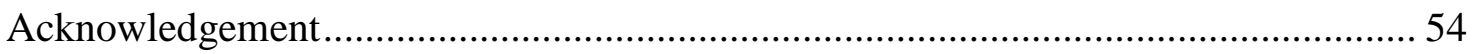

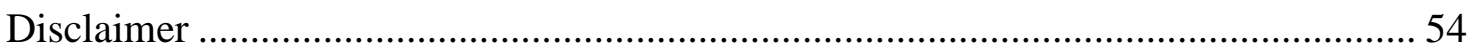

\section{CHAPTER 4}

A Preliminary Investigation on the Feasibility of Developing "low-flow" Loose-fitting Powered Air-purifying Respirators for Healthcare Workers (Specific Aim 4) ....................................................................................... 55

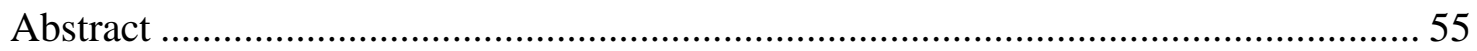

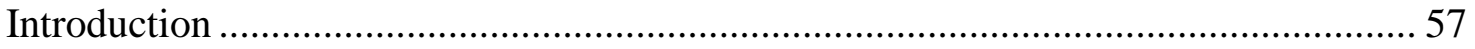

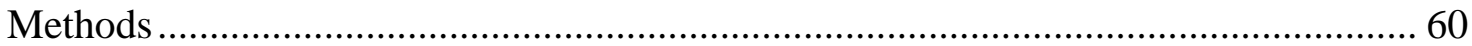

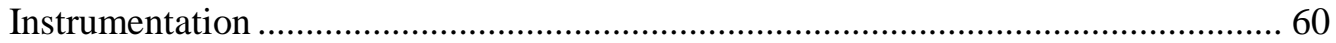

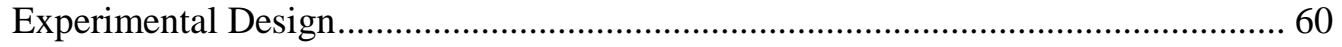

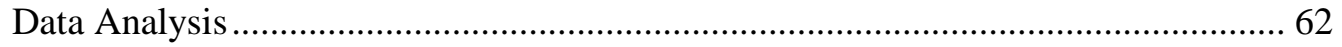

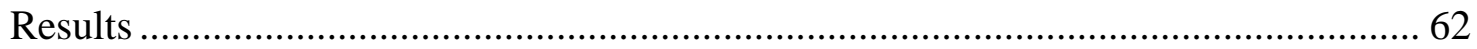

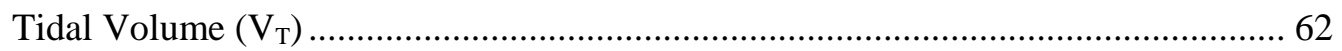

Percentages of Overflow Volume $\left(\mathrm{V}_{\text {over }} \%\right)$ and Time $\left(\mathrm{T}_{\text {over }} \%\right)$................................ 63

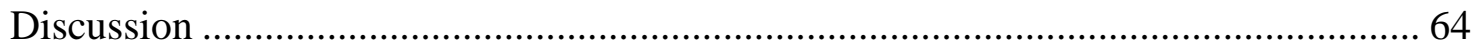

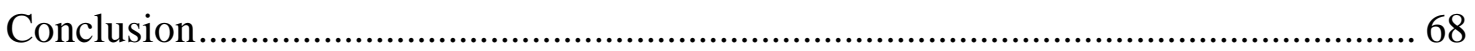

Overall Conclusions and Future Directions ..................................................... 70 
Overall Conclusions ....................................................................................... 70

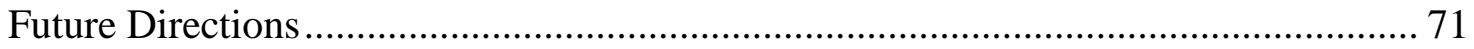

REFERENCES.................................................................................. 73

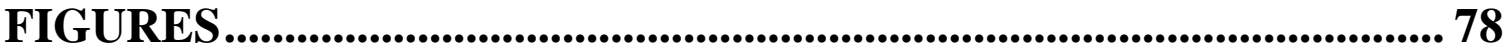

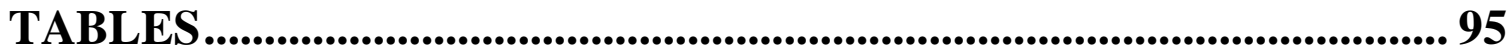




\section{Acknowledgements}

Foremost, I would like to express my deepest enthusiastic appreciation to my advisor Dr. Xinjian (Kevin) He. Without the support from him, I would not have the opportunity to persue my Ph.D. degree in the United States. I thank Dr. He wholeheartedly, not only for his tremendous and continuous academic support, but also for his patience, motivation, and immense knowledge. Dr. He has shown me, by his example, what a good scientist (and person) should be. Dr. He has taught me more than I could ever give him credit for here. I could not have imagined having a better advisor and mentor for my Ph.D. study.

I am also hugely indebted to Dr. Steve Guffey for providing me extensive personal and professional guidance and teaching me a great deal about both scientific research and life in general. Dr. Guffey has been a truly dedicated mentor. I am extremely grateful and indebted to him.

I wish to express my sincere thanks to Mr. Michael S. Bergman, and Dr. Ziqing Zhuang of NIOSH for being ever so kind to provide me with all the necessary support. This work would not have been possiblely completed without their endless help.

Special thanks go to the rest of my committee members: Dr. Ashish Nimbarte and Dr. Feng Yang for their sincere guidance, valuable suggestions, and insightful comments.

Great gratitude also goes to Dr. Sergey A. Grinshpun of University of Cincinnati, who has been so willingly sharing his expertise in the respiratory protection research area.

I am grateful to my labmates: Mr. Raphael W. Alwin Dodrill, Mrs. Huihui Yang, and Dr. Brian S. Geissler for the excellent cooperation. Special appreciation is given to Mr. Dodrill for his constant support and technical assistance.

I would like to acknowledge that this research was supported by the NPPTL/NIOSH (Contract No. 200-2015-M-62385). The breathing recording devices 
were made available thanks to courtesy of SEA Pty Ltd. (Sydney, Australia) and Koken Inc. (Tokyo, Japan).

I am also taking this opportunity to record my sincere thanks to all the faculty members of the Department of Industrial and Management Systems Engineering for their help and encouragement.

Last but not the least, I would like to thank my parents and my elder brother for their unceasing encouragement and support throughout my life. 


\section{List of Peer-reviewed Publications}

This dissertation includes the results presented in the following four peer-reviewed journal articles:

1. Zhu J, He X, Guffey SE, Bergman MS, Lee EG, Zhuang Z. Assessment of two personal breathing recording devices in a simulated healthcare environment. PLOS ONE. (Submitted in March 2018) (See Chapter 1)

2. Zhu J, He X, Guffey SE, Bergman MS, Zhuang Z. Exploring Two Novel Personal Respiratory Flow Recording Systems for Utilization in Respiratory Protection Studies. Journal of the International Society for Respiratory Protection. (Submitted in April 2018) (See Chapter 2)

3. Zhu J, He X, Bergman MS, Guffey SE, Zhuang Z. A Pilot Study of Minimum Operational Flow for Loose-fitting Powered Air-purifying Respirators Used in Healthcare Settings. Journal of Occupational and Environmental Hygiene. (Submitted in February 2018) (See Chapter 3)

4. Zhu J, He X, Guffey SE. A Preliminary Investigation on the Feasibility of Developing "low-flow" Loose-fitting Powered Air-purifying Respirators for Healthcare Workers. American Journal of Industrial Medicine (In preparation) (See Chapter 4) 


\section{List of Conference Posters}

The findings described in this dissertation were also presented in four conferences posters listed below:

1. Zhu J, He X, Guffey SE, Bergman MS, Zhuang Z. “Assessment of Two Portable Breathing Recording Devices in a Simulated Healthcare Environment." Student Poster \#880. American Industrial Hygiene Conference \& Exposition (AIHce) 2017, Seattle, U.S., 04-07 June.

2. Zhu J, He X, Guffey SE, Bergman MS, Zhuang Z. "A Hospital Study of Respiratory Flow Characteristics of Healthcare Workers Using a Portable Flow Recording Device.” Student Poster \#883. American Industrial Hygiene Conference \& Exposition (AIHce) 2017, Seattle, U.S., 04-07 June.

3. Zhu J, He X, Guffey SE, Bergman MS, Zhuang Z. "A Comparision of Two Portable Breathing Recording Devices in a Simulated Healthcare Environment." Student Poster. ISRP Americas Section Technical and Annual General Meeting, Pittsburgh, U.S., September 13, 2017.

4. He X, Zhu J, Guffey SE, Bergman MS, Zhuang Z. "Respiratory Flow Characteristics of Healthcare Workers: A Field Study." ISRP Americas Section Technical and Annual General Meeting, Pittsburgh, U.S., September 13, 2017. 


\section{List of Figures}

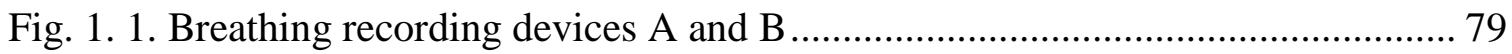

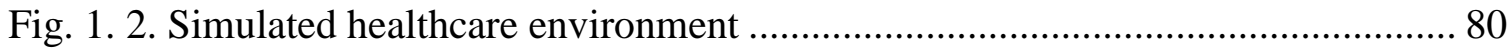

Fig. 1. 3. Bland-Altman plots of MV (a), MIF (b) and PIF (c) for A1 and A2. The solid line indicates mean difference; the dashed lines indicate 95\% LoAs; the dotted

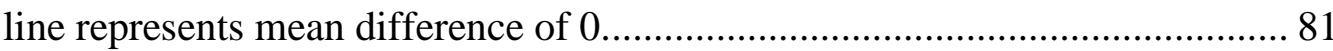

Fig. 1. 4. Bland-Altman plots of MV (a), MIF (b) and PIF (c) for B1 and B2. The solid line indicates mean difference; the dashed lines indicate 95\% LoAs; the horizontal dotted line represents mean difference of 0 , the vertical dotted line represents the upper measurement limit of device B.

Fig. 2. 1. Experimental set-up for testing the respiratory flow recording systems.......83

Fig. 2. 2. Minute volume (MV) measured by the dry gas meter (DGM) and different Systems A 84

Fig. 2. 3. Differences between the dry gas meter (DGM) and different Systems A........ 85

Fig. 2. 4. Percent differences between the dry gas meter and different Systems A......... 86

Fig. 2. 5. Measurements (left), differences (middle), and percent differences (right) reported by the dry gas meter (DGM) and two Systems B

Fig. 2. 6. Measurements (left), differences (middle), and percent differences (right) reported by the dry gas meter (DGM) and two Systems A-3M

Fig. 3. 1. Subject worn respiratory flow recording device while performing isolation unit work.

Fig. 3. 2. Fluctuations of MV, MIF, PIF, and $\mathrm{PIF}_{\max }$ along with time 90

Fig. 3. 3. Changes of $\mathrm{T}_{\mathrm{I}}, \mathrm{f}$, and $\mathrm{TV}$ as time elapses 91

Fig. 3. 4. Fluctuations of PIF/MV and MIF/MV ratios along with time 92

Fig. 3. 5. Changes of PIF/MV and MIF/MV ratios along with $\mathrm{MV}$ 93

Fig. 4. 1. Illustration of $\mathrm{V}_{\mathrm{T}}, \mathrm{V}_{\text {over }} \%$, and $\mathrm{T}_{\text {over }} \%$ by representative sinusoidal breathing pattern .94 


\section{List of Tables}

Table 1. 1. Specifications of breathing recording devices A and B .............................. 96

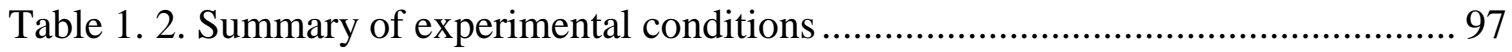

Table 1. 3. Definitions of inhalation parameters.......................................................... 98

Table 1. 4. Measurements of breathing responses to exercises by devices A1 and A2 .... 99

Table 1. 5. Duncan's grouping of MV, MIF, and PIF for devices A1 and A2 ….......... 100

Table 1. 6. Measurement of breathing responses to exercises by devices B1 and B2 ... 101

Table 1. 7. Duncan's grouping of MV, MIF, and PIF for B1 and B2 ......................... 102

Table 2. 1. Summary of experimental conditions................................. 103

Table 2. 2. Mean differences, $95 \%$ LoAs, and ICCs between the dry gas meter and different Systems A......................................................................... 104

Table 2. 3. Grouping of the difference between the dry gas meter and different flow

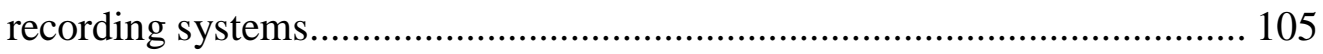

Table 3. 1. Physical measurements of the subjects............................ 106

Table 3. 2. Summary of experimental conditions ................................................... 107

Table 3. 3. Average inhalation parameters in the field and lab based study.................. 108

Table 3. 4. Theoretical MV, PIF, and PIF/MV under Speech and Non-speech Conditions

Table 3. 5. Correlations of MV, MIF, and PIF with Age, Weight, Height, ADu and BMI

Table 3. 6. Expression of inspiratory flow by age, weight, height, $A_{D u}$ and BMI......... 111

Table 3. 7. Different PIF percentiles measured in field and lab-based study ................ 112

Table 4. 1. $\mathrm{V}_{\mathrm{T}}$ for different exercises performed in both lab-based and field studies.....100

Table 4. 2. $\mathrm{V}_{\text {over }} \%$ for different exercises performed in both lab-based and field studies

Table 4. 3. $\mathrm{T}_{\mathrm{over}} \%$ for different exercises performed in both lab-based and field studies

Table 4. 4. Estimated fifth percentile $\mathrm{PF}_{\text {over }}$ for loose-fitting PAPRs during different exercises 


\section{INTRODUCTION}

\section{Background}

There are 18 million U.S. healthcare workers (HCWs) relying on personal protective equipment (PPE) (CDC, 2014). Various studies have shown surgical masks offer minimal protection and that N95 filtering facepiece respirators (FFRs) are not comfortable to use (Davidson et al. 2013; He et al. 2013a b; 2014; Rengasamy et al. 2014). Since the outbreaks of 2003 SARS, 2009 H1N1, and 2015 Ebola, more and more attentions have been attracted towards using powered air purifying respirators (PAPRs) for HCWs (IOM, 2015). The performance of both FFRs and PAPRs are significantly affected by users' inspiratory flow rates (He et al. 2013a; 2014; Mackey et al., 2005). Current NIOSH certification test flow rates for FFRs $(85 \mathrm{~L} / \mathrm{min})$ and PAPRs (115 and $170 \mathrm{~L} / \mathrm{min}$ for tight and loose fitting PAPRs, respectively) are largely based on data collected more than fifty years ago (Bloomfield and Greenburg, 1933; Silverman et al., 1943; Burgess and Reist, 1969). The data are mainly obtained in industrial settings through the equipment that, by today's standards, is obsolete (Anderson et al., 2006). Due to non-portable flow meter designs, previous assessment of respiratory data was limited, and there are no published data available regarding the characteristics of breathing waveforms for HCWs when performing their work activities. It will be helpful to fully characterize the respiratory flow of HCWs through innovative personal breathing recording devices that have been developed specifically for field sampling under actual human breathing conditions. 


\section{Objective}

This study was conducted to investigate the breathing characteristics of HCWs utilizing an innovative wearable personal breathing recording device, and to determine the minimum operational flow that is required for using loose-fitting PAPRs.

\section{Hypothesis}

Current NIOSH certification test flow rates for PAPRs do not reflect HCWs' actual respiratory flow characteristics.

\section{Specific Aims}

Aim 1: Assess the variability of two novel personal breathing recording devices in a simulated healthcare environment

Aim 2: Explore the accuracy and compatibility of two portable pespiratory flow recording systems (devices) for utilization in respiratory protection studies

Aim 3: Characterize worker respiratory flow in hospital environment using a portable flow recording device

Aim 4: Investigate the feasibility of lowering the minimum operational flow for loosefitting powered air-purifying respirators used by HCWs

\section{Executive Summary}

In the first study (Chapter 1, Specific Aim 1), the performance of two portable breathing recording devices from manufactures "A" and "B" was assessed using 15 
human subjects while performing a series of simulated healthcare work activities. The minute volume (MV, L/min), mean inhalation flow (MIF, L/min), average peak inhalation flow (PIF, L/min), maximum peak inhalation flow (PIF $\left.{ }_{\max }, \mathrm{L} / \mathrm{min}\right)$, breathing frequency (f, breaths/min), tidal volume ( $\mathrm{TV}, \mathrm{L} / \mathrm{min})$, and inhalation time per minute $\left(\mathrm{T}_{\mathrm{I}}\right.$, sec), as well as the ratios among them, such as PIF/MV, MIF/MV and duty time (DC, \%) measured by each device were analyzed. Bland-Altman method was applied to explore the variability of devices A and B. Duncan's multiple range test was used to investigate the differences among exercise-specific inspiratory flow rates. The average MV, MIF and PIF reported by device A were 23,54 , and $82 \mathrm{~L} / \mathrm{min}$ with $95 \%$ upper confidence intervals (CIs) of 25, 60 and $92 \mathrm{~L} / \mathrm{min}$; the mean differences of MV, MIF and PIF presented by device A were $0.9,1.3$, and $2.8 \mathrm{~L} / \mathrm{min}$, respectively. The average values and mean differences of MV, MIF and PIF found with device B were significantly higher $(\mathrm{P}<0.05)$, showing a high variability. During non-speech exercises, the PIF/MV and MIF/MV ratios were $>3.14$ and $>2$, while with speech, the ratios increased to $>6$ and $>3$. The $\mathrm{T}_{\mathrm{I}}$ per minute during speech $(20 \mathrm{sec})$ was found to be significantly shorter than non-speech exercises $(25-28 \mathrm{sec})$. The $\mathrm{f}$ during speech (15 breaths/min) was significantly lower than non-speech activities (20-25 breaths/min). Duncan's groupings showed that among different exercises, PIF of "patient assessment" was the highest. Overall, the findings suggest that both manufacturers' devices are suitable for characterizing breathing flows for HCWs. However, the device from Manufacturer A produced less variability, thus is more applicable to investigate the respiratory characteristics of HCWs in a real hospital environment. The reported data could be useful in the development of future respirator test standards. 
In the second study (Chapter 2, Specific Aim 2), a laboratory experiment was set up to test the accuracy and compatibility of the devices " $\mathrm{A}$ " (two units of pressure data loggers $\times$ four different breathing masks) and "B" (two units of pressure data loggers). Five simulated breathing flow rates (MV =7.5, 15, 22.5, 30, and 42.5 L/min) were introduced to simulate various workload activities. The MVs measured by different test devices were compared to those reported by a dry gas meter. Bland-Altman method together with intraclass correlation coefficient were applied to evaluate the accuracy and compatibility of devices A and B. Duncan's multiple range test was also performed to investigate the differences between the dry gas meter and different tested systems. Device A showed a high accuracy and good compatibility with an average difference of around 1 L/min, while device B was found with a low accuracy (mean difference nearly $30 \mathrm{~L} / \mathrm{min}$ ). Duncan's multiple range tests demonstrated that device A can be installed in respirators with different sizes and models. It was concluded that flow recording device A have a high accuracy and good compatibility, thus can be applicable for characterizing respiratory flow of HCWs in situ.

In the third study (Chapter 3, Specific Aim 3), the device "A" was worn by nine HCWs in a hospital to investigate their respiratory flow when performing the "isolation unit work" (a more physical demanding work exposed to possible contiguous diseases). The average MV, MIF, PIF, PIF $\max , \mathrm{f}, \mathrm{TV}, \mathrm{T}_{\mathrm{I}}$, as well as PIF/MV, MIF/MV and DC \% were obtained and compared with the lab-based values from the first study. Average MV, $\mathrm{PIF}$, and PIF/MV were also compared with the theoretical values obtained from the empirical formula. The correlations of MIV, MIF, and PIF with subjects' age, weight, height, body surface area $\left(A_{D u}\right)$, and body mass index $(B M I)$ were analyzed. Regressions 
of MIV, MIF, and PIF on subjects' physical characteristics were also performed. The fluctuations of different inhalation parameters along with working time were analyzed. A list of PIF percentiles was reported. The average MV, MIF, and PIF during "isolation unit work" were 33, 74, and $107 \mathrm{~L} / \mathrm{min}$, with $95 \%$ CIs of 29-36, 66-82, and 96-118 L/min, respectively, which were relatively higher than the corresponding lab-based values. The "isolation unit work" can be classified as a moderate workload task. The MV and PIF of HCWs when performing "isolation unit work" can be estimated from the empirical formula under no speech condition. The measured PIF and MIF were slightly more than $\pi$ and two times of MV. Correlation and regression analysis showed that as the weight of the subject increased, the inhalation flow increased significantly. Per minute values of $\mathrm{MV}, \mathrm{PIF}$ and $\mathrm{f}$ tend to increase as the work activities proceeded, while MIF, $\mathrm{PIF}_{\max }, \mathrm{T}_{\mathrm{I}}$, TV, PIF/MV and MIF/MV just showed fluctuations. The $95^{\text {th }}, 70^{\text {th }}, 60^{\text {th }}, 20^{\text {th }}$, and $10^{\text {th }}$ percentiles for PIF was $157,120,113,90$, and $80 \mathrm{~L} / \mathrm{min}$, respectively. The reported data indicates that NIOSH PAPR update standards may consider lowering the $170 \mathrm{~L} / \mathrm{min}$ minimum operational flow for loose fitting PAPRs needed by HCWs.

The aim of the fourth study (Chapter 4, Specific Aim 4) was to determine the feasibility of lowering the blower flow of loose-fitting PAPRs through the characterization of breathing flow for HCWs. The study consists two stages: 1) lab-based investigation of 15 human subjects' breathing pattern during a series of simulated healthcare work activities; 2) field characterization of respiratory flow for nine HCWs when performing the "isolation unit work" (thorough cleaning and disinfecting of a patient room, a more physical demanding work). Mean inspiratory tidal volume $\left(\mathrm{V}_{\mathrm{T}}, \mathrm{L}\right)$, the percentages of overflow volume $\left(\mathrm{V}_{\text {over }}, \%\right)$ and time $\left(\mathrm{T}_{\text {over }}, \%\right)$ with inhalation flow > 
85,115 , and $170 \mathrm{~L} / \mathrm{min}$ were calculated and compared with the NIOSH respirator approval test flow requirements. The protection factor of overbreathed loose-fitting PAPRs $\left(\mathrm{PF}_{\text {over }}\right)$ was estimated based on $\mathrm{V}_{\text {over }} \%$ and $\mathrm{T}_{\text {over }} \%$. Much lower than $1 \%$ of $\mathrm{V}_{\text {over }}$ $\%$ and $\mathrm{T}_{\text {over }} \%$ with inhalation flow $>170 \mathrm{~L} / \mathrm{min}$ were observed during the simulated exercise of "patient assessment" and field "isolation unit work", which indicates that there is a very small possibility of exceeding $170 \mathrm{~L} / \mathrm{min}$ in terms of breathing volume and duration. Without considering dead volume $\left(\mathrm{V}_{\text {dead }}=0\right.$, worst case $)$, the fifth percentile $\mathrm{PF}_{\text {over }}$ values were 156 and 257 for the above two job tasks, respectively; considering $\mathrm{V}_{\text {dead }}=1.4 \mathrm{~L}$ as buffer, fifth percentile $\mathrm{PF}_{\text {over }}$ values were infinite. It was concluded that during HCWs' light/moderate routine job tasks, momentary overbreathing events have minimal effect on protection offered by loose-fitting PAPRs. The findings suggest that NIOSH may consider updating respirator test standards to approve a new class of "lowflow" loose-fitting PAPRs to be used in healthcare settings. In addition, this study points a novel approach to characterize breathing flow and to evaluate respirator efficacy.

Overall, this study demonstrated a novel approach to characterize respiratory flow for HCWs using an innovative wearable flow recording device. The results obtained from this investigation can be considered for respirator certification, standards development, and respirator design to improve respiratory protection for HCWs. 


\section{CHAPTER 1}

\section{Assessment of Two Personal Breathing Recording Devices in a Simulated Healthcare Environment (Specific Aim 1)}

\section{Abstract}

Objectives: To assess the performance of two respiratory flow recording devices in a laboratory-based healthcare environment.

Methods: Breathing recording devices " $A$ " and " $B$ " were assessed using 15 subjects while performing a series of simulated healthcare work activities. The minute volume (MV, L/min), mean inhalation flow (MIF, L/min), average peak inhalation flow (PIF, $\mathrm{L} / \mathrm{min}$ ), maximum peak inhalation flow $\left(\mathrm{PIF}_{\max }, \mathrm{L} / \mathrm{min}\right)$, breathing frequency (f, breaths/min), tidal volume (TV, L/min), and inhalation time per minute $\left(\mathrm{T}_{\mathrm{I}}, \mathrm{sec}\right)$, as well as the ratios among them, such as PIF/MV, MIF/MV and duty time (DC, \%) measured by each device were analyzed. Bland-Altman method was applied to explore the variability

of devices A and B. Duncan's multiple range test was used to investigate the differences among exercise-specific inspiratory flow rates.

Results: The average MV, MIF and PIF reported by device A were 23,54 , and $82 \mathrm{~L} / \mathrm{min}$ with $95 \%$ upper confidence intervals (CIs) of 25, 60 and $92 \mathrm{~L} / \mathrm{min}$; the mean differences of MV, MIF and PIF presented by device A were $0.9,1.3$, and $2.8 \mathrm{~L} / \mathrm{min}$, respectively. The average values and mean differences of MV, MIF and PIF found with device B were significantly higher $(\mathrm{P}<0.05)$, showing a high variability. During non-speech exercises, the PIF/MV and MIF/MV ratios were $>3.14$ and >2, while with speech, the ratios increased to $>6$ and $>3$. The $T_{\text {I }}$ per minute during speech $(20 \mathrm{sec})$ was found to be significantly shorter than non-speech exercises $(25-28 \mathrm{sec})$. The f during speech (15 breaths/min) was significantly lower than non-speech activities (20-25 breaths/min). 
Duncan's groupings showed that among different exercises, PIF of "patient assessment" was the highest.

Conclusions: This study demonstrated a novel approach to characterize respiratory flow for healthcare workers using an innovative wearable flow recording device. The reported data could be useful in the development of future respirator test standards.

Keywords: Healthcare worker, breathing, respiratory flow, minute volume, mean inhalation flow, peak inhalation flow 


\section{Introduction}

Healthcare personnel are at risk for exposure to various infectious respiratory viruses (for example, the highly prevalent and seasonal respiratory syncytial virus (RSV)) and bacterial pathogens (OSHA, 2007; IOM, 2015; Liverman and Larson, 2011). Currently, there are 18 million U.S. healthcare workers (HCWs) relying on personal protective equipment (PPE) (e.g., respirators, gloves, gowns, face shields, etc.) when exposed to a range of known and unknown occupational infectious agents (CDC, 2014). Traditionally, surgical masks and N95 filtering facepiece respirators (FFRs) are widely used to reduce exposure to airborne hazards in healthcare settings, even though various studies have demonstrated that surgical masks offer minimal protection and N95 FFRs are not comfortable to use due to the high air resistance of the filter (Davidson et al., 2013; He et al., 2013b; He et al., 2014; Rengasamy et al., 2014). Following the 2003 severe acute respiratory syndrome (SARS), 2009 H1N1 influenza, and the recent Ebola outbreak, significant attention has been directed towards using powered air-purifying respirators (PAPR) for HCWs (IOM, 2015).

According to the Occupational Safety and Health Administration (OSHA), a PAPR is "an air-purifying respirator that uses a blower to force the ambient air through air-purifying elements to the inlet covering" (OSHA, 2006). There are two types of PAPR: 1) tight-fitting (full facepiece or half-mask facepiece) that is designed to seal to the face or neck, and 2) loose-fitting (hood, helmet, or loose-fitting facepiece) that is designed to contact, but not seal completely to, the face or neck. The National Institute for Occupational Safety and Health (NIOSH) certifies respirators including PAPRs (OSHA, 1998). A NIOSH approval criterion is the minimum air flow rate: a tight-fitting PAPR must provide a constant flow of at least $115 \mathrm{~L} / \mathrm{min}$, and $170 \mathrm{~L} / \mathrm{min}$ 
for a loose-fitting PAPR. Compared to N95 FFRs, PAPRs feature several advantages to the wearers. PAPRs offer higher assigned protection factors (APFs) ranging from 25 to 1000, whereas the APF for N95 FFRs is 10 (OSHA, 2006). In addition, loose-fitting PAPRs do not require annual fit testing, and they can be used by HCWs who cannot achieve a good faceseal due to facial hair or other factors (Roberge, 2008). Another significant benefit offered by PAPRs is the airflow supplied by the blower can overcome the air resistance of the filter as well as reduce heat build-up inside the worker's breathing zone; these features add to the comfort of wearing PAPRs.

The performance of both FFRs and PAPRs are significantly affected by users' inspiratory flow rate (He et al., 2014; Mackey et al., 2005). The influence of testing flow on N95 FFRs have been studied extensively (Coffey et al., 2004; Grinshpun et al., 2009; Rengasamy et al., 2012; Zhuang et al., 2013). However, PAPRs have received much less research attention (Cohen et al., 2001; Roberge et al., 2008). PAPRs were originally developed in the 1960's to protect various industrial workers from respiratory and dermal hazards (IOM, 2015). A silica dust loading test incorporating the complete PAPR system is part of the NIOSH approval testing requirements. This test simulates a work condition found in industrial settings, primarily in mining. Industrial settings such as mining are often associated with a dusty environment and require workers to perform moderate to high exertion job activities. This means that PAPRs used in those conditions must have high supplied air flows to satisfy the breathing demands for the workers.

The workplace environments experienced by HCWs differ significantly from industrial conditions, especially when it pertains to physical exertion when performing routine work activities (ISO/TS 16976-1:2015). Because the work intensity levels for HCWs are lower, it may be necessary to develop a new class - "low-flow" PAPRs to be used in healthcare settings. There 
are several advantages associated with this type of PAPR. By adopting lower flow rates, the size of the blower, filter, and the battery can be reduced, which means that the overall size and weight of a PAPR becomes smaller, and more HCWs may consider using PAPRs to alleviate the burden of using N95 FFRs. One significant challenge to using PAPRs is the cost. The average price of a PAPR currently sold on the U.S. market is about $\$ 1,000$ (IOM, 2015). By reducing the capacity of individual elements, the cost of a newly developed "low-flow" PAPR can be reduced, making them more affordable for end users. One complaint from HCWs when using regular PAPRs is the wind noise produced by the high air flow, which can interfere with communication and affects workers' ability to perform certain practices effectively (Khoo et al., 2005). This problem may be lessened with a new "low-flow" PAPR class.

Currently, no national or international standards are available regarding the minimum required operational flow for PAPRs used by HCWs. Given that a loose-fitting PAPR facepiece does not form a tight fit to its wearer, flow rates supplied by PAPRs must be adequate to prevent airborne contaminates from entering the respirator. It will be very helpful if inhalation flow rates, dependent on wearers and types of work being performed, are fully characterized for HCWs. The results will help determine the minimum operational flow that is required for PAPRs when used by HCWs. The objective of this research was to assess two types of wearable/portable breathing recording devices using 15 subjects in a simulated healthcare environment. The purpose was to optimize the sampling system and compare the performance of the two devices. The model with lower variability will be selected for use in future field studies to characterize HCW's respiratory flows. 


\section{Methods}

\section{Instrumentation}

Four breathing recording devices from two different manufacturers " $\mathrm{A}$ " and " $\mathrm{B}$ " (devices of A1, A2, B1 and B2) were employed for this laboratory evaluation. As shown in Fig. 1. 1, both devices feature a similar mechanism by including a pressure data logger module which can be belt or pocket mounted, thus allowing continuous respiratory flow monitoring for different types of occupational work. Each device contains a differential pressure sensing system that uses a mask-mounted sensor to measure the pressure drop inside the mask (see Fig. 1. 1). After sampling, the pressure data is converted to breathing flow data via a calibration curve. Detailed specifications for devices A and B are listed in Table 1. 1.

\section{Participants}

A group of 15 human subjects (eight male and seven female) was recruited for this laboratory based study. Institutional Review Board (IRB) approval from West Virginia University (WVU) was obtained prior to subject recruitment. Before participating in the test, subjects were given the OSHA Respirator Medical Evaluation Questionnaire (OSHA, 1998). Only those who were medically cleared based on the questionnaire were allowed to continue this study. Subjects' age, weight, and height were $27.3 \pm 3.9$ years, $69.8 \pm 12.9 \mathrm{~kg}$, and $171.7 \pm 10.5$ cm (means \pm standard deviation), respectively. 


\section{Experimental Set-up}

A manikin lying on a hospital bed was set in the laboratory to simulate the hospital environment. Infusion support and apparatus were set beside the bed to allow the human subjects to simulate intravenous (IV) treatment. Likewise, a sphygmomanometer and an echometer were employed to simulate the activities of measuring blood pressure and heart rate. The simulated healthcare environment is depicted in Fig. 1. 2. Individual subjects each wore all four devices and performed six exercises to simulate routine tasks commonly seen in healthcare settings (see Table 1. 2). Each exercise lasted 1-min and was repeated once. A randomized block design was applied in this study. For each subject, a breathing recording device was randomly chosen, and the 6 exercises were fully randomized for each device to minimize the effect of experimental error. The experimental conditions are summarized in Table 1. 2.

\section{Data Analysis}

The minute volume (MV, L/min), mean inhalation flow (MIF, L/min), average peak inhalation flow (PIF, L/min), maximum peak inhalation flow rate (PIF $\left.\mathrm{max}_{\mathrm{x}}, \mathrm{L} / \mathrm{min}\right)$, breathing frequency (f, breaths/min), tidal volume $(T V, L)$, and inhalation time per minute $\left(\mathrm{T}_{\mathrm{I}}, \mathrm{sec}\right)$ obtained by those 4 devices, as well as the ratios among them, such as PIF/MV, MIF/MV and duty time (DC, \%) were analyzed. The definition of each parameter is listed in Table 1. 3.

The variability of each model of devices A and B, as well as the agreement between them was investigated by Bland-Altman plots, a graphical agreement evaluation method, through which the distribution of differences and their change with average measurement can be observed directly. By adding mean difference (bias) and 95\% limit of agreement (LoA) into the plot, the agreement between two devices can be evaluated (Bland and Altman, 2003; 2007). 
Mean differences and 95\% LoAs of MV, MIF and PIF were calculated and presented in the Bland-Altman plots. Duncan's multiple range test (MRT) was performed by SAS version 9.3

(SAS Institute Inc., Cary, NC, USA) to investigate the differences among exercise-specific MV, MIF and PIF. All other data analyses were performed using Excel software (Analysis ToolPak for Microsoft ${ }^{\circledR}$ Excel 2017). A P-value<0.05 was considered significant.

\section{Results and Discussion}

\section{Performance Evaluation of Device A}

The measurements of breathing responses to different exercises by devices A1 and A2 are shown in Table 1. 4. Regardless of different exercises, the overall average MV obtained by device A (A1 and A2) was $23 \mathrm{~L} / \mathrm{min}$ with $95 \%$ confidence interval (CI) of 20-25 L/min. Since MVs for a medium sized people (body surface area $=1.84 \mathrm{~m}^{2}$ ) to perform light, moderate and heavy workloads are 15, 30, and $85 \mathrm{~L} / \mathrm{min}$, respectively (ISO/TS 16976-1:2015), the data measured by device A reasonably reflected the MV needed by the subjects (body surface area $=1.81 \pm 0.22 \mathrm{~m}^{2}$ ) when performing the six light-moderate exercises in the study. The average MIF was $54 \mathrm{~L} / \mathrm{min}$ with $95 \% \mathrm{CI}$ of $48-60 \mathrm{~L} / \mathrm{min}$, significantly lower than the NIOSH approval test flow (85 L/min) for N95 FFRs. The average PIF was reported as $82 \mathrm{~L} / \mathrm{min}$ with the upper 95\% CI of $92 \mathrm{~L} / \mathrm{min}$, indicating that future development of NIOSH PAPR standards may consider lowering the $170 \mathrm{~L} / \mathrm{min}$ minimum operational airflow for loose fitting PAPRs. Since this is a lab-based simulation study, the above findings need to be further verified in the real healthcare settings.

The MV, MIF, PIF, PIF ${ }_{\max }, \mathrm{f}, \mathrm{TV}, \mathrm{T}_{\mathrm{I}}$ during different exercises measured by A1 and A2 were not significantly different $(\mathrm{P}>0.05)$, suggesting that the breathing recording device A has a 
small variability. Duncan's multiple range test (MRT) was also applied to investigate the differences among different exercises reported by A1 and A2. The groupings of MV, MIF, and PIF reported by A1 and A2 were almost in the same order (see Table 1. 5), which further confirmed the low variance between A1 and A2. Among the six exercises, the MV during patient assessment (PA) —asking questions was the lowest, recorded as $16 \mathrm{~L} / \mathrm{min}$, while the highest MV of $26-28 \mathrm{~L} / \mathrm{min}$ was recorded during changing linen $(\mathrm{CL})$ and carrying a $5 \mathrm{lb}$. weight while walking (CW). All other exercises reported approximately $20 \mathrm{~L} / \mathrm{min}$ for MV. The lowest MIF of $45 \mathrm{~L} / \mathrm{min}$ was found for subjects performing normal breathing while standing (NB) instead of PA. MIF of CL was the highest, slightly over $60 \mathrm{~L} / \mathrm{min}$. As expected, the PIF of PA ranked the highest, since subjects kept talking in this process. The inhalation time was significantly reduced while speech happened during the exhalation phase (Table 1.4). The $T_{I}$ per minute during speech was only $20 \mathrm{sec}$, while the DC was only 33\%, which was significantly less than other non-speech exercises, whose $\mathrm{T}_{\mathrm{I}}$ per minute was $25-28 \mathrm{sec}$ with DC of 42-46\%. Under speech conditions, the subject had to increase the PIF to get enough air inhaled during this short $\mathrm{T}_{\mathrm{I}}$.

Interestingly, during no speech exercises, the ratios of PIF/MV were generally greater than 3.14. It is well known that human breathing pattern can be represented by a sinusoidal waveform, and the PIF/MV ratio equals $\pi$ or approximately 3.14 (Cooper, 1960). This study, however, indicates that actual human breathing flow patterns may be different from the sinus cycle. It has been concluded that PIF rates were 2.5 to 3.7 times as high as the MV (Silverman et al., 1945; Lafortuna et al., 1984; Kaufman and Hastings, 2005). The PIF/MV ratios obtained in this study were between 3.3 and 3.5 , which was consistent with those studies. Under speech conditions, the PIF/MV reached as high as 6, similar ratios (PIF/MV=6) have been reported by Holmér et al. (2007). As discussed above, during the PA process, the inhalation time was 
significantly reduced, correspondingly, the PIF/MV increased two times to ensure adequate air supply to the human body. Similar results were seen in MIF/MV ratios - during no speech exercises, the MIF/MV ratios were slightly higher than 2.0, because the DC was generally less than 0.5 , which means that during those light to moderate activities, the subject spent less than

half of the time to inhale. The breathing frequency (f) during speech was only 16 breaths/min, which was significantly lower than any other non-speech activities (20-26 breaths/min). This was caused by the relatively longer time spent for speaking, resulting in extended exhalation time and longer breath cycle time - the longer the cycle time, the lower the breathing frequency would be. The values of TV were relatively unchanged among different exercises $(1-1.1 \mathrm{~L} / \mathrm{breath})$. Combined with the variation of $\mathrm{f}$ among different exercises (see Table 1. 4), it was concluded that the increase of MV was mainly attributed to the increase of $\mathrm{f}$. This finding suggests that with the increased workload from light to moderate, human breathing rates become faster rather than deeper.

To further analyze the variability between devices A1 and A2, the mean differences and 95\% LoAs of MV, MIF and PIF for devices A1 and A2 were obtained and presented in the Bland-Altman plots, as shown in the Fig. 1. 3. The mean differences of MV, MIF and PIF between devices A1 and A2 were 0.9, 1.3, and 2.8 L/min, which were all close to zero, demonstrating the low variability of device A.

\section{Performance Evaluation of Device B}

The breathing responses to different exercises measured by devices B1 and B2 are shown in Table 1. 6. Among different exercises, the overall average MV, MIF and PIF reported by devices B1 and B2 were 29, 75, $123 \mathrm{~L} / \mathrm{min}$ with $95 \%$ CIs of 19-38, 47-103, and 72-174 L/min, 
respectively, which were significantly higher than the corresponding values presented by device A (A1 and A2). Both devices A and B confirmed that the six simulated exercises (see Table 1. 2) could be classified as light-moderate workload activities, and the $170 \mathrm{~L} / \mathrm{min}$ minimum operational airflow was adequate for loose fitting PAPRs worn by HCWs.

As listed in Table 1. 6, the MV, MIF, PIF, $\mathrm{PIF}_{\max }, \mathrm{f}, \mathrm{TV}$, and $\mathrm{T}_{\mathrm{I}}$ during different exercises measured by devices B1 and B2 agreed with each other. Duncan's grouping of MV, MIF, and PIF for B1 and B2 were performed (see Table 1. 7) to further evaluate the agreement between devices B1 and B2. It was observed that groupings reported by B1 and B2 were almost in the same order. Specifically, the highest MV was reported around $35 \mathrm{~L} / \mathrm{min}$ with the subjects changing linen (CL). Unlike the device A, the MV of PA, reported as $31 \mathrm{~L} / \mathrm{min}$, did not rank the lowest. For both MIF and PIF, the groupings of the six exercises can be categorized into three groups: 1) PA; 2) CW and CL; 3) IV, V and NB. Specifically, PA ranked the highest, with the average MIF and PIF of 110 and $200 \mathrm{~L} / \mathrm{min}$, followed by the exercises of CW and CL, and the lowest MIF and PIF values were found during exercises of IV, V and NB.

As expected, the high PIF of PA was caused by significant reduction of the inhalation time. As shown in Table 1. 6, the TI per minute during speech was only 18 sec. with DC of $30 \%$, which was significantly lower than that of other non-speech exercises, whose $\mathrm{T}_{\mathrm{I}}$ per minute was 23-28 sec. with DC of 40-47\%. Similarly, the subjects had to increase the PIF to breathe in enough air in this short $\mathrm{T}_{\mathrm{I}}$ during PA exercise. To be noted, the $\mathrm{T}_{\mathrm{I}}$ and $\mathrm{DC}$ values reported by device B agreed well with that of device A, indicating both of these two devices can reasonably detect the length of inhalation time. 
During no speech exercises, the PIF/MV ratios were generally > 3.14 (see Table 1. 6), which was similar to that of devices A1 and A2. Under speech conditions, the PIF/MV was around 7 , which was close to the ratios reported by device A. PIF/MV ratios $>6$ have also been reported by other researchers (Holmér et al., 2007). A similar finding was seen in MIF/MV ratios: during no speech exercises, the MIF/MV ratios were slightly > 2, resulting in the values of DC generally < 0.5, i.e., the MIF was over two times of MV; during PA process, the MIF/MV ratio was around 4, significantly higher than other non-speech exercises, which was caused by the significant reduction of $\mathrm{T}_{\mathrm{I}}$. It was noted that the PIF/MV and MIF/MV ratios during each exercise reported by devices A and B were very close to each other, indicating a good agreement in measuring those ratios.

As can be seen in Table 1. 6, the f during PA exercise (15 breaths/min) was significantly lower than any other non-speech activities (20-24 breaths/min); As stated earlier, this lower value was caused by the extended exhalation time during speech and the longer breath cycle time. The TV among different exercises can be categorized into the same three groups as the MIF and PIF, that is, 1) PA; 2) CL and CW; 3) IV, V and NB, with TV values of 2.0, 1.6, and 1.2 L/breath, respectively. The TV reported by devices B1 and B2 were significantly higher than the values reported by devices A1 and A2, all of which were around 1 L/breath (see Table 1. 4). This higher TV values should be the reason for the significantly higher MV, MIF and PIF measured by devices B1 and B2. Since there were significant differences in both TV and f, it was concluded that the increase of MV values measured by devices B1 and B2 was associated with simultaneous increase of TV and f, i.e., to get more air volume inhaled, the subjects breath deeper and faster. 
The variability of device B was evaluated by the Bland-Altman method, and the mean differences and 95\% LoAs of MV, MIF and PIF between B1 and B2 were presented in Fig. 1. 4. To better evaluate the variability of device B, the average measurements of B1 and B2 were divided into two levels with the upper limit flows of MV, MIF and PIF for device B (70, 140 and $220 \mathrm{~L} / \mathrm{min}$, respectively). It was found that, even within the measurement range, the mean differences of MV, MIF and PIF between devices B1 and B2 were 6.9, 9.6, and $15.3 \mathrm{~L} / \mathrm{min}$, all of which were significantly higher than those of device A. It was concluded that device B had a significantly higher variability when compared with the device A; thus the former may not be applicable for characterizing HCWs' breathing flow in the real healthcare environment.

\section{Performance Comparison of Devices A and B}

The average MV, MIF and PIF measured by device A were 23,54 , and $82 \mathrm{~L} / \mathrm{min}$ with 95\% CIs of 20-25, 48-60, and 72-92 L/min, respectively; the corresponding values reported by device B were significantly higher. This difference was mainly caused by the higher values of TV found with device B compared to that of A. The device A showed that TV stayed unchanged while $f$ increased significantly with the increase of MV, i.e., human breathing was faster rather than deeper, whereas device B reported that TV and f simultaneously increased in response to the increase of MV. Both devices A and B confirmed that all six simulated healthcare work activities (see Table 1.2) can be classified as light-moderate workload tasks, and that NIOSH PAPR standards development may consider lowering the $170 \mathrm{~L} /$ min minimum operational flow for loose-fitting PAPRs used in the healthcare environment.

The mean differences of MV, MIF, and PIF between devices A1 and A2 were 0.9, 1.3, and $2.8 \mathrm{~L} / \mathrm{min}$, which were much lower than the corresponding values $(6.9,9.6$, and $15.3 \mathrm{~L} / \mathrm{min}$, 
respectively) presented by devices B1 and B2. Therefore, the conclusion was that the device A featured lower variability, suggesting that it could be a preferred choice for field applications, e.g., used in a field study of HCWs' breathing flow.

\section{Limitations}

There are a few limitations in this study. For example, neither device A nor B is a "gold standard" method, that is, the true value of the measurements is still unknown. Through the variability comparison and agreement analysis between the two methods, we can only determine which method is more reliable. In the repeated measurements design of this study, we selected six tasks to simulate the routine healthcare activities. Whether this selection agrees with the real healthcare practices needs to be further investigated.

\section{Conclusion}

Overall, the findings suggest that both manufacturers' devices are suitable for characterizing breathing flows for HCWs. However, the device from Manufacturer A produced less variability, thus is more applicable to investigate the respiratory characteristics of HCWs in a real hospital environment. The results obtained from this investigation can be considered for respirator certification, standards development, and respirator design to improve respiratory protection for HCWs. 


\section{Acknowledgement}

I wish to express my sincere gratitude to Andy Palmiero, Kenny Kim, and Matt Horvatin of NIOSH/NPPTL for their useful suggestions and critique review. This study was supported by the National Institute for Occupational Safety and Health (NIOSH), National Personal Protective Technology Laboratory (NPPTL) (Contract \# 200-2015-M-62385).

\section{Disclaimer}

The findings and conclusions of this article are those of the authors and do not necessarily represent the views of the National Institute for Occupational Health and Safety. Mention of a commercial product or trade name does not constitute endorsement by the National Institute for Occupational Safety and Health. 


\section{CHAPTER 2}

\section{Exploring Two Novel Personal Respiratory Flow Recording Systems for Utilization in Respiratory Protection Studies (Specific Aim 2)}

\section{Abstract}

Objective: To explore the feasibility, accuracy, and compatibility of two newly developed personal breathing recording systems for utilization in respiratory protection studies.

Methods: A laboratory experiment was set up to test the accuracy and compatibility of the innovative flow recording systems from manufacturers " $A$ " (two units of pressure data loggers $\times$ four different breathing masks) and "B" (two units of pressure data loggers). Five simulated breathing flow rates (minute volume $(\mathrm{MV})=7.5,15,22.5,30$, and $42.5 \mathrm{~L} / \mathrm{min}$ ) were introduced to simulate various workload activities. The MVs measured by different test systems were compared to those reported by a dry gas meter. Bland-Altman method together with intraclass correlation coefficient were applied to evaluate the accuracy and compatibility of Systems A and B. Duncan's multiple range test was also performed to investigate the differences between the dry gas meter and different tested systems.

Results: System A showed a high accuracy and good compatibility with an average difference of around $1 \mathrm{~L} / \mathrm{min}$, while System B was found with a low accuracy (mean difference nearly 30 $\mathrm{L} / \mathrm{min}$ ). Duncan's multiple range tests demonstrated that System A can be installed in respirators with different sizes and models.

Conclusion: One flow recording system was identified with high accuracy and good compatibility, which may be applicable for respiratory protection studies.

Keywords: respirator testing, respiratory flow, breathing, minute volume 


\section{Introduction}

In America, there are more than 3 million workers in 282, 000 establishments that are required to wear respirators (Doney et al., 2005). The performance of both widely used filtering facepiece respirators (FFRs) and powered air-purifying respirators (PAPRs) are significantly affected by users' inspiratory flow rates (He et al. 2013a b; 2014; Mackey et al., 2005). To be specific, the filter efficiency of FFRs are highly dependent on the residence time (the length of time for a particle to traverse through the respirator filter). Residence time decreases as the breathing flow increases, resulting in less probability of particles being captured by diffusion or electrostatic attraction (Bałazy et al., 2005; Eninger et al., 2008; Boskovic et al., 2007; 2008; Eshbaugh et al., 2008; Haruta et al., 2008; Cho et al., 2009; He et al., 2013a b). Since contaminants are unlikely to migrate from lower pressure to higher pressure, PAPRs are by design intended to maintain a positive pressure in the inlet covering (facepiece, hood or helmet) during wearers' breathing (OSHA, 2006). However, the inside positive pressure of a PAPR can momentarily become negative if a user's breathing flow exceeds the fan's delivery airflow plus the dead volume of the facepiece (over breathing). At that time, inward leakage of hazardous particles could occur for a loose-fitting PAPR which does not form an ideal seal to the wearer's face (Berndtsson et al., 2003).

Current NIOSH-approved FFRs are tested at a constant flow rate of $85 \mathrm{~L} / \mathrm{min}$ during particle penetration testing; the NIOSH approval minimum operational flows for tight-fitting and loose-fitting PAPRs are 115 and 170 L/min, respectively (NIOSH, 1995). However, these test flow rates are largely based on human inspiratory flow data collected more than 50 years ago (Bloomfield and Greenburg, 1933; Silverman et al., 1945; Burgess and Reist, 1969), through the 
equipment that, by today's standards, is obsolete. The relevance and adequacy of these flow rates has been a longstanding debate.

Due to non-portable flow meter designs, previous assessment of respiratory data was limited to laboratory testing, and there is a dearth of data available on inspiratory flow rates and breathing patterns of workers when performing daily tasks in actual occupational settings. It will be helpful if inhalation flow rates, dependent on wearers and types of job tasks being performed, are fully characterized. The result will help to determine the minimum operational flow required for PAPRs when used by different types of workers and will assist in improving the scientific basis for future updates to 42 CFR Part 84 . Thus, a portable/wearable respiratory flow meter in situ is needed. In addition, since the inspiratory flow of human breathing reaches its peak rapidly, to obtain an accurate picture of a breath cycle, it is important to achieve readings with as a high resolution (i.e., frequency and accuracy of data samplings) (Lafortuna et al., 1984). However, when inspiratory flow data was collected fifty years ago, there were no respiratory flow meters with a speed high enough to record such data. In summary, an effort is warranted that develops a flow recording device capable of sampling inspiratory flow data without disrupting the users' normal work activities. The aforementioned requirements are now possible to be achieved due to the advent of two novel portable (wearable) respiratory flow recording systems. This study sought to test the accuracy and compatibility of these two systems to see if they are applicable for characterizing the respiratory flow of workers in situ. 


\section{Methods}

\section{Instrumentation}

Personal Respiratory Flow Recording Systems

Personal respiratory flow recording systems from two different manufacturers (" $\mathrm{A}$ " and "B") were employed for this laboratory evaluation. Systems A and B feature a similar mechanism by including three parts: data logger, pressure sensor, and the breathing mask, both systems are small enough to be carried by a worker while performing regular job tasks. The data logger can be belt or pocket mounted, the mask-mounted pressure sensor samples the change of pressure drop between inside and outside of the breathing mask. After sampling, the pressure data is then converted into breathing flow rate data through a calibration curve. The sampling interval of System A is $0.02 \mathrm{~s}$, under this speed, the data logger A can log for at least an $8 \mathrm{hr}$ shift.

For System B, the sampling rate in this study was set as $0.2 \mathrm{~s}$, under which speed, the data logger B can record up to 13 min. The maximum measurement for System A is $400-500 \mathrm{~L} / \mathrm{min}$, which is around two times that of B $(220 \mathrm{~L} / \mathrm{min})$. System A has three sizes of elastomeric half masks (S/M, M/L, and L/XL) for subjects with different facial dimensions to choose, and two data loggers of A (A1 and A2) can be adapted to different sizes of respirators, thus providing totally six combinations of Systems A (A1-S/M, A1-M/L, A1-L/XL, A2-S/M, A2-M/L, and A2-L/XL). For System B, there are only one size of the elastomeric half mask and two data loggers (B1 and B2), which can be simply characterized as B1 and B2.

\section{Dry Gas Meter}

As a qualified device to precisely measure the volume of airflow, a dry gas meter DTM200A (American Meter Co., Philadelphia, PA, USA) was applied in this study. The capacity of 
DTM-200A is $93.33 \mathrm{~L} / \mathrm{min}$ with a resolution of $1 \mathrm{~L} / \mathrm{min}$. Hart et al. (1992) have already validated the accuracy of two DTM-325 dry gas meters (capacity $153.38 \mathrm{~L} / \mathrm{min}$ ) at both continuous and sinusoidal flows, where continuous flows (air saturated with water vapor) between 60 and $150 \mathrm{~L} / \mathrm{min}$ were measured with an error of $<1 \%$; sinusoidal flows (ambient air) between 8 and $100 \mathrm{~L} / \mathrm{min}$ were misread by $<1 \%$ and the error was still within $2 \%$ at $140 \mathrm{~L} / \mathrm{min}$, showing a very high accuracy of the tested dry gas meter. The DTM-200A is of the same design but with different capacity, which can be assumed of similar performance.

To confirm that, the accuracy of the DTM-200A dry gas meter was validated by a TSI 4045 mass flow meter. The response time of the flow meter was 4 millisecond, with error less than $2 \%$ within the flow range of $0-300 \mathrm{~L} / \mathrm{min}$. The two devices were connected together by plastic tubing which was then connected to a pump system, where continuous flow was increased from 0 to $135 \mathrm{~L} / \mathrm{min}$ (correspond to the value of PIF when $\mathrm{MV}$ is $42.5 \mathrm{~L} / \mathrm{min}$, i.e. MIF $=85$ $\mathrm{L} / \mathrm{min}$ ). The flow was increased at a $2.5 \mathrm{~L} / \mathrm{min}$ by each increment and was tested for $5 \mathrm{~min}$. The average MVs reported by the dry gas meter and TSI flow meter were compared. It was found that when the MVs were $<93.33 \mathrm{~L} / \mathrm{min}$, the percent difference (i.e., difference divided by average of measurements) between the dry gas meter and flow meter was $<2 \%$; as the flow rates increased to $>93.33 \mathrm{~L} / \mathrm{min}$, the mean percent difference was around $5 \%$. Therefore, the DTM200A dry gas meter in itself has an accuracy high enough to test the accuracy and compatibility of different respiratory recording systems.

\section{Experimental Set-up}

An experimental set-up was designed to test the accuracy of the respiratory flow recording systems, as shown in Fig. 2. 1. For both Systems A and B, the respirators with the 
pressure sensors were fully sealed on a manikin headform, which was connected to the dry gas meter through the three-way-valve(1). A breathing flow machine combined with a simulated human lung box were used to produce simulated human breathing flows. Three-way-valves(1) and (2) were placed before and after the dry gas meter in order to achieve accurate measurements for inhalation flows. Different test flows (MV=7.5, 15, 22.5, 30, and 42.5 L/min with breathing frequencies of $10,15,20,25,30$ breaths/min) were introduced to simulate various work rates from low to high. Each flow rate run $5 \mathrm{~min}$ and the 5-min's average MVs obtained by the dry gas meter were compared to the tested breathing recording systems to determine their accuracy. All aforementioned six configurations of System A and two configurations of System B were tested. With each test condition repeated three times, the total runs of the accuracy tests were 8 systems $(6$ Systems $A+2$ Systems B $) \times 5$ test flow rates $\times 4$ replicates $=160$. Trials were randomized to reduce experimental error.

The half-mask respirator included in the System A is also produced by manufacturer A, which is not a common respirator used by U.S. workers. Therefore, the compatibility of the System A was tested when connected to a widely used NIOSH-approved elastomeric half-mask respirators (EHRs, 3M 6200) (System B cannot be detached thus is not compatible with other respirators). The compatibility was assessed by the same methods developed in the accuracy test (i.e., testing the accuracy of the System A when connected to another EHR). The total runs of the compatibility test were $2 \mathrm{~A}-3 \mathrm{M}$ systems $(\mathrm{A} 1-3 \mathrm{M}$ and $\mathrm{A} 2-3 \mathrm{M}) \times 5$ flow rates $\times 4$ replicates $=40$. A summary of experimental conditions is shown in Table 2. 1. 


\section{Data Analysis}

All data were recalculated back to STPD (Standard Temperature Pressure Dry) for ease of comparison. Bland-Altman method was applied to test the accuracy of Systems A and B, and to explore the compatibility of System A. Mean difference and 95\% limit of agreements (LoAs) were reported to determine whether the measurements reported by two devices agree with each other or not. Intraclass correlation coefficients (ICC), which take both systemic and random error into consideration, were also obtained using IBM SPSS Statistics 20.0 (SPSS Inc, Chicago, Ill, USA). The higher ICC between two groups of data means the better they agree with each other, with ICC of 1.00 indicates perfect agreement. Using SAS version 9.3 (SAS Institute Inc., Cary, NC, USA), Duncan's multiple range test was performed to investigate the measurement differences between the dry gas meter and different flow recording systems. P-values $<0.05$ were considered significant. ICC values $>0.90$ indicated good agreement.

\section{Results and Discussion}

\section{Accuracy of Respiratory Flow Recording System A}

The MV measured by the dry gas meter and different Systems A, as well as the differences and percent differences between them were presented in Fig. 2. 2 2. 4. As can be seen in Fig. 2. 2, the MVs reported by different Systems A were very close to that of the dry gas meter. Fig. 2. 3 showed that as the increase of test flow, the differences between the dry gas meter and different Systems A decreased (except for the system A2-M/L), the largest difference was around $4 \mathrm{~L} / \mathrm{min}$ (System A2-S/M) at MV of 7.5 L/min; interestingly, when highest test flow ( $\mathrm{MV}=42.5 \mathrm{~L} / \mathrm{min}$ ) was applied, the difference was generally less than $1 \mathrm{~L} / \mathrm{min}$. 
The percent differences followed the same rule, that is, as the increase of test flow, the percent difference kept decreasing - under the MV of $7.5 \mathrm{~L} / \mathrm{min}$, the percent difference was generally > 15\%; while when MV= 42.5 L/min was applied, the percent differences were $<3 \%$. Another interesting finding is that almost all Systems A obtained relatively higher MV than the dry gas meter (except for the system of A2-M/L). The reason may be attributed to the inhalation airflow leakage caused by the three-way-valve(1) (see Fig. 2. 1): the valve's opening was made of elastic membrane, whose open and close are controlled by the airflow pressure, thus there should be inevitable airflow leakage into the exhalation circuit, resulting in a lower air volume passing through the dry gas meter compared to the tested Systems A, thus a relatively higher MV was measured by Systems A. As the increase of test flow, higher inhalation flow would generate higher air pressure, thus the opening of the three-way-valve to inhalation circuit would be more unobstructed, and air leakage to the exhalation circuit would be further reduced because of a better sealing condition created by the higher pressure flow effect, increasingly the same amount of air volume would pass through the dry gas meter as the Systems A, and the MVs measured by the dry gas meter and different Systems A would be almost the same at highest test flow $(\mathrm{MV}=42.5 \mathrm{~L} / \mathrm{min})$.

To better evaluate the agreement between the dry gas meter and different Systems A thus to assess the accuracy of them, Bland-Altman method together with ICC analysis were applied, mean differences, 95\% LoAs, and ICC values are listed in Table 2. 2. As can be seen, the largest mean difference was $2 \mathrm{~L} / \mathrm{min}$, while the smallest difference was only $0.35 \mathrm{~L} / \mathrm{min}$. The maximum 95\% LoA was around $4 \mathrm{~L} / \mathrm{min}$, which was acceptable. It was found that all ICCs were $>0.99$, showing a nearly perfect agreement. In total, all data showed a high accuracy of different tested flow recording systems A. 


\section{Accuracy of Respiratory Flow Recording System B}

The measurements, differences, and percent differences reported by the dry gas meter and Systems B1 and B2 are presented in Fig. 2. 5. It was shown that the MVs obtained by both B1 and B2 were significantly higher than that of the dry gas meter, specifically, under test flow of 22.5 L/min, the MVs reported by B1 and B2 were nearly twice of the dry gas meter, and when test flows were $>22.5 \mathrm{~L} / \mathrm{min}$, the measurements of B1 and B2 were over two times of the dry gas meter. Contrary to the Systems A, as the increase of test flow, the differences between the dry gas meter and systems B increased significantly, when $\mathrm{MV}=42.5 \mathrm{~L} / \mathrm{min}$ was applied, the largest difference was over $75 \mathrm{~L} / \mathrm{min}$, even higher than the test flow itself, meantime, the percent difference was $>95 \%$. However, at $\mathrm{MV}=7.5 \mathrm{~L} / \mathrm{min}$, the system B1 reported almost the same result as the dry gas meter with the difference and percent difference of $0.4 \mathrm{~L} / \mathrm{min}$ and $5 \%$, respectively; while the MV reported by $\mathrm{B} 2$ was $2 \mathrm{~L} / \mathrm{min}$ higher.

Bland-Altman analysis reported a significant higher value (mean differences $\approx 30 \mathrm{~L} / \mathrm{min}$ ) for both Systems B1 and B2 than that the dry gas meter. The upper 95\% LoAs were over 80 $\mathrm{L} / \mathrm{min}$, which is unacceptable. ICC values between the dry gas meter and Systems B were around 0.50 , much less than 0.90 . Therefore, we can conclude that there is a very low accuracy of the tested Systems B. which may not be applicable to accurately record human respiratory flow.

\section{Compatibility of Respiratory Flow Recording System A}

The measurements, differences, and percent differences reported by the dry gas meter and two Systems A-3M were presented in Fig. 2. 6. It was found that the MV obtained by the dry gas meter and Systems A1-3M and A2-3M were very close to each other, indicating a good compatibility of System A. Similar to the results of the other tested Systems A, as the increase of 
test flow, the differences between the dry gas meter and Systems A-3M decreased, the largest difference was around $2 \mathrm{~L} / \mathrm{min}$ when $\mathrm{MV}=7.5 \mathrm{~L} / \mathrm{min}$ was applied. At the highest test flow (42.5 $\mathrm{L} / \mathrm{min}$ ), the differences were less than $1 \mathrm{~L} / \mathrm{min}$. The percent differences followed the same rule, under test flow $7.5 \mathrm{~L} / \mathrm{min}$, the percent difference was over $15 \%$; when test flow was > $30 \mathrm{~L} / \mathrm{min}$, both A1-3M and A2-3M reported percent difference less than 5\%. Similar as for the other flow recording Systems A, both two systems of A-3M reported slightly higher MV values than that of the dry gas meter, which may be caused by the sealing problems of three-way-valve(1) in the experimental setup as stated earlier.

Mean differences between the dry gas meter and two systems A-3M were around 1 L/min. 95\% LoAs lied within $3 \mathrm{~L} / \mathrm{min}$, which was acceptable; ICC values were > 0.99, indicating a nearly perfect agreement. Therefore, both Bland-Altman and ICC analyses showed a high accuracy of the tested systems A-3M, manifesting a good compatibility of the System A.

\section{Duncan's Multiple Range Test (MRT)}

Duncan's grouping on the differences between the dry gas meter and different respiratory flow recording systems is listed in Table 2. 3. As expected, both Systems B1 and B2 ranked the highest with mean difference nearly $30 \mathrm{~L} / \mathrm{min}$. For all eight Systems A, there was no significant differences between each other (mean difference $=1 \mathrm{~L} / \mathrm{min}$ ), which means that the System A can be installed in respirators with different sizes (e.g., S/M vs. M/L vs. L/XL) and models (e.g.,

respirator A vs. 3M respirator). The huge difference measured by the System B was probably caused by its intrinsic inaccuracy; while for the slightly higher values reported by Systems A, it may be raised by the inhalation airflow leakage to the exhalation circuit through the three-wayvalve(1) in the experimental setup, or maybe there was still little discrepancy between the 
measurements reported by the dry gas meter and Systems A. However, it is for sure that the System A has an accuracy high enough to measure human breathing flows.

\section{Conclusion}

One personal/wearable flow recording system which can measure and download instantaneous breathing airflows was identified with high accuracy and good compatibility, thus may be applied to characterize respiratory flow of workers in situ. 


\section{Acknowledgement}

This study was supported by the National Institute for Occupational Safety and Health (NIOSH), National Personal Protective Technology Laboratory (NPPTL) (Contract \# 200-2015-M-62385).

\section{Disclaimer}

The findings and conclusions of this article are those of the authors and do not necessarily represent the views of the National Institute for Occupational Safety and Health. Mention of a commercial product or trade name does not constitute endorsement by the National Institute for Occupational Safety and Health. 


\section{CHAPTER 3}

\section{A Hospital Study of Respiratory Flow Characteristics of Healthcare Workers Using a Portable Flow Recording Device (Specific Aim 3)}

\section{Abstract}

Objectives: To investigate the respiratory flow characteristics of healthcare workers (HCWs) to determine the minimal operational flow for powered air-purifying respirators (PAPRs).

Methods: An innovative respiratory flow recording device was worn by a group of 9 HCWs when performing "isolation unit work" (thorough cleaning and disinfecting of a patient room with infectious disease within 30-min). The average minute volume (MV, $\mathrm{L} / \mathrm{min}$ ), mean inhalation flow (MIF, $\mathrm{L} / \mathrm{min}$ ), average peak inhalation flow (PIF, $\mathrm{L} / \mathrm{min}$ ), maximum peak inhalation flow rate ( $\left.\mathrm{PIF}_{\max }, \mathrm{L} / \mathrm{min}\right)$, breathing frequency (f, breaths/min), tidal volume (TV, L), inhalation time per minute $\left(\mathrm{T}_{\mathrm{I}}, \mathrm{sec}\right)$, as well as PIF/MV, MIF/MV and duty time (DC, \%) were obtained and compared with the lab-based values from the previous study. Average MV, PIF, and PIF/MV were also compared with the theoretical values obtained from the empirical formula. The correlations of MIV, MIF, and PIF with subjects' age, weight, height, body surface area $\left(\mathrm{A}_{\mathrm{Du}}\right)$, and body mass index $(\mathrm{BMI})$ were analyzed. Regressions of MIV, MIF, and PIF on subjects' physical characteristics were also performed. The fluctuations of different inhalation parameters along with working time were analyzed. A list of PIF percentiles was reported.

Results: The average MV, MIF, and PIF during "isolation unit work" were 33, 74, and $107 \mathrm{~L} / \mathrm{min}$, with 95\% CIs of 29-36, 66-82, and 96-118 L/min, respectively, which were relatively higher than the corresponding lab-based values. The "isolation unit work" can be classified as a moderate workload task. The MV and PIF of HCWs when performing 
"isolation unit work" can be estimated from the empirical formula under no speech condition. The measured PIF and MIF were slightly more than $\pi$ and two times of MV. Correlation and regression analysis showed that as the weight of the subject increased, the inhalation flow increased significantly. Per minute values of MV, PIF and $\mathrm{f}$ tend to increase as the work activities proceeded, while MIF, PIF max $, \mathrm{T}_{\mathrm{I}}, \mathrm{TV}, \mathrm{PIF} / \mathrm{MV}$ and MIF/MV just showed fluctuations. The $95^{\text {th }}, 70^{\text {th }}, 60^{\text {th }}, 20^{\text {th }}$, and $10^{\text {th }}$ percentiles for PIF was $157,120,113,90$, and $80 \mathrm{~L} / \mathrm{min}$, respectively. The reported data indicates that NIOSH PAPR update standards may consider lowering the $170 \mathrm{~L} / \mathrm{min}$ minimum operational flow for loose fitting PAPRs needed by HCWs.

Conclusion: This study demonstrated a novel approach to characterize respiratory flow for HCWs using an innovative wearable flow recording device. The results obtained from this investigation can be considered for respirator certification, standards development, and respirator design to improve respiratory protection for HCWs.

Keywords: Healthcare workers, breathing, respiratory flow, powered air-purifying respirators, minute volume, mean inhalation flow, peak inhalation flow 


\section{Introduction}

Due to the special nature of working environment, there is a high risk of occupational exposure for HCWs to influenza, viruses, bacterial pathogens, and emerging diseases (OSHA, 2009; IOM, 2010; IOM, 2015). The outbreak of severe acute respiratory syndrome (SARS) in 2003 highlighted the risk of disease transmission among HCWs, who accounted for $20 \%$ of critically ill SARS cases (Nicas et al., 2004). The 2009 H1N1 influenza and the recent Ebola outbreak has further amplified the concerns of HCWs for adequate personal protective equipment (PPE).

The most common PPE used by HCWs are surgical masks and N95 filtering facepiece respirators (FFRs) (Carias et al., 2015; Wizner et al., 2016). Surgical masks are designed to protect the wearer from splashes $(>100 \mu \mathrm{m})$ and droplets $(>5 \mu \mathrm{m})$ expelled from an infected individual (coughing or sneezing) and to protect others from the wearer as a source of infection, which were not able to provide barrier to sub-micrometer-size $(<1 \mu \mathrm{m})$ bioaerosols (Chen \& Willeke, 1992; Weber et al., 1993).

Studies suggested that N95 FFRs are more effective than surgical masks (He et al., 2013a; 2014). However, the users have to increase their breathing effort to overcome the resistance of the N95 respirator filter, difficulty breathing was therefore identified, leading to hypoventilation and elevated $\mathrm{CO}_{2}$ level inside the respirator, which maybe the reason for one-third of HCWs' headaches for long-term use of N95 FFRs (Lim et al., 
2006). Since improperly fitted N95 FFR would lead to significant leakage and noteworthy decrements in protection level (He et al., 2013b; Rengasamy and Eimer, 2011), annual fit-testing is required for N95 FFRs. An assigned protection factor (APF) of N95 FFR is 10 , indicating properly fitted wearers could expect to inhale no more than one-tenth of the concentration of aerosols in the workplace (OSHA, 2006). However, it is important to recognize that, for pathogenic microorganisms there are generally no safe exposure levels or limits (Musher, 2003), and there is no assurance that any PPE could completely remove infectious biological aerosols.

The finding that HCWs were infected with SARS despite the use of N95 FFRs, resulted in promoting the use of PAPRs when highly contagious pathogens pose a major occupational hazard for HCWs (Loeb et al., 2004). A questionnaire-based survey among HCWs who had used PAPRs during the SARS outbreak showed that $84 \%$ of the respondents preferred to use PAPRs rather than N95 FFRs (Khoo et al., 2005). Therefore, significant attention has been attracted towards using PAPRs for HCWs (IOM, 2015).

OSHA defines PAPR as "an air-purifying respirator that uses a blower to force the ambient air through air-purifying elements to the inlet covering” (OSHA, 2006). Therefore, a significant benefit of PAPR is the decreased breathing effort and the cooling effect on the user's face. Another important benefit of PAPRs is that they do not require the annual fit-testing. In addition, PAPRs can be used by individuals with facial hair and various facial structures, who may not be well fitted for N95 FFRs (Roberge, 2008). 
When donning on a loose fitting PAPR, the pressure inside the facepiece decreases as the wearer breaths in, if the inhalation flow rate exceeds the airflow delivered by the blower (overbreathing), negative pressure would present, given that a loose-fitting PAPR facepiece does not form a tight fit to its wearer. In this case, unfiltered air may leak in. If the airflow supplied by the blower is too high, the power consumption of the battery would sharply increase, which would significantly reduce the effective working time of the PAPR. Therefore, the determination of minimum operational flow is crucial for a loose-fitting PAPR.

The NIOSH approval minimum operational flow rates for a tight-fitting and loose-fitting PAPR are $115 \mathrm{~L} / \mathrm{min}$ and $170 \mathrm{~L} / \mathrm{min}$, respectively (OSHA, 2006). PAPRs were originally developed to protect industrial workers from respiratory and dermal hazards (IOM, 2015). Current standards are largely based on human inspiratory airflow data collected in industrial workplace (primarily in mining) (Bloomfield and Greenburg, 1933; Silverman et al., 1943; Burgess and Reist, 1969), which means that PAPRs must feature high airflow rates. However, the work intensity levels for HCWs are lower.

In recent years, NIOSH has been working on revising its certification requirements for PAPRs. According to the relationship between workloads and inspiratory flow rates (ISO/TS 16976-1:2015), the requirements for the delivery airflow would be different for different classes of workloads. Therefore, linking the minimum operational flow with labor intensity is a possible consideration for future PAPR 
standards. The work intensity levels for HCWs are lower than that of workers in industrial settings, therefore, it may be necessary to develop a new class - "low-flow" PAPRs for HCWs to be applied in the hospital environment.

Since the main complaints from HCWs when using current PAPRs are that they are cumbersome, expensive and noisy, there will be several advantages associated with a "low-flow" PAPR. When operational flow is reduced, the blower, filter, and the battery can be designed to be smaller and lighter, and thus easier for HCWs to wear. The average price of a PAPR currently sold on the U.S. market is about $\$ 1,000$ (IOM, 2015). By reducing the operational flow, "low-flow" PAPRs would be more inexpensive so that more medical institutions could afford them. In addition, the effect of interference with patient communications caused by excess noise may also be reduced.

Currently, there are no scientific studies on the respiratory flow characteristics of HCWs, thus no national or international standards are available regarding the minimum required operational flow for PAPRs needed by HCWs. The objective of this study was to investigate the breathing characteristics of $\mathrm{HCWs}$ to determine the minimum operational flow that is required for PAPRs when used in hospital environment. The result will assist in improving the scientific basis for future updates to NIOSH PAPR certification standards. Recently, we have conducted a lab-based study to assess on the performance of two portable breathing recording devices using 15 human subjects while performing a series of work activities in a simulated healthcare environment. One model 
of flow recording device identified with lower variability was used in this field study to characterize $\mathrm{HCW}$ 's respiratory flows.

\section{Methods}

\section{Instrumentation}

A newly developed respiratory flow recording device (Safety Equipment

Australia (SEA) Pty Ltd., Australia) was employed in this field study, the device is small and light enough $(<0.5 \mathrm{~kg}$.) to be carried by a HCW while performing regular job tasks.

The flow recording device consists of three parts: data logger, pressure sensor and breathing mask. The differential pressure sensor is mounted inside the mask to measure the pressure drop. A reading is taken every $0.02 \mathrm{~s}$ and stored by the data logger, which is belt or pocket mounted. The battery capability allows sampling for at least an $8 \mathrm{hr}$ shift. After sampling, the pressure drop is then converted into respiratory flow through a predetermined calibration curve. The maximum measurement for the device is $400-500$ $\mathrm{L} / \mathrm{min}$, which is high enough to cover the PIF reported during the maximal work rates (Cohen et al., 2001; Berndtsson, 2004; Janssen et al., 2005; Martin et al., 2006). There were three sizes of elastomeric half masks (Small/Medium, Medium/Large, and Large/Extra Large) for subjects with different facial dimensions to choose wear. The masks had an exhalation valve which helped with subject comfort. 


\section{Experimental Set-up}

To better represent the airflow needed by HCWs, activities with higher work intensity should be chosen first, through the investigation of HCWs with previous experiences of using PAPRs, the "isolation unit work" -which includes thorough cleaning and disinfecting of a patient room with infectious diseases within 30 minuteswas identified as a physically demanding task with a risk of infectious exposure. One HCW would clean up to 12 units per day.

A group of nine $\mathrm{HCWs}$ were recruited from the Environmental Services Department, Monongahela General Hospital, Morgantown, WV. Internal Review Board (IRB) approval was obtained through the West Virginia University (WVU) prior to subject recruiting. Test subjects signed a consent form and a photo release. Physical measurements of the subjects are summarized in Table 3. 1.

Each subject wore the respiratory flow recording device while performing the isolation unit work (Fig. 3. 1). Inspiratory flow rates were real-time recorded (50 HZ) during the entire task. Sampling time for each subject was adjusted depending on the completion of the isolation unit work. A summary of experimental conditions is listed in Table 3. 2.

$\mathrm{A}_{\mathrm{Du}}$ and BMI are the body surface area and body mass index for the subjects, respectively. As defined by ISO 8996: 2004 and Ancel Keys et al. (1972), ADu and BMI were calculated as follows: 


$$
\begin{gathered}
\mathrm{A}_{\mathrm{Du}}=0.202 \times \mathrm{W}_{\mathrm{b}}^{0.425} \times \mathrm{H}_{\mathrm{b}}^{0.725} \\
\mathrm{BMI}=\mathrm{W}_{b} / \mathrm{H}_{b}^{2}
\end{gathered}
$$

where $\mathrm{W}_{\mathrm{b}}$ and $\mathrm{H}_{\mathrm{b}}$ represent the weight $(\mathrm{kg})$ and height $(\mathrm{m})$, respectively.

\section{Data Analysis}

All data was corrected to STPD (Standard Temperature Pressure Dry) for ease of comparison. The minute volume ( $\mathrm{MV}, \mathrm{L} / \mathrm{min})$, mean inhalation flow (MIF, L/min), average peak inhalation flow (PIF, L/min), maximum peak inhalation flow $\left(\mathrm{PIF}_{\max }\right.$, $\mathrm{L} / \mathrm{min}$ ), breathing frequency (f, breaths/min), tidal volume (TV, L), and inhalation time per minute $\left(\mathrm{T}_{\mathrm{I}}, \mathrm{sec}\right)$, as well as ratios among them, such as PIF/MV, MIF/MV and duty time (DC, \%) were analyzed. The definition of each parameter is presented in Table 3.3.

Different average inhalation parameters were compared with the corresponding values obtained in the lab-based study; the average MV, PIF, and PIF/MV were compared with the theoretical values obtained from the empirical formula listed in ISO/TS 16976-1:2015. Specific calculation procedures are as follows:

Firstly, according to the classification of work rates (ISO/TS 16976-1:2015), the average metabolic rate of this "isolation unit work" was estimated as $165 \mathrm{~W} / \mathrm{m}^{2}$; then based on the relationship between metabolic rate and oxygen consumption (ISO/TS 16976-1:2015), assuming the energetic equivalent (EE) of oxygen is $5.815 \mathrm{Wh} / \mathrm{L} \mathrm{O}_{2}$, the 
theoretical oxygen consumption $\left(\mathrm{VO}_{2}, \mathrm{~L} / \mathrm{min}\right)$ when subjects performing the "isolation unit work" can be expressed by the A $A_{D u}$.

$$
\mathrm{VO}_{2}=\frac{165 \times A_{\text {Du }}}{60 \times 5.815}=0.4729 A_{\text {Du }}
$$

For 95\% of the populations, the estimated MV is

$$
\mathrm{MV}=41.48 \times \mathrm{VO}_{2}
$$

Several investigators reported that speech would change the respiratory dynamics, because speech is performed during the expiration phase of the breathing cycle, the inspiration phase is shortened accordingly (Dunn, 1996; Holmér et al., 2007; Wallaart \& Winder, 2002; Berndtsson, 2004). According to previous research, MV under speech condition was linearly related to MV under non-speech condition (Holmér et al., 2007; Berndtsson, 2004; ISO/TS 16976-1:2015), as summarized below:

$$
\mathrm{MV}_{\text {speech }}=0.8 \times \mathrm{MV}_{\text {no speech }}
$$

With shorter inhalation time, the PIF rates during speech were reported to increase even higher than during a non-speech breath (Holmér et al., 2007). Estimation of PIF based on MV under speech and non-speech conditions has been investigated by some scholars (Holmér et al., 2007; Berndtsson, 2004), the power function regression lines were found to report the highest correlation factors (ISO/TS 16976-1:2015), which were listed below: 


$$
\begin{gathered}
\mathrm{PIF}_{\text {speech }}=(0.8 \times \mathrm{MV}) \times 36.707 \times(0.8 \times \mathrm{MV})^{-0.4743} \\
\mathrm{PIF}_{\text {no speech }}=\mathrm{MV} \times 5.605 \times(\mathrm{MV})^{-0.1675}
\end{gathered}
$$

The correlations of MV, MIF and PIF with subjects' age, weight, height, $A_{D u}$ and BMI were analyzed; stepwise regressions of MV, MIF and PIF on subjects' physical characteristics were also performed. The linear regression model was established as shown below,

$$
\mathrm{MV}, \mathrm{MIF} \text { or } \mathrm{PIF}=\mu+\alpha \mathrm{Age}+\beta \mathrm{W}_{b}+\gamma \mathrm{H}_{b}+\tau \mathrm{A}_{\mathrm{D}_{\mathrm{u}}}+v \mathrm{BMI}+\varepsilon
$$

Where $\varepsilon \sim \mathrm{N}\left(0, \sigma^{2}\right)$.

For each subject, the fluctuations of per minute inhalation parameters along with time were analyzed. Through the combined PIF $F_{i}$ values (PIF rate during each breath cycle) of all subjects, a list of PIF percentiles was presented. All data analysis was performed by SAS version 9.3 (SAS Institute Inc., Cary, NC, USA). A P-value $<0.05$ was considered significant.

\section{Results and Discussion}

\section{Average Inhalation Parameters}

The average and $95 \%$ confidence intervals (CI) of the inhalation parameters during the 30-min "isolation unit work" were reported in Table 3. 3; the corresponding average values found with the lab-based study was also listed in the table to make a better comparison. 
As defined in ISO/TS 16976-1:2015, the estimated MV values for a small, medium, and large sized person $\left(\mathrm{A}_{\mathrm{Du}}=1.69,1.84\right.$, and $2.11 \mathrm{~m}^{2}$, respectively) when performing moderate work under no speech condition were 33,36 and $41 \mathrm{~L} / \mathrm{min}$, respectively. Since most subjects in this study are small/medium size (see Table 3. 1), and the average measured MV was $33 \mathrm{~L} / \mathrm{min}$, with $95 \% \mathrm{CI}$ of $29-36 \mathrm{~L} / \mathrm{min}$, it was concluded that the "isolation unit work" can be classified as a moderate workload task. The $95 \%$ CI for MIF was reported as $66-82 \mathrm{~L} / \mathrm{min}$, with the upper limit lower than the NIOSH filtration approval test flow rate for FFRs $(85 \mathrm{~L} / \mathrm{min})$. The PIF and $\mathrm{PIF}_{\max }$ were close to 115 and $170 \mathrm{~L} / \mathrm{min}$, the corresponding NIOSH testing flow rates for tight and loose fitting PAPRs, respectively. Field measured MV, MIF, PIF and PIF max were found to be significantly higher than that of the lab-based study. In the lab-based study, human subjects were allowed to take a 30 -second break between each two simulated exercises (each task run 1-min), while in this field study the workers performed tasks consistently without any breaks and there were a lot bent over postures when the subjects performing tasks such as Clean restroom, Dust mop, and Damp mop (Fig. 3. 1.), which were relatively heavier work activities than that of lab-based study, thus consequently resulted in higher inhalation flow rates.

There was no significant difference in $\mathrm{f}$ between the field ( 24 breaths/min) and lab based studies (22 breaths/min), thus the significantly higher MV, MIF, and PIF in this field study were mainly caused by the increase of TV, i.e., compared to the lab-based 
simulated exercises (1.04 L/breath), the HCWs during "isolation unit work" breath deeper (1.37 L/breath) to get more air inhaled.

At rest, a sinusoidal waveform would adequately represent the human breathing pattern (Cooper, 1960), then the PIF/MV ratio is equal $\pi$ or approximately 3.14 . As the increase of workload, the breathing pattern transformed to a more flatten shape (rectangular or trapezoidal) (Silverman et al., 1943; Lafortuna et al., 1984; Kaufman and Hastings, 2005). The PIF/MV ratio in this field study (3.33) was significantly lower than that of lab-based ratios (3.80), which was consistent with the above finding (i.e., the workload of tasks performed by HCWs in the field was higher than that of lab-based exercises). Both studies reported PIF/MV ratios $>3.14$, which may be caused by the influence of speech: In the lab-based study, the exercise of "Patient assessment—asking questions" involves subjects of speaking; while during the process of "isolation unit work", the HCWs made small talk with their colleagues occasionally. Since speech happened during the expiration phase of the breath cycle, it accordingly shortens the inspiration phase, within shorter $\mathrm{T}_{\mathrm{I}}$, the PIF was higher, resulting in higher PIF/MV ratios.

The MIF/MV in this study (2.30) was close to that of lab-based study (2.46), with both ratios $>2$, indicating that the inhalation time was less than half of the total breath time (this point can be further confirmed by the values of $\mathrm{T}_{\mathrm{I}}$ per minute $<30 \mathrm{sec}$ and DC\% > 0.5). It was believed this slight discrepancy between measured ratios and theory 
may be caused by two reasons. One was the speech influence, as aforementioned, speech happened during the exhalation phase thus the $\mathrm{T}_{\mathrm{I}}$ was significantly reduced. Another reason was the existence of pausing duration in the breath cycles. As reported by Silverthorn (2001), under rest, a breath cycle consists of three phases, exhalation, pause, and inhalation, with the increase of workload, the pause duration would be reduced. Under light or moderate activities, the "pause" still exists although reduced, thus the MIF/MV should be $>2$ regardless of with or without speech.

Since the "isolation unit work" can be classified as a moderate workload task, according to the physical characteristics of subjects in Table 3.1 and the empirical formulas 3-7 listed above (ISO/TS 16976-1:2015), the theoretical MV, PIF, and PIF/MV under both speech and non-speech conditions when HCWs performing the "isolation unit work" were obtained, as presented in Table 3. 4.

It was found that there was no significant difference between the theoretical MV, $\mathrm{PIF}$, and PIF/MV under non-speech condition and the corresponding measured values as listed in Table 3. 3. However, estimation of MV, PIF, and PIF/MV under speech condition was significantly different from the measured values (Table 3. 3 vs. Table 3. 4). Specifically, the theoretical MV was significantly lower than the measured value, while the theoretical PIF was significantly higher, resulting in significantly higher theoretical PIF/MV ratios (7-8) than the measured ratios. Therefore, it was concluded that the "isolation unit work" is very close to a non-speech condition, based on moderate 
workload and subjects' physical characteristics, the inspiratory flow of HCWs when performing "isolation unit work" can be estimated by the empirical formula listed in ISO/TS 16976-1:2015.

To investigate the relationship between inspiratory flow rates and subjects' physical characteristics, the correlations of MV, MIF and PIF with age, weight, height, $\mathrm{A}_{\mathrm{Du}}$ and BMI were shown in the Table 3.5.

As shown in Table 3. 5, the correlations of MV, MIF and PIF with weight, $\mathrm{A}_{\mathrm{Du}}$ and BMI were positive and significant; the correlations of inspiratory flow rates with subjects' height were also positive but insignificant. The correlations of MV, MIF and PIF with age were negative, indicating that with the increase of age, inspiratory flow tends to decrease, although this decrement was insignificant.

The expressions of MV, MIF and PIF as functions of age, weight, height, $A_{D u}$ and BMI were listed in Table 3. 6.

We can see that BMI had a significant effect on MV and PIF, while weight had a significant effect on MIF. Since both $A_{D u}$ and BMI are expressions of weight and height (ISO 8996:2004; Ancel Keys et al., 1972), height is insignificant; it can be concluded that weight has a significantly effect on subjects' inspiratory flow, as the increase of subjects' weight, the inspiratory flow increased significantly. Furthermore, from Table 3. 1 we can see that among nine HCWs, one subject is overweight, three subjects are obese; Pohjonen (2001) once reported that there was a prevalence of obesity among HCWs. Combining 
the above finding in this study, it was concluded that the prevalence of obesity may indirectly expose the HCWs to higher risk.

\section{Per Minute Inhalation Parameters}

Fluctuations of per minute MV, MIF, PIF, and $\mathrm{PIF}_{\max }$ during the "isolation unit work" were presented in Fig. 3. 2. We can see that with the increase of working time, MV and PIF tend to increase, while the increase of MIF and PIF $_{\max }$ were not obvious. The results reported here were reasonable, because in the latter process of the "isolation unit work", subjects need to bend over when performing tasks such as Clean restroom (clean stool, washbasin, bathtub, etc.), Dust mop (use a dry mop to clean the floor) and Damp mop (use a wet mop to clean the floor), which were relatively higher work rates.

The changes of $T_{I}, f$, and TV as time elapses were shown in Fig. 3. 3. It was found that minute $\mathrm{T}_{\mathrm{I}}$ and TV fluctuated during the "isolation unit work". Meantime, as the working process going on, breathing frequency (f) tend to increase, i.e., the subjects breath faster to get more air needed (increase of MV).

The fluctuations of PIF/MV and MIF/MV ratios along with time were presented in Fig. 3. 4. As can be seen, there were several peak values for both PIF/MV and MIF/MV ratios (when subjects occasionally talked with their colleagues). Except for these peak values, both PIF/MV and MIF/MV ratios fluctuated during the whole “isolation unit work". In addition, there was only small portion of PIF/MV and MIF/MV 
ratios $<3.14$ or 2.0 , which means that if we simply use the sinusoidal waveform to calculate PIF and MIF based on MV, the values of PIF and MIF may be underestimated.

Since time was not a significant factor that influences the PIF/MV and MIF/MV ratios, the real factor that may affect these rations was further investigated. As various studies have demonstrated that with the increase of workload, human breathing pattern transforms from a predominantly sinusoidal at rest to a rectangular or trapezoidal shape at higher work rates (Silverman et al., 1943, Lafortuna et al., 1984, Kaufman and Hastings, 2004), resulting in a decrease of PIF/MV ratio, the changes of PIF/MV and MIF/MV ratios along with MV were shown in Fig. 3. 5. We can see that as the increase of MV, both PIF/MV and MIF/MV decreased.

\section{PIF Percentiles}

The PIF values discussed above were either per minute averaged ones or average value during the whole "isolation unit work". Due to its great importance, a list of PIF percentiles for the peak inhalation flow rates during each breath cycle $\left(\mathrm{PIF}_{\mathrm{i}}\right)$ was shown in Table 3. 7. To make a better comparison, the percentiles of lab based data measured by SEA devices were also listed in the table. As expected, filed data reported significantly higher percentile values than that of lab based data, indicating that lab-based study may not be a good reflection of field study in measuring the PIF values. The $95^{\text {th }}$ percentile of 
field PIF was $157 \mathrm{~L} / \mathrm{min}$, lower than NIOSH approval minimum operational flow for loose fitting PAPRs.

\section{Summary}

The average MV, MIF, and PIF during "isolation unit work" were 33, 74, and 107 L/min, with 95\% CIs of 29-36, 66-82, and 96-118 L/min, respectively, which were higher than the corresponding lab-based values. The "isolation unit work" may be classified as a moderate workload task. It can be inferred that the significantly higher MV, MIF, and PIF were mainly caused by the increase of TV (from $1.04 \mathrm{~L} /$ breath in lab to $1.37 \mathrm{~L} /$ breath in field), since field study reported the close average $\mathrm{f}$ ( 24 breaths/min) as lab-based study (22 breaths/min). The field measured MV and PIF were very close to the theoretical values under no speech condition (35 and $108 \mathrm{~L} / \mathrm{min}$ ). The average field PIF/MV (3.33) and MIF/MV (2.30) ratios were close to the lab based values; average field PIF/MV was slightly higher than the theoretical ratio under non-speech condition (3.09), but significantly lower than that of the speech condition (7.59). Field average $T_{I}$ per minute was $26.4 \mathrm{sec}$. Correlation and regression analysis showed that as the weight of the HCWs increased, the inhalation flow increased significantly.

Per minute values of MV, PIF and $\mathrm{f}$ tend to increase as the work activities proceeded, while MIF, $\mathrm{PIF}_{\max }, \mathrm{T}_{\mathrm{I}}, \mathrm{TV}, \mathrm{PIF} / \mathrm{MV}$, and MIF/MV just showed fluctuations. The increase of MV may be attributed to the increase of f, i.e., as the increase of 
workload, the HCWs breathed faster rather than deeper. As the increase of MV, both PIF/MV and MIF/MV ratios decreased.

The $95^{\text {th }}, 70^{\text {th }}, 60^{\text {th }}, 20^{\text {th }}$, and $10^{\text {th }}$ percentiles of field PIF rates was $157,120,113$, 90, and $80 \mathrm{~L} / \mathrm{min}$, respectively, indicating that NIOSH may consider lowering the 170 $\mathrm{L} /$ min minimum operational flow for loose-fitting PAPRs used in healthcare environment when updating the future PAPR standards.

\section{Limitations}

There are still some limitations in this study. Firstly, only nine subjects (required number for a NIOSH pilot study) were recruited, a relatively small sample size; the age of the subjects distributed between 21-49 years old, to better estimate the respiratory flow characteristics of the whole population of $\mathrm{HCWs}$, more $\mathrm{HCW}$ s with wider range of age need to be recruited; only one department (Environmental Services Department) was investigated, data may vary for $\mathrm{HCWs}$ from other departments performing different daily work activities. Therefore, further studies on characterizing respiratory flow of HCWs from more departments are needed. 


\section{Conclusion}

The "isolation unit work" (a more physical demanding work in healthcare)

qualifies as a moderate workload activity. Correlation analysis showed that as the weight of the HCWs increased, the inhalation flow increased significantly. The MV, MIF, and

PIF during the "isolation unit work" were 33, 74, and $107 \mathrm{~L} / \mathrm{min}$, with $95 \%$ CIs of 29-36, 66-82, and 96-118 L/min, respectively, indicating that for NIOSH's future PAPR standards development, it may consider lowering the $170 \mathrm{~L} / \mathrm{min}$ minimum operational flow for loose-fitting PAPRs worn by HCWs in healthcare environment. The results obtained from this investigation can be considered for respirator certification, standards development, and respirator design to improve respiratory protection for HCWs. 


\section{Acknowledgement}

I'm grateful to Jim Harris, Dana Rottach, and Lew Radonovich of NIOSH/NPPTL for their valuable suggestions and critique review. This study was supported by the National Personal Protective Technology Laboratory (NPPTL), National Institute for Occupational Safety and Health (NIOSH) (Contract \# 200-2015-M-62385).

\section{Disclaimer}

The findings and conclusions of this article are those of the authors and do not necessarily represent the views of the National Institute for Occupational Safety and Health. Mention of a commercial product or trade name does not constitute endorsement by the National Institute for Occupational Safety and Health. 


\section{CHAPTER 4}

\section{A Preliminary Investigation on the Feasibility of Developing}

\section{"low-flow" Loose-fitting Powered Air-purifying Respirators for Healthcare Workers (Specific Aim 4)}

\section{Abstract}

Background: Loose-fitting powered air-purifying respirators (PAPRs) are increasingly being used by healthcare workers (HCWs). Current NIOSH approval minimum operational flow for PAPRs are based on data collected from industrial workers who perform moderate to high work activities. As the work intensity levels for HCWs are lower, it may be necessary to develop a "low-flow" PAPR to be used in hospital environment.

Objective: Through characterization of the breathing flow for HCWs to determine the feasibility of lowering the blower flow of loose-fitting PAPRs.

Methods: The study consists two stages: 1) lab-based investigation of 15 human subjects' breathing pattern during a series of simulated healthcare work activities; 2) field characterization of respiratory flow for nine HCWs when performing the "isolation unit work" (thorough cleaning and disinfecting of a patient room, a more physical demanding work). Mean inspiratory tidal volume $\left(\mathrm{V}_{\mathrm{T}}, \mathrm{L}\right)$, the percentages of overflow volume $\left(\mathrm{V}_{\text {over, }} \%\right)$ and time $\left(\mathrm{T}_{\text {over }}, \%\right)$ with inhalation flow $>85,115$, and $170 \mathrm{~L} / \mathrm{min}$ were presented and compared with the NIOSH respirator approval test flow requirements. The protection factor of overbreathed loose-fitting PAPRs ( $\mathrm{PF}_{\text {over }}$ ) was estimated based on $\mathrm{V}_{\text {over }} \%$ and $\mathrm{T}_{\text {over }} \%$.

Results: Much lower than $1 \%$ of $\mathrm{V}_{\text {over }} \%$ and $\mathrm{T}_{\text {over }} \%$ with inhalation flow $>170 \mathrm{~L} / \mathrm{min}$ were observed during the simulated exercise of "patient assessment" and field "isolation unit work", which indicates that there is a very small possibility of exceeding $170 \mathrm{~L} / \mathrm{min}$ in terms of breathing volume and duration. Without considering dead volume $\left(\mathrm{V}_{\text {dead }}=0\right.$, worst case), the fifth percentile $\mathrm{PF}_{\text {over }}$ values were 156 and 257 for the above two job tasks, respectively; considering $\mathrm{V}_{\text {dead }}=1.4 \mathrm{~L}$ as buffer, fifth percentile $\mathrm{PF}_{\text {over }}$ values were infinite. It was concluded that during 
HCWs' light/moderate routine job tasks, momentary overbreathing events have minimal effect on protection offered by loose-fitting PAPRs.

Conclusion: The findings suggest that NIOSH may consider updating respirator test standards to approve a new class of "low-flow" loose-fitting PAPRs to be used in healthcare settings. In addition, this study points a novel approach to characterize breathing flow and to evaluate respirator efficacy.

Keyword: healthcare worker, powered air-purifying respirator, overbreathing, protection factor, dead volume 


\section{Introduction}

In America, more than 18 million healthcare workers (HCWs) are relying on respirators, face shields, gowns, and/or gloves to reduce the occupational exposure to various infectious agents (CDC, 2014). Surgical masks and N95 filtering facepiece respirators (FFRs) are traditional respiratory protection equipment (RPE) used by HCWs in hospital environment (Carias et al., 2015; Wizner et al., 2016). However, various studies have shown that surgical masks are not designed to protect against bioaerosols $<1 \mu \mathrm{m}$, and N95 FFRs are not comfortable to use due to high breathing resistance (Davidson et al., 2013; He et al., 2013b; 2014; Rengasamy et al., 2014). Frequently outbreaks of highly contagious pathogens (e.g., 2003 SARS, 2009 H1N1, and 2014 Ebola) have emphasized the need of powered air-purifying respirators (PAPRs) for HCWs (Khoo et al., 2005; IOM, 2015; Wizner et al., 2016).

Defined as "an air-purifying respirator that uses a blower to force the ambient air through air-purifying elements to the inlet covering" (OSHA, 2006), a PAPR is by design intended to maintain a positive pressure in the inlet covering, thus offering dramatically higher assigned protection factors (APFs, vary from 25-1000) than that of FFRs (APF = 10) (OSHA, 2006). The National Institute for Occupational Safety and Health (NIOSH) approved PAPRs can be classified into two types, i.e., tight-fitting (sealed completely to the face/neck) and loose-fitting (no airtight seal with face/neck) (OSHA, 2006). Compared to N95 FFRs, a loose-fitting PAPR features several additional benefits to HCWs: 1) requires no annual fit testing (compatibility with facial hair, corrective eyewear and various facial structures) (Roberge, 2008; Johnson et al., 2008; IOM, 2015); 2) provides barrier against infectious blood or body fluid spray to the neck or shoulders (Bergman et al., 2017); 3) alleviates humidity/moisture building up inside the wear's 
breathing zone; 4) requires no breathing resistance even overbreathed (i.e., inspiratory flow exceeds the airflow supplied by the blower and therefore negative pressure presents in the inlet covering) (Johnson et al., 2011; Bergman et al., 2017). Consequently, loose-fitting PAPRs are preferred by HCWs (Baig et al., 2010).

Under overbreathing condition of a tight-fitting PAPR, the wearer will have to increase the respiratory effort to breathe through the filter resistance (Johnson et al., 2005a); while for a loose-fitting PAPR, aerosols may bypass the filter and leak directly into the mask through the gaps between the face-to-facepiece seal, potentially exposing wearers to leakage contaminants. Therefore, to receive approval from NIOSH, loose-fitting PAPRs must provide a minimum of $170 \mathrm{~L} /$ min constant flow, apparently higher than the $115 \mathrm{~L} / \mathrm{min}$ for tight-fitting PAPRs (OSHA, 1998). Since PAPRs were originally developed to protect industrial workers (OSHA, 1998), these testing flow rates were collected based on the workloads found in industrial settings (primarily in mining) half century ago (Bloomfield and Greenburg, 1933; Burgess and Reist, 1969). Nowadays, several great changes have taken place (Johnson et al., 2005b):1) as the advance of respiratory flow recording technology, breathing flow could be sampled almost instantaneously (e.g., 50 or $100 \mathrm{HZ}$; collected data can be influenced by sampling rate because airflow changes rapidly); 2) workers' physical characteristics (e.g., weight, height, etc.) were different; and 3) employee pools have also changed (e.g., more females, mixed races, etc.). Loose-fitting PAPRs are increasingly being used in hospital environment, in which the work rates experienced by HCWs were significantly lower than that of the industrial workers (ISO/TS 16976-1:2015). Therefore, different approval standards for PAPRs (perhaps lower minimum operational flow) to be applied in healthcare settings may be required. If a new type of "lowflow" PAPRs would be introduced with more compact designs (less airflow passing through the 
filter and less power required from the battery resulting in quieter blower motor and smaller sizes of battery and filter), it would be favorably more acceptable for medical institutions.

Currently, there are limited data available regarding the inspiratory flow for industrial workers when performing the daily work activities, and no traceable investigations were published on breathing flow required by HCWs. Peak inhalation flow (PIF, L/min) is generally reported as a key value to characterize airflow achieved by subjects; to assure protection, it was assumed that PAPR blower should be operated at the flowrate no less than the PIF ( $>300 \mathrm{~L} / \mathrm{min}$ ) measured at heavy to maximal work rates (Cohen et al., 2001; Berndtsson, 2004; Janssen et al., 2005; Martin et al., 2006). However, it should be noted that those workloads were nonsustainable, and that the duration of PIF was generally no more than 0.01-0.1s per breath (Bryant and Mensch, 2011). The dose of a toxic material received by an individual is the product of the contaminant concentration, inspiratory flow rate, and inhalation time; therefore, from the perspective of inhalation exposure control, the investigation on the percentages of overflow volume $\left(\mathrm{V}_{\text {over }} \%\right)$ and overflow time $\left(\mathrm{T}_{\text {over }} \%\right)$, defined as the fraction of inspiratory air volume during certain period of breath time with inhalation flow exceeding a specific airflow rate (e.g., 115 or $170 \mathrm{~L} / \mathrm{min}$ ), are very important. To assess the overbreathing issue of respiratory protection devices (including PAPRs), $\mathrm{V}_{\text {over }} \%$ and $\mathrm{T}_{\text {over }} \%$ are more meaningful indicators of an individual's inspiratory flow than the PIF rates that occur so brief and infrequently.

With the help of a novel personal breathing recording device, this study sought to characterize HCWs' breathing flow in a new view of $\mathrm{V}_{\text {over }} \%$ and $\mathrm{T}_{\text {over }} \%$, based on which simple calculation models were applied to estimate the protection factor offered by loose-fitting PAPRs. The study consists of two stages: 1) lab-based investigation of subjects' breathing pattern during a series of simulated healthcare work activities; 2) field characterization of HCWs' respiratory 
flow when performing their daily work activities. The overall goal was to determine the feasibility of lowering the minimum operational flow requirement for loos-fitting PAPRs when used by HCWs.

\section{Methods}

\section{Instrumentation}

An innovative respiratory flow recording device (SEA Pty Ltd., Australia) was employed in this study. The device contains a rapid response differential pressure sensor built inside an elastomeric half-mask respirator (Small/Medium, Medium/Large, or Large/Extra Large), thus can be worn by users with different facial dimensions without interfering with their routine job tasks. Pressure change between outside and inside of the respirator filter can be instantaneously measured and stored in a data logger (a reading is taken per 20 millisecond, i.e., $50 \mathrm{HZ}$ ), which is then converted into respiratory flow rate through the predetermined relationship curve between pressure drop and airflow rate. The data logger is small enough to be belt or pocket mounted and can operate through the entire 8-hour work shift. The device is capable of measuring inspiratory flow rates up to $400-500 \mathrm{~L} / \mathrm{min}$, high enough to cover the PIF reported during the maximal work rates (Cohen et al., 2001; Berndtsson, 2004; Janssen et al., 2005; Martin et al., 2006).

\section{Experimental Design}

In the lab-based stage, a group of 15 human subjects (eight males and seven females with the average age, height, and weight of $27.3 \pm 3.9$ years, $171.7 \pm 10.5 \mathrm{~cm}$, and $69.8 \pm 12.9 \mathrm{~kg}$ ) were recruited from the general population. Prior to subject recruitment, Internal Review Board (IRB) (protocol No. 1507752444) from the West Virginia University (WVU) was obtained. 
Potential subjects were given the OSHA Respirator Medical Evaluation Questionnaire (OSHA, 1998), and only those who were medically cleared were allowed to participate in the test. Subjects were asked to perform the following work activities to simulate those commonly seen in the healthcare settings: 1) Patient assessment - asking questions; 2) Vitals - measuring blood pressure, temperature, and heart rate; 3) IV treatment - administering IV care using a manikin; 4) Changing linen; 5) Carrying $2.5 \mathrm{~kg}$ weight while walking; 6) Normal breathing while standing. Each task lasted 1-min and was repeated three times, resulting in total runs of 15 subjects $\times 6$ exercises $\times 4$ replicates $=360$. During each replicated test, the six exercises were fully randomized to minimize the effect of experimental error (i.e., a randomized block experimental design).

In the field investigation, the selection of test subjects (HCWs) was based on previous experience of using PAPRs. Activities with higher work load intensity (i.e., higher inspiratory flow required) were given the first consideration. After discussing with potential subjects, the "isolation unit work" - which includes thorough cleaning and disinfecting of a patient room within 30 minutes - was identified as a physically demanding task with a risk of infectious exposure. Nine HCWs (two males and seven females) from the Environmental Services Department, Monongahela General Hospital, Morgantown, WV participated in this field investigation. Subjects' age, height, and weight were $37.1 \pm 10.6$ years, $161.4 \pm 4.9 \mathrm{~cm}$, and 76.5 $\pm 23.9 \mathrm{~kg}$ (means \pm standard deviation), respectively. Recruitment procedures were in accordance with the ethical approvals of the WVU and the Monongahela General Hospital. The breathing flow for HCWs when performing the "isolation unit work" were recorded; sampling time was around 30-min for each HCW. 


\section{Data Analysis}

Mean inspiratory tidal volumes $\left(\mathrm{V}_{\mathrm{T}}, \mathrm{L}\right)$ for each of the six simulated exercises as well as for the field "isolation unit work" were reported. The percentages of overflow volume $\left(\mathrm{V}_{\text {over, }} \%\right)$ and time $\left(\mathrm{T}_{\mathrm{over}}, \%\right)$ with inhalation flow exceeding 85,115 , and $170 \mathrm{~L} / \mathrm{min}$ were calculated and compared with the current NIOSH respirator approval test flow requirements. Illustration of $\mathrm{V}_{\mathrm{T}}$, $\mathrm{V}_{\text {over }} \%$, and $\mathrm{T}_{\text {over }} \%$ were shown in Fig. 4. 1. Based on $\mathrm{V}_{\text {over }} \%$ and $\mathrm{T}_{\text {over }} \%$ with airflow $>170$ $\mathrm{L} / \mathrm{min}$, simple calculation models were applied to estimate the protection factor of overbreathed loose-fitting PAPRs ( $\left.\mathrm{PF}_{\text {over }}\right)$.

\section{Results}

\section{Tidal Volume $\left(\mathbf{V}_{\mathbf{T}}\right)$}

The $\mathrm{V}_{\mathrm{T}}$ values for the six exercises in the simulated healthcare environment and the "isolation unit work" in an actual hospital were presented in Table 4. 1. As can be seen, the values of $\mathrm{V}_{\mathrm{T}}$ were relatively unchanged among the six simulated exercises $(0.96-1.10 \mathrm{~L})$. Analysis of variance (ANOVA) revealed that there was no significant difference $(p>0.05)$. Compared to the lab-based data, field investigation reported a significantly higher $\mathrm{V}_{\mathrm{T}}(1.32 \mathrm{~L})$. The $\mathrm{V}_{\mathrm{T}}$ measured in this study was consistent with the values reported by Kaufman and Hastings (2005) for rest condition $(0.97 \pm 0.22 \mathrm{~L})$ or light to moderate work rates $(1.23 \pm 0.27 \mathrm{~L})$, while significantly lower than the $\mathrm{V}_{\mathrm{T}}$ values found with Sue and Hansen (1984) $(2.28 \pm 0.43 \mathrm{~L})$ and Blackie et al. (1991) (1.9 $\pm 0.4 \sim 2.7 \pm 0.5 \mathrm{~L})$ at maximal exercise, or Kaufman and Hastings (2005) $(2.33 \pm 0.63 \mathrm{~L})$ and Lerman et al. (1983) $(1.78 \mathrm{~L})$ during heavy exertion. The results suggest that 
HCWs' daily job activities can be classified as light/moderate workload tasks, which were much lower than heavy/maximal physical exertion.

\section{Percentages of Overflow Volume $\left(\mathrm{V}_{\text {over }} \%\right)$ and Time $\left(\mathrm{T}_{\text {over }} \%\right)$}

$\mathrm{V}_{\text {over }} \%$ and $\mathrm{T}_{\text {over }} \%$ (when inhalation flow $>85,115$, and $170 \mathrm{~L} / \mathrm{min}$ ) during the six simulated healthcare job tasks and the field "isolation unit work" were reported in Tables 4. 2 and 4. 3 .

During six simulated exercises, $5 \%-37 \%$ of air volume during $1 \%-8 \%$ of the exercise time was inhaled by the subjects with inhalation flow rate exceeding $85 \mathrm{~L} / \mathrm{min}$. Around $10 \%$ of air volume during $1 \%$ of breath time flow over $115 \mathrm{~L} / \mathrm{min}$ was discovered during the "patient assessment" activity, while all other five "non-speech" exercises sparsely reported $\mathrm{V}_{\text {over }} \%$ and $\mathrm{T}_{\text {over }} \%$ with small values. The reported data here indicates that doctors and nurses should use NIOSH approved N95 FFRs with caution in the hospital environment, especially when communicating with infectious patients, as considerable amount of air would exceed the N95 FFRs' approval test flow rate (85 L/min constant flow). Since numerous studies have demonstrated that tight-fitting PAPRs allow negative pressure excursions in the inlet covering (Raven et al., 1982; Dahlback and Novak, 1983), although overbreathing happened, it may have neglectable effect on the protection offered by a tight-fitting PAPR. On the other hand, much lower than $1 \%$ of $\mathrm{T}_{\text {over }} \%$ and $\mathrm{V}_{\text {over }} \%$ were observed for inhalation flow $>170 \mathrm{~L} / \mathrm{min}$ (the current NIOSH testing flow for loose-fitting PAPRs), which indicates that there is a very small possibility of exceeding $170 \mathrm{~L} / \mathrm{min}$ in terms of breathing duration and breathing volume.

During the field "isolation unit work", over half of the air volume (57\%) during certain period of working time $(18 \%)$ was inhaled with flow rate $>85 \mathrm{~L} / \mathrm{min}$. Over $15 \%$ of the inhaled 
air volume and approximately only $4 \%$ of the breath time was measured with breathing flow $>115 \mathrm{~L} / \mathrm{min}$. The inspiratory flow $>170 \mathrm{~L} / \mathrm{min}$ was very small $\left(\mathrm{V}_{\text {over }}=0.33 \%\right)$ and extremely short ( $\mathrm{T}_{\text {over }}<0.1 \%$ ), indicating that the airflow supply of a loose-fitting PAPR blower is more than adequate for HCWs when performing the "isolation unit work". Compared to the "non-speech" simulated exercises, the $\mathrm{V}_{\text {over }} \%$ and $\mathrm{T}_{\text {over }} \%$ obtained in the hospital study were significantly higher, which may be caused by the higher $\mathrm{V}_{\mathrm{T}}$ values (see Table 4. 1), indicating that the labbased study may underestimate the inspiratory flow needed by HCWs in actual healthcare environment.

Through literature review, it was found that limited data were available regarding $\mathrm{V}_{\text {over }} \%$ and $\mathrm{T}_{\text {over }} \%$. During an agility test performed by the US marine corps, Berndtsson et al. (2002) reported that $78 \pm 10 \%$ and $36 \pm 14 \%$ of air volume was flowing faster than 85 and $115 \mathrm{~L} / \mathrm{min}$, respectively. Their test included exercises such as stair climb, horse drag, forced entry, and open/close a smoke hatch, which were much heavier exertions than the healthcare work activities, therefore significantly higher $\mathrm{V}_{\text {over }} \%$ and $\mathrm{T}_{\text {over }} \%$ were reported in that study.

\section{Discussion}

The prevailing assumption surrounding a loose-fitting PAPR is that, as long as positive pressure is maintained within the inlet covering, over supplied air would flow from inside to the outside, thus inward leakage of contaminants would not occur even break/opening exists at the interface of the facepiece and the wearer's face/neck (Johnson et al., 2011; Bergman et al., 2017). However, based on current NIOSH PAPR approval standards, a loose-fitting PAPR is not certified as a "positive-pressure" device (Bergman et al., 2017). By determining the occurrence of negative pressure inside the facepiece, overbreathing of loose-fitting PAPRs has been reported 
by various studies (Cohen et al., 2001; Mackey et al., 2005; Sinkule et al., 2016). Since these negative pressure events are brief and infrequent (on the order of several tenths of inspiratory phase during a breath cycle), the influence of overbreathing on the protection offered by loosefitting PAPRs has been a longstanding debate (Cohen et al., 2001).

Both mainkin- and human- based studies have been designed to assess the performance of losse-fitting PAPRs (Cohen et al., 2001; Koivisto et al., 2015; Gao et al., 2016; Bergman et al., 2017). Particle counters were applied to measure aerosol concentration outside ( $\left.\mathrm{C}_{\mathrm{out}}\right)$ and inside $\left(\mathrm{C}_{\mathrm{in}}\right)$ the inlet covering. Protection factor $(\mathrm{PF})$ was determined as the ratio of $\mathrm{C}_{\text {out }}$ to $\mathrm{C}_{\text {in. }}$. It was found that, even under overbreathing condition, the fifth percentile PFs of loose-fitting PAPRs $\left(769\right.$ to $>10^{6}$ ) were still significantly greater than their designated OSHA APFs ( 25 or 1000-only when demonstrated by the manufacturer; to be simplify, in the following discussion, we would assume the APF of a loose-fitting PAPR=25) (OSHA, 2006). However, the sampling rates of current particle counters ( 1 reading/second) were typically longer than the momentary overbreathing durations $(0.01-0.1 \mathrm{sec})$, thus it is possible that the peak values of $\mathrm{C}_{\mathrm{in}}$ were missed (Johnson et al., 2011).

When a loose fitting PAPR was overbreathed, the dose of contaminants received by the wearer depends, therefore, on the level and duration of the overbreathing flow (i.e., $\mathrm{V}_{\text {over }}$ and $\mathrm{T}_{\text {over }}$ ), which can be characterized as $\mathrm{V}_{\text {over }} \%$ and $\mathrm{T}_{\text {over }} \%$ when divided by the total inspired air volume $\left(\mathrm{V}_{\mathrm{T}}\right)$ and breath time $\left(\mathrm{T}_{\mathrm{tot}}\right)$ (see Fig. 4. 1). Since in this study, we were more concerned about the inward leakage of unfiltered air, the PAPR filters were assumed to have a $100 \%$ filtration efficiency (i.e., the air volume supplied by the blower was particle free). Thus, according to the mass/count conservation of aerosols inside and outside the mask, the following equation can be obtained (Johnson et al., 2011; Mukhametzanov et al., 2016): 


$$
Q_{\text {leak }} \times C_{\text {out }}=V_{T} \times C_{\text {in }}
$$

Where $Q_{\text {leak }}$ is the leak-in air volume. Because $\mathrm{V}_{\text {over }}$ may come from air volume breathed through the filters (i.e., increasing respiratory effort), the dead volume of the inlet covering $\left(\mathrm{V}_{\text {dead }}\right)$, or the $\mathrm{Q}_{\text {leak }}$, it was reasonable to say that:

$$
V_{\text {over }} \geq Q_{\text {leak }}
$$

Based on the definitions of $\operatorname{PF}\left(\mathrm{C}_{\text {out }} / \mathrm{C}_{\text {in }}\right)$ and $\mathrm{V}_{\text {over }} \%\left(\mathrm{~V}_{\text {over }} / \mathrm{V}_{\mathrm{T}}\right)$, and equations 1 and 2 , the protection offered by a loose-fitting PAPR when overbreathed $\left(\mathrm{PF}_{\text {over }}\right)$ and during the total breath time $\left(\mathrm{PF}_{\mathrm{ave}}\right)$ can be estimated as:

$$
\begin{gathered}
P F_{\text {over }}=\frac{V_{T}}{Q_{\text {leak }}} \geq \frac{V_{T}}{V_{\text {over }}}=\frac{1}{V_{\text {over }} \%} \\
P F_{\text {Ave. }} \geq P F_{\text {over }} \times T_{\text {over }} \%+A P F \times\left(1-T_{\text {over }} \%\right) \\
\geq A P F+\left(\frac{1}{V_{\text {over }} \%}-A P F\right) \times T_{\text {over }} \%
\end{gathered}
$$

The measurements of $\mathrm{V}_{\text {over }} \%$ with breathing flow $>170 \mathrm{~L} / \mathrm{min}$ (Table 4. 2) were applied in equation 3, fifth percentile $\mathrm{PF}_{\text {over }}$ during each exercise was presented in Table 4.4 (first column). It was found that all $\mathrm{PF}_{\text {over }}$ values were significantly greater than 25 . According to equation 4 , it was found that when $\mathrm{V}_{\text {over }} \%$ was $<4 \%$, the time weighted average $\mathrm{PF}-\mathrm{PF}_{\text {ave. }}$ should always be $>A P F=25$. Since $V_{\text {over }} \%$ values in Table 4. 2 were much lower than $4 \%$, it can be concluded that the momentary overbreathing excursions during either simulated "patient assessment" or field "isolation unit work" have no effect on overall protection performance of a loose-fitting PAPR. 
Above analysis was based on the worst case HCWs may experience, that is, all overbreathed volume of air was leaked into the inlet covering through the break between the face/neck-to-facepiece, and there is a preferential path for the inward leakage air flow directly into mouth/nose of the wearer during the inspiratory phase of a breath cycle (i.e., $V_{\text {dead }}=0$ ). In reality, the dead volume within the PAPR enclosure can act as a buffer. Before leaked contaminants reaching the mouth, inspiratory phase may cease, and clean air supplied by the blower during exhalation would swept the contaminant-laden air out of the breathing zone (Johnson et al., 2011). In this case, overbreathing a loose fitting PAPR would have no effect on the wearer (Bostock, 1985). More and more loose-fitting PAPRs apply the principle of dead volume protection (Johnson et al., 2011), and current measurements of $\mathrm{V}_{\text {dead }}$ ranged from 1.4-2 L (Mackey et al., 2005; Johnson et al., 2011). Assuming the $\mathrm{V}_{\text {dead }}=1.4 \mathrm{~L}$ and whole volume works perfectly as buffer (an ideal condition), the $\mathrm{PF}_{\text {over }}$ would be:

$$
P F_{\text {over }} \leq \frac{V_{T}}{V_{\text {over }}-V_{\text {dead }}}=\frac{1}{V_{\text {over }} \%-\frac{V_{\text {dead }}}{V_{T}}}
$$

The resulting fifth percentile $\mathrm{PF}_{\text {over values were all infinite (see Table 4. 4), which means }}$ that the leakage air volumes during routine job tasks tested in both simulated and actual hospital environment were less than the $1.4 \mathrm{~L}$ dead volume. It tells us that even mild overbreathing conditions ("patient assessment" and "isolation unit work") occurred, and contaminants may leak into the inlet covering. Buffered by the large dead volume of the facepiece, contaminated air cannot reach the mouth and be inhaled by the $\mathrm{HCW}$. Consequently, overbreathing a loose-fitting PAPR during light/moderate workload activities is not necessarily going to compromise its protection. 
It is unlikely for a RPE to protect $100 \%$ of the population at all times (such a device would be either too bulky or too expensive to be acceptable) (Johnson et al., 2005b), however, it might be necessary to design a specialized device to be used by a certain group of workers $100 \%$ of the time (e.g., a new class of "low-flow" loose-fitting PAPRs to be worn by HCWs). From the inhalation exposure control perspective, it is suggested that $\mathrm{V}_{\text {over }} \%$ and $\mathrm{T}_{\text {over }} \%$ can be incorporated into respiratory testing standards. Such terms are useful for predicting the level of protection offered by the respirators. Even in the worst case $\left(\mathrm{V}_{\text {dead }}=0\right)$, the analysis of $\mathrm{V}_{\text {over }} \%$ and $\mathrm{T}_{\text {over }} \%$ showed that HCWs would be well protected by loose-fitting PAPRs when performing daily work activities. Therefore, it is safe to conclude that NIOSH may consider lowering the $170 \mathrm{~L} / \mathrm{min}$ minimum operational flow for loose-fitting PAPRs used in healthcare settings when updating the future PAPR standards.

\section{Limitations}

There are still some limitations in this study. Only nine (required number of a NIOSH pilot study) HCWs from one department (workers from Environmental Services Department performing a physical demanding job task) were employed in the field study. How applicable are these results to HCWs in other departments performing different tasks is unknown and warrants for future investigations.

\section{Conclusion}

The findings suggest that it may be necessary for NIOSH to consider adopting a new class - "low-flow" loose-fitting PAPRs into the certification program to be used by HCWs. In addition, this study points to a different way to evaluate the efficiency of respirators (e.g., using the percentages of overflow volume and time to estimate the protection factor of an overbreathed 
loose-fitting PAPR). The reported data would fill the gap of filed investigation of respiratory

flow characteristics of HCWs, and could be served as a reference for respirators' design, test and certification to improve respiratory protection for HCWs. 


\section{Limitations, Overall Conclusions, and Future Directions}

\section{Limitations}

There are still some limitations in this study.

1) Only nine HCWs from one department (workers from Environmental Services

Department performing a physical demanding job task) was investigated, data may vary for HCWs from other departments performing different daily work activities.

2) Only healthy non-pregnant workers were considered and investigated. The inspiratory flow rates of those with anxiety, asthma, early fibrotic disease, and pregnancy may be greater.

Due to the limited tasks assessed in this study, it is important to not over-interpret the study findings to the broader list of healthcare worker activities which were not studied and could, if different, might leave HCW unprotected during other patient handling activities, for example.

\section{Overall Conclusions}

In summary, the reported data in this dissertation would fill the gap of filed investigation of respiratory flow characteristics of healthcare workers (HCWs), and could be served as a reference for respirator manufacturers, regulatory agencies, and respiratory protection researchers when designing, certifying, and testing respirators to be used in healthcare environment. The following conclusions were drawn from this research. 
3) This study demonstrated a novel approach to characterize respiratory flow for HCWs using an innovative wearable flow recording device;

4) HCWs' daily work activities can be classified as light/moderate workload tasks;

5) Based on body measurements and workloads, the inspiratory flow of HCWs can be estimated from the empirical formula listed in ISO/TS 16976-1:2015;

6) Speech would significantly increase the peak inhalation flow (PIF), resulting in considerable and slight overbreathing of filtering facepiece respirators (FFRs) and loose-fitting PAPRs, respectively;

7) During HCWs' light/moderate routine job tasks, momentary overbreathing events have minimal effect on protection offered by loose-fitting PAPRs;

8) NIOSH may consider updating respirator test standards to approve a new class of "low-flow" loose-fitting PAPRs worn by HCWs;

9) This study points to a different way to evaluate the efficiency of respirators, i.e., using the percentages of overflow volume $\left(\mathrm{V}_{\text {over }} \%\right)$ and time $\left(\mathrm{T}_{\text {over }} \%\right)$ to estimate the protection factor of an overbreathed loose-fitting PAPR.

\section{Future Directions}

The following three main directions are to be considered for the future research efforts:

1) Further studies on characterizing respiratory flow of HCWs from differeent departments are needed.

2) Future evaluations should utilize a particle counter with a faster sampling rate (e.g., $50 \mathrm{HZ}$ ) to determine the protection factor of an overbreathed PAPR (PFover), thus the relationship between the $\mathrm{PF}_{\text {over }}$ and $\mathrm{V}_{\text {over }} \%$ (or $\mathrm{T}_{\text {over }} \%$ ) could be established. 
3) The workplace protection factor (WPF) of FFRs when HCWs performing their routine job tasks, expecially when communicating with patients with infectious disease, should be tested in future investigations. 


\section{REFERENCES}

Baig, AS, Knapp S, Eagan AE, Radonovich LJ. (2010) Health care workers' views about respirator use and features that should be included in the next generation of respirators. Am. J. Infect Control.; 38(1): 18-25.

Bałazy A, Toivola M, Reponen T, Podgórski A, Zimmer A, Grinshpun SA. (2005) Manikin-based performance evaluation of N95 filtering-facepiece respirators challenged with nanoparticles. Ann. Occup. Hyg.; 50: 259-269.

Bergman MS, Basu R, Lei Z, Niezgoda G, Zhuang Z. (2017) Development of a Manikin-Based Performance Evaluation Method for Loose-Fitting Powered Air-Purifying Respirators. J. Int. Soc. Resp. Prot.; 34: 40-57.

Berndtsson G. (2004) Peak inhalation air flow and minute volumes measured in a bicycle ergometer test. J. Int. Soc. Resp. Prot.; 21(1-2): 21-29.

Berndtsson G, Howie R, Kjellberg B, Simmons P, Berndtsson F, Berndtsson K. November 272002. "Peak Inhalation Air Flow During an Agility Test Performed by the U.S. Marine Corps". November 27, S.E.A. Group Report.

Blackie SP, Fairbarn MS, McElvaney NG, Wilcox PG, Morrison NJ, Pardy RL. (1991) Normal values and ranges for ventilation and breathing pattern at maximal exercise. Chest; 100: 136-142.

Bland JM, Altman DG. (2003) Applying the right statistics: Analyses of measurement studies. Ultrasound Obstet Gynecol; 22: 85-93.

Bland JM, Altman DG. (2007) Agreement between methods of measurement with multiple observations per individual. J. Biopharm Stat.; 17: 571-82.

Bloomfield J, Greenburg L. (1933) Sand and metallic abrasive blasting as an industrial health hazard. J. Ind. Hyg.; 15: 184-204.

Boskovic L, Agranovski IE, Altman IS, Braddock RD. (2008) Filter efficiency as a function of nanoparticle velocity and shape. J. Aerosol Sci.; 39: 635-644.

Boskovic L, Agranovski IE, Braddock RD. (2007) Filtration of nanosized particles with different shape on oil coated fibres. J. Aerosol Sci.; 38: 1220-1229.

Bostock JG. (1985) An investigation into the performance of positive pressure powered dust hoods and blouses at low flow rates, Ann. Occup. Hyg.; 29(3): 415-420.

Bryant RA, Mensch A. (2011) Characterizing inward leakage in a pressure-demand, self-contained breathing apparatus. J. Occup. Environ. Hyg.; 8(7): 437-446.

Burgess WA, Reist PC. (1969) Supply rates for powered air-purifying respirators. Am. Ind. Hyg. Assoc. J.; 30: 1-6.

Carias C, Rainisch G, Shankar M, Adhikari BB, Swerdlow DL, Bower WA et al. (2015) Potential Demand for Respirators and Surgical Masks during a Hypothetical Influenza Pandemic in the United States. Clin. Infect. Dis. 60 (suppl_1): S42-S51. 
Castro M. (1998). Control of breathing. Physiology, 4th ed. Mosby, St. Louis.

CDC. (2014) Workplace safety and health topics: Healthcare workers. https://www.cdc.gov/niosh/topics/healthcare/. Accessed 11 March 2018.

Chen CC, \& Willeke K. (1992). Aerosol penetration through surgical masks. Am. J. Infect Control.; 20(4), 177-184.

Cho KJ, Reponen T, Mckay R, Shukla R, Haruta H, Sekar P, Grinshpun SA. (2009) Large particle penetration through N95 respirator filters and facepiece leaks with cyclic flow. Ann. Occup. Hyg. 54: 68-77.

Coffey CC, Lawrence RB, Campbell DL, Zhuang Z, Calvert CA, Jensen PA. (2004) Fitting characteristics of eighteen N95 filtering-facepiece respirators. J. Occup. Environ. Hyg.; 1: 262-271.

Cohen HJ, Hecker LH, Mattheis DK, Johnson JS, Biermann AH, Foote KL. (2001) Simulated workplace protection factor study of powered air-purifying and supplied air respirators. Am. Ind. Hyg. Assoc. J.; 62: 595-604.

Cooper E. (1960) A comparison of the respiratory work done against an external resistance by man and by a sine-wave pump. Exp. Physiol.; 45: 179-191.

Dahlback, G.O. and L. Novak. (1983) Do pressure-demand breathing systems safeguard against inward leakage? Am. Ind. Hyg. Assoc. J.; 44(5): 336-340.

Davidson CS, Green CF, Gibbs SG, Schmid KK, Panlilio AL, Jensen PA, Scarpino PV. (2013) Performance evaluation of selected N95 respirators and surgical masks when challenged with aerosolized endospores and inert particles. J. Occup. Environ. Hyg.; 10: 461-467.

Doney BC, Groce DW, Campbell DL, Greskevitch MF, Hoffman WA, Middendorf PJ, Syamlal G, Bang KM. (2005) A survey of private sector respirator use in the United States: an overview of findings. J. Occup. Environ. Hyg.; 2: 267-276.

Dunn, B. (1996). A study of the relationship between minute volume and instantaneous peak flows during the inspiration phase of the respiratory cycle and the factors influencing the worker's respiration (Master of Applied Science): University of South Wales.

Eninger RM, Honda T, Adhikari A, Heinonen TH, Reponen T, Grinshpun SA. (2008) Filter performance of N99 and N95 facepiece respirators against viruses and ultrafine particles. Ann. Occup. Hyg.; 52: 385-396.

Eshbaugh JP, Gardner PD, Richardson AW, Hofacre KC. (2008) N95 and P100 respirator filter efficiency under high constant and cyclic flow. J. Occup. Environ. Hyg.; 6: 52-61.

Grinshpun SA, Haruta H, Eninger RM, Reponen T, Mckay RT, Lee SA. (2009) Performance of an N95 filtering facepiece particulate respirator and a surgical mask during human breathing: two pathways for particle penetration. J. Occup. Environ. Hyg.; 6: 593-603.

Hart J, Withers R, Ilsley A. (1992) The accuracy of dry gas meters at continuous and sinusoidal flows. Eur. Respir. J.; 5: 1146-1149.

Haruta H, Honda T, Eninger R, Reponen T, McKay R, Grinsphun S. (2008) Experimental and theoretical investigation of the performance of N95 respirator filters against ultrafine aerosol particles tested at constant and cyclic flows. J. Int. Soc. Respir. Prot.; 25: 75-88. 
He X, Grinshpun SA, Reponen T, McKay R, Bergman MS, Zhuang Z. (2013a) Effects of breathing frequency and flow rate on the total inward leakage of an elastomeric half-mask donned on an advanced manikin headform. Ann. Occup. Hyg.; 58: 182-194.

He X, Reponen T, McKay R, Grinshpun SA. (2013b) Effect of particle size on the performance of an N95 filtering facepiece respirator and a surgical mask at various breathing conditions. Aerosol Sci. Technol.; 47: 1180-1187.

He X, Reponen T, McKay R, Grinshpun SA. (2014). How does breathing frequency affect the performance of an N95 filtering facepiece respirator and a surgical mask against surrogates of viral particles? J. Occup. Environ. Hyg.; 11(3): 178-185.

Holmér I, Kuklane K, Gao C. (2007) Minute volumes and inspiratory flow rates during exhaustive treadmill walking using respirators. Ann. Occup. Hyg.; 51(3): 327-335.

IOM. (2010) Preventing Transmission of Pandemic Influenza and Other Viral Respiratory Diseases: Personal Protective Equipment for Healthcare Workers. Update 2010. Washington, DC: The National Academies Press.

IOM. (2015) The Use and Effectiveness of Powered Air Purifying Respirators in Health Care. Mccoy, MA, Domnitz SB, and Liverman CT (eds.), Washington, DC: National Academies Press.

ISO, B. 8996: 2004 Ergonomics of the thermal environment - determination of metabolic rate. BSI, London.

ISO/TS 16976-1:2015. Respiratory protective devices - Human factors - Part 1: Metabolic rates and respiratory flow rates. Geneva, Switzerland: ISO Copyright Office.

Janssen LL, Anderson NJ, Cassidy PE, Weber RA, Nelson TJ. (2005) Interpretation of Inhalation Airflow Measurements for Respirator Design and Testing. J. Int. Soc. Resp. Prot.; 22 (Fall/Winter 2005): $122-141$.

Johnson AT, Koh FC, Jamshidi S, Rehak TE. (2008) Human subject testing of leakage in a loose-fitting PAPR. J. Occup. Environ. Hyg.; 5: 325-329.

Johnson AT, Koh FC, Scott WH, Rehak TE. (2011). Using $\mathrm{CO}_{2}$ to Determine Inhaled Contaminant Volumes and Blower Effectiveness in Several Types of Respirators. J Environ. Public Health; 2011.

Johnson AT, Mackey KR, Scott WH, Koh FC, Chiou KY, Phelps SJ. (2005a) Exercise performance while wearing a tight-fitting powered air purifying respirator with limited flow. J. Occup. Environ. Hyg.; 2(7): 368-373.

Johnson AT, Koh FC, Scott WH, Jr.,K.M. Mackey, K. Y. S. Chen, Rehak T. (2005b) Inhalation flow rates during strenuous exercise. J. Int. Soc. Resp. Prot.; 22: 79-96.

Kaufman JW, Hastings S. (2005) Respiratory demand during rigorous physical work in a chemical protective ensemble. J. Occup. Environ. Hyg.; 2: 98-110.

Keys, Ancel; Fidanza, Flaminio; Karvonen, Martti J.; Kimura, Noboru; Taylor, Henry L. (1972) Indices of relative weight and obesity. J. Chronic Dis.; 25 (6-7): 329-343.

Khoo KL, Leng PH, Ibrahim IB, Lim T. (2005) The changing face of healthcare worker perceptions on powered air purifying respirators during the SARS outbreak. Respirology; 10(1): 107-10. 
Koivisto AJ, Aromaa M, Koponen IK, Fransman W, Jensen KA, Mäkelä JM, Hämeri KJ. (2015) Workpla ce performance of a loose-fitting powered air purifying respirator during nanoparticle synthesis. J. Nanopart Res.; 17:177.

Lafortuna CL, Minetti AE, Mognoni P. (1984) Inspiratory flow pattern in humans. J. Appl. Physiol.; 57 : 1111-1119.

Lerman, Y., A. Shefer, Y. Epstein, and G. Keren. (1983) External inspiratory resistance of protective respiratory devices: Effects on physical performance and respiratory function. Am. J. Ind. Med.; 4:733-740.

Liverman CT, Larson EL. (2011) Preventing transmission of pandemic influenza and other viral respiratory diseases: Personal protective equipment for healthcare personnel. Update 2010: National Academies Press.

Lim, E. C. H., Seet, R. C. S., Lee, K. H., Wilder-Smith, E. P. V., Chuah, B. Y. S., \& Ong, B. K. C. (2006). Headaches and the N95 face-mask amongst healthcare providers. Acta Neurologica Scandinavica, 113(3), 199-202.

Loeb, M., McGeer, A., Henry, B., Ofner, M., Rose, D., Hlywka, T., ..., Smith, A. (2004). SARS among critical care nurses, Toronto. Emerging Infect. Dis.; 10(2), 251.

Mackey KR, Johnson AT, Scott WH, Koh FC. (2005) Over breathing a loose-fitting PAPR. J. Int. Soc. Respir. Prot.; 22(1/2): 1-10.

Martin S, Moyer E, Jensen P. (2006) Powered Air-Purifying Particulate Respirator Filter Penetration by a DOP Aerosol. J. Occup. Environ. Hyg.; 3(11): 620-630.

Musher DM (2003). How contagious are common respiratory tract infections? N. Engl. J. Med.; 348(13): 1256-1266.

Nicas M, Harrison R, Charney W, Borwegan B. (2004). Respiratory protection and severe acute respiratory syndrome. J. Occup. Environ. Med.; 46(3): 195-197.

NIOSH. (1995) Federal Register: Respiratory Protective Devices. 42 CFR Part 84. Washington, DC: US Government Printing Office, Office of the Federal Register.

OSHA. (1998) Respiratory protection: Final rule. U.S. Department of Labor, U.S. Government Printing Office, Washington, DC. Federal Register 63:1152-1300.

OSHA. (2006) Assigned Protection Factors: Final Rule, 2006, Department of Labor, OSHA, National Archives and Records Administration. Federal Register, 71(164): 50121-50192. (24 August 2006)

OSHA. (2007) Guidance on preparing workplaces for an influenza pandemic. Federal Publications; 617.

OSHA. (2009) Guidance on Preparing Workplaces for an Influenza Pandemic. May, 2009. OSHA 332705R.

Pohjonen T. (2001). Age-related physical fitness and the predictive values of fitness tests for work ability in home care work. J. Occup. Environ. Med.; 43(8): 723-730.

Raven PB, Bradley O, Rohm-Young D, McClure F, Skaggs B. (1982) Physiological response to "pressure-demand" respirator wear. Am. Ind. Hyg. Assoc. J.; 43(10): 773-781. 
Rengasamy S, Eimer BC, Shaffer RE. (2012) Evaluation of the performance of the N95-companion: effects of filter penetration and comparison with other aerosol instruments. J. Occup. Environ. Hyg.; 9: 417-26.

Rengasamy S, Eimer BC, Szalajda J. (2014) A quantitative assessment of the total inward leakage of $\mathrm{NaCl}$ aerosol representing submicron-size bioaerosol through $\mathrm{N} 95$ filtering facepiece respirators and surgical masks. J. Occup. Environ. Hyg.; 11: 388-96.

Roberge RJ. (2008) Evaluation of the rationale for concurrent use of N95 filtering facepiece respirators with loose fitting powered air-purifying respirators during aerosol generating medical procedures. Am. J. Infect. Control; 36(2): 135-141.

Roberge MR, Vojtko MR, Roberge RJ, Vojtko RJ, Landsittel DP. (2008) Wearing an N95 respirator concurrently with a powered air-purifying respirator: Effect on protection factor. Respir. Care; 53: 1685-90.

Silverman L, Robert CL, George L, Drinker KR, Carpenter TM (1943) Fundamental Factors in the Design of Protective Respiratory Equipment, Inspiratory Air Flow Measurements on Human Subjects with and without Resistance. OSRD Report No. 1222 Harvard School of Public Health, Boston MA.

Sinkule E, Powell J, Rubenstein E, McWillimas L, Quinn T, Pugliese M. (2016) Physiologic Effects from Using Tight- and Loose-Fitting Powered Air-Purifying Respirators on Inhaled Gases, Peak Pressures, and Inhalation Temperatures During Rest and Exercise. J. Int. Soc. Resp. Prot.; 33(2): 36-52.

Sue DY, Hansen JE. (1984) Normal Values in adults during exercise testing. Clin. Chest Med.; 5: 89-98.

Wallaart J, Winder C. (2002). The determination of peak inspiratory air flows (PIAF) at various levels of work and the increased air flows that result when communicating in the workplace. Journal of Occupational Health and Safety-Australian and New Zealand Submitted

Weber A, Willeke K, Marchloni R, Myojo T, Mckay R, Donnelly J, Liebhaber F. (1993) Aerosol penetration and leakae characteristics of masks used in the health care industry. Am. J. Infect Control.; 21(4): 167-173.

Wizner K, Stradtman L, Novak D, Shaffer R. (2016) Prevalence of Respiratory Protective Devices in US Health Care Facilities: Implications for Emergency Preparedness. Workplace Health Saf.; 64(8): 359-368.

Zhuang Z, Bergman MS, Eimer BC, Shaffer RE. (2013) Laboratory faceseal leakage evaluation of N95 filtering facepiece respirators against nanoparticles and "All Size" particles. J. Occup. Environ. Hyg.; 10: 496-504. 


\section{FIGURES}



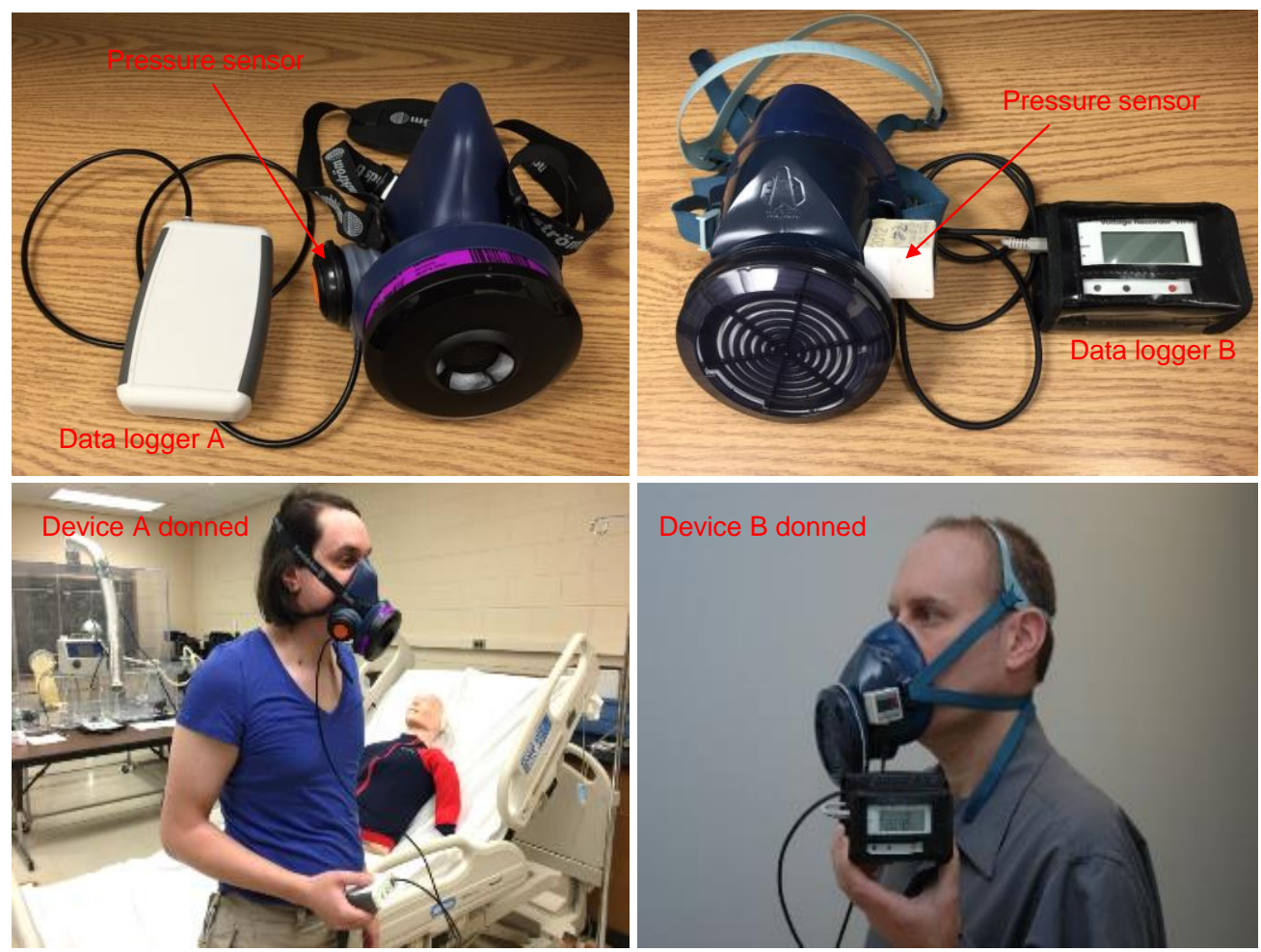

Fig. 1. 1. Breathing recording devices $A$ and $B$ 


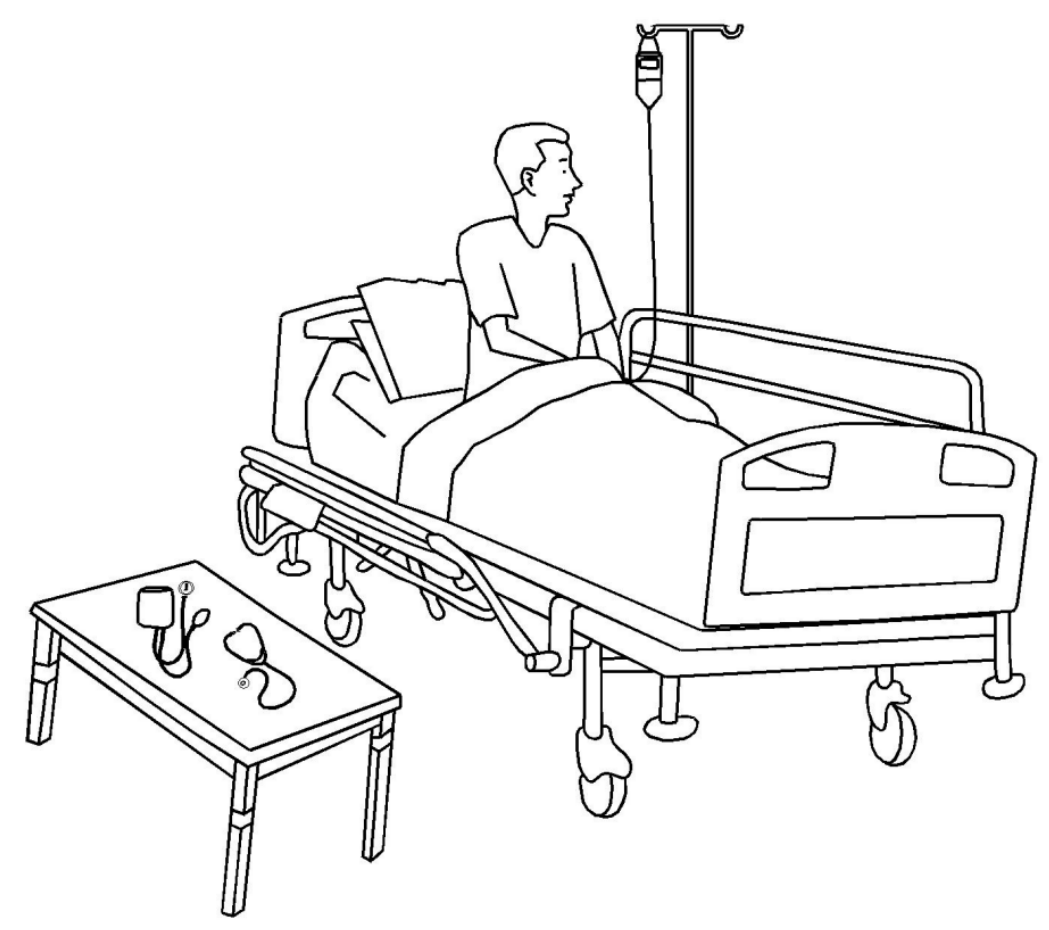

Fig. 1. 2. Simulated healthcare environment 

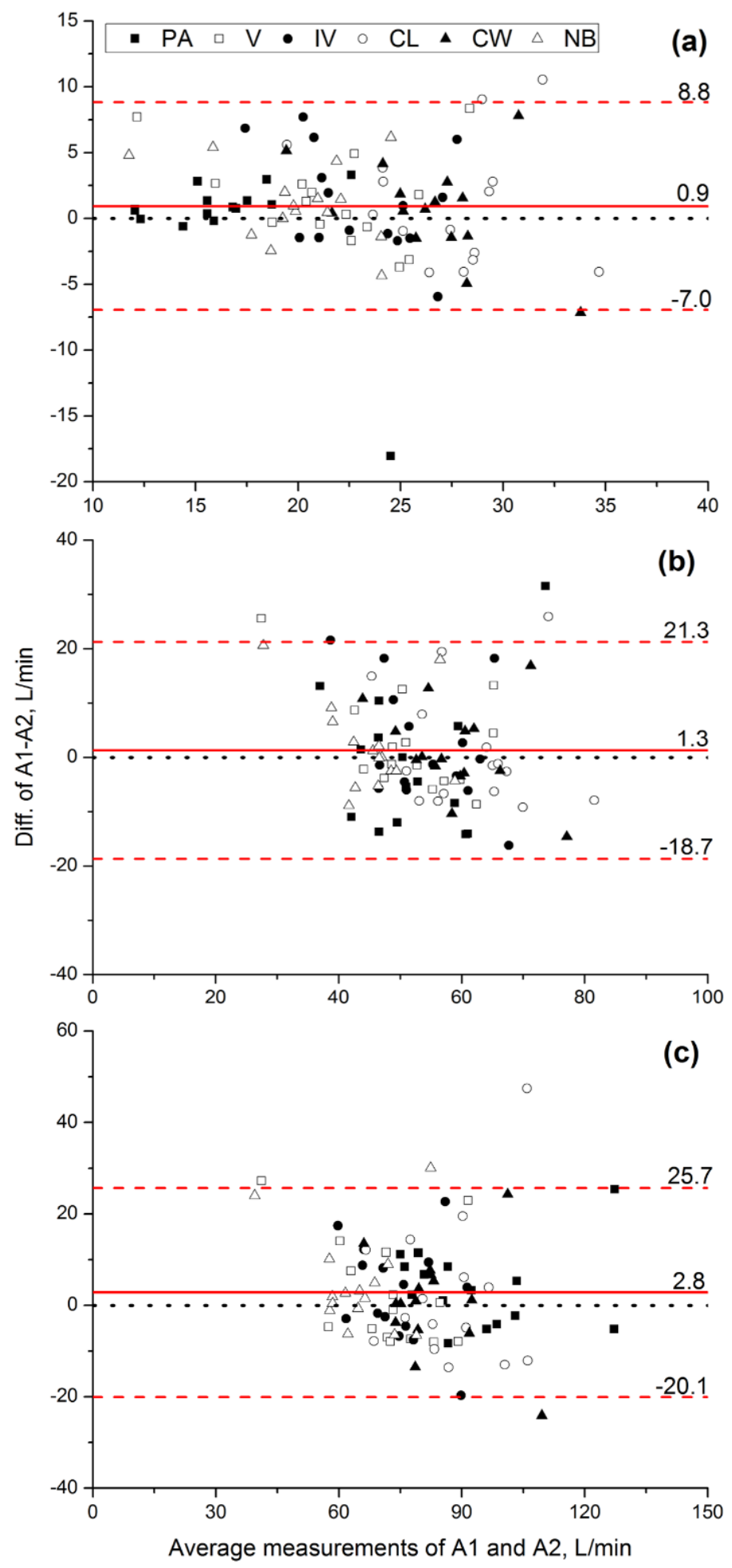

Fig. 1. 3. Bland-Altman plots of MV (a), MIF (b) and PIF (c) for A1 and A2. The solid line indicates mean difference; the dashed lines indicate $95 \%$ LoAs; the dotted line represents mean difference of 0. 

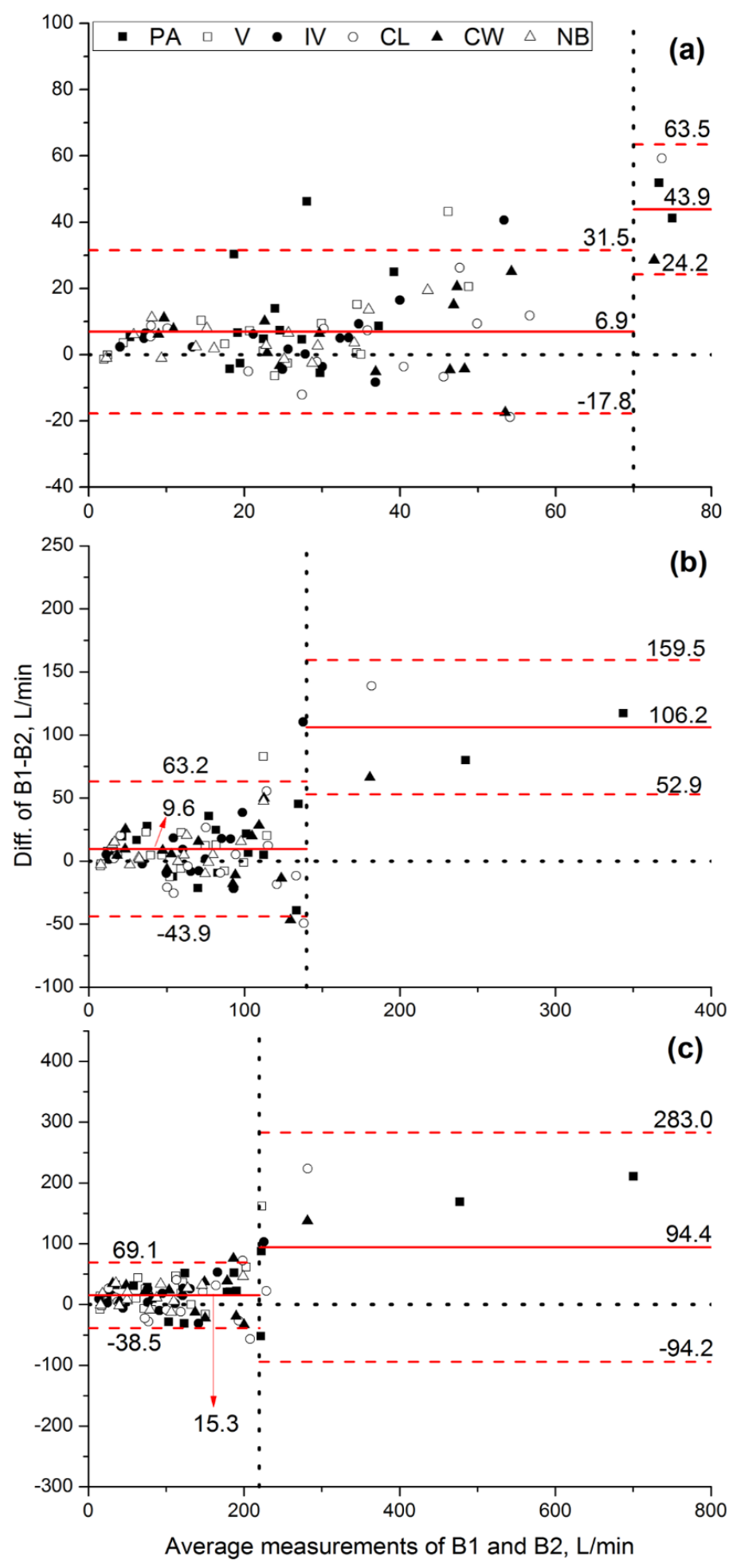

Fig. 1. 4. Bland-Altman plots of MV (a), MIF (b) and PIF (c) for B1 and B2. The solid line indicates mean difference; the dashed lines indicate $95 \%$ LoAs; the horizontal dotted line represents mean difference of 0 , the vertical dotted line represents the upper measurement limit of device B. 


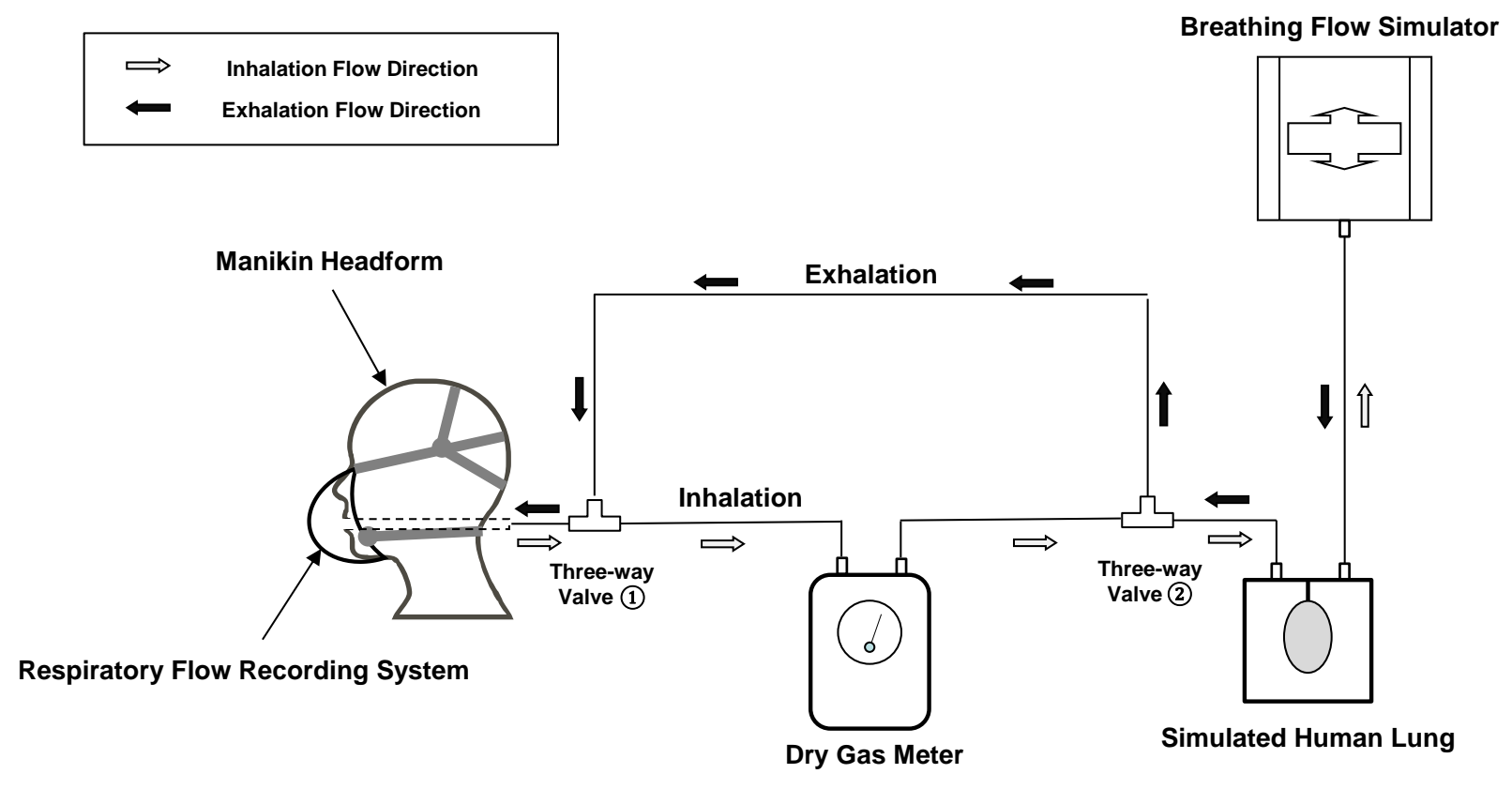

Fig. 2. 1. Experimental set-up for testing the respiratory flow recording systems 


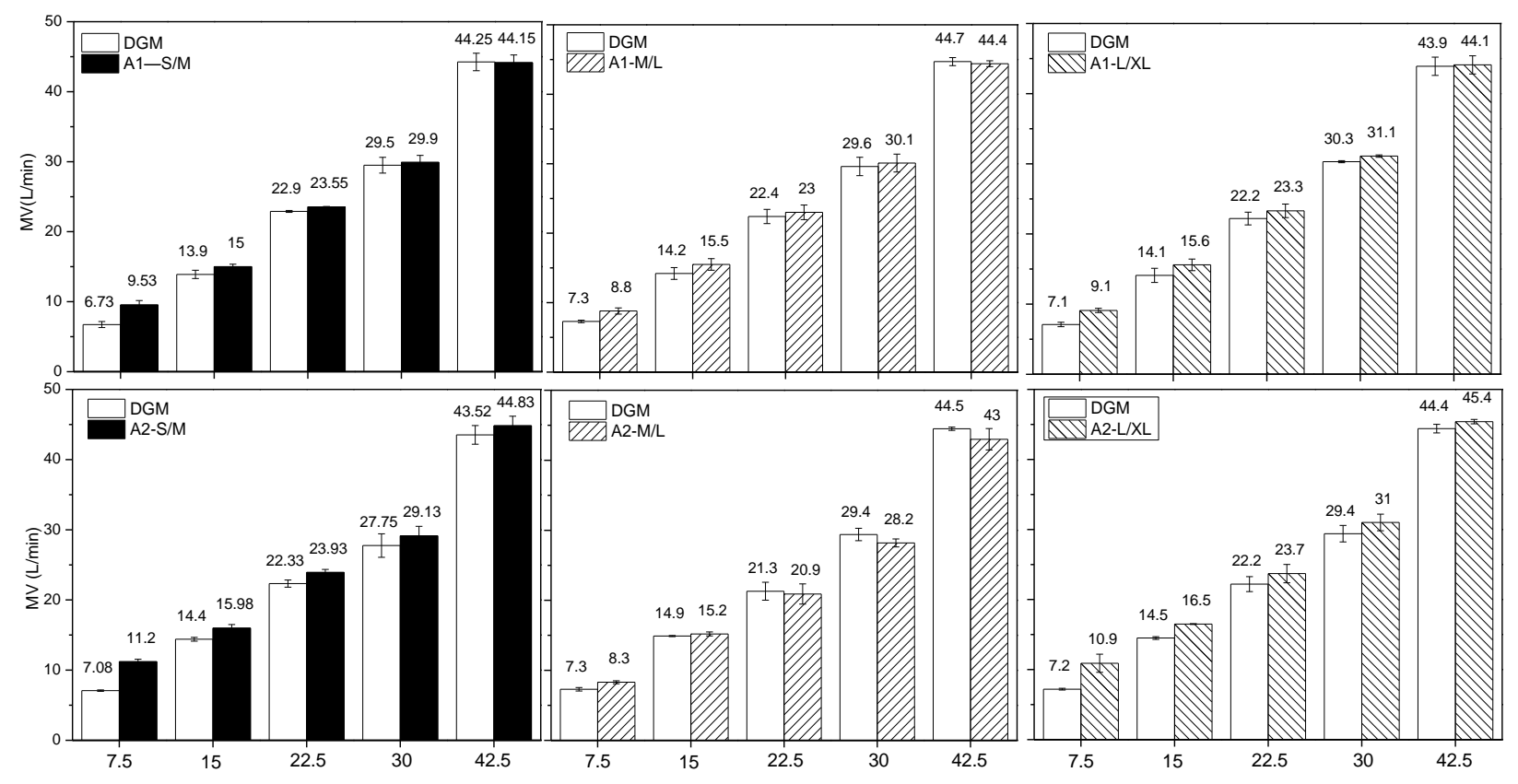

Fig. 2. 2. Minute volume (MV) measured by the dry gas meter (DGM) and different Systems A 

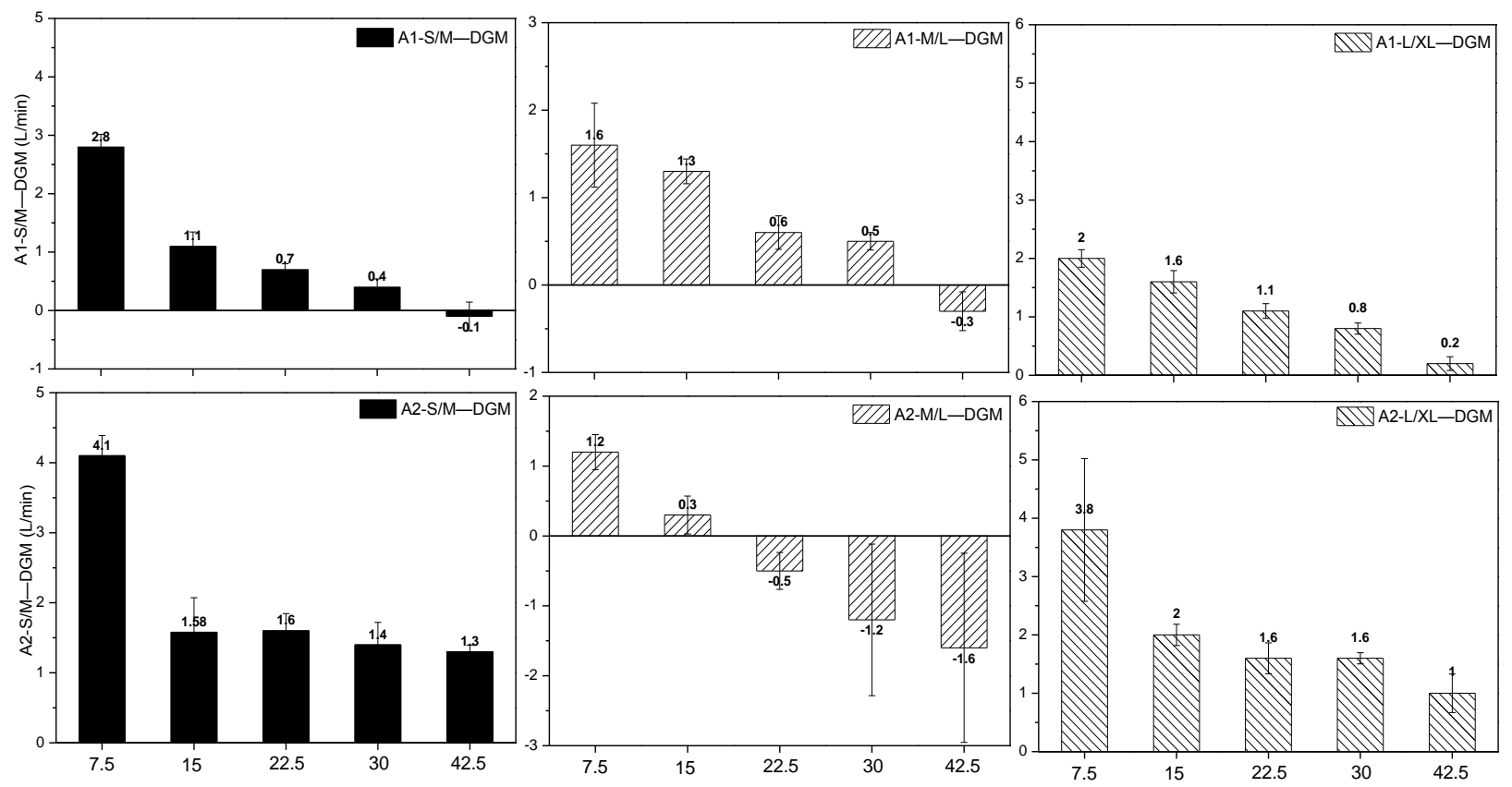

Fig. 2. 3. Differences between the dry gas meter (DGM) and different Systems A 

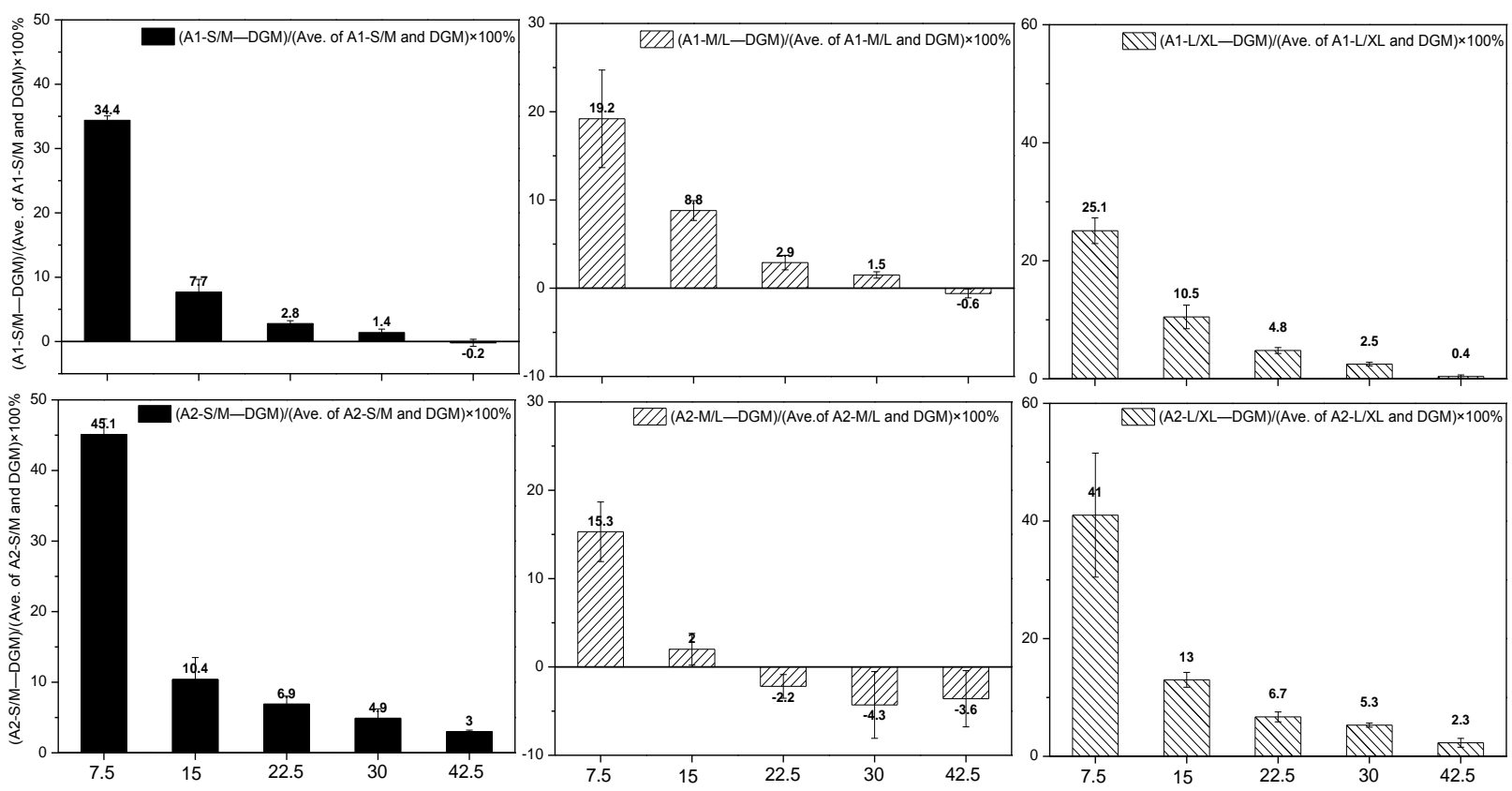

Fig. 2. 4. Percent differences between the dry gas meter (DGM) and different Systems A 

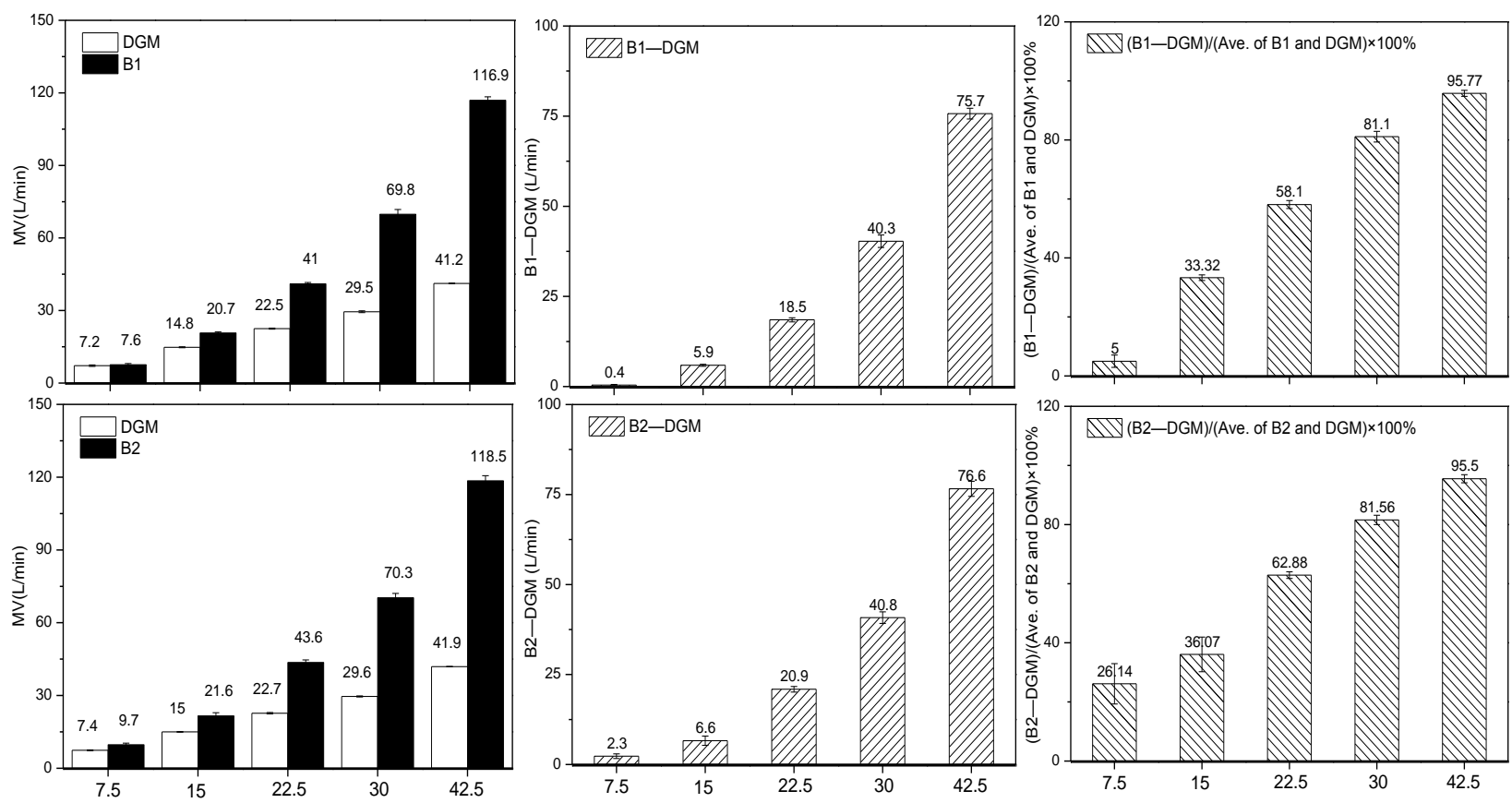

Fig. 2. 5. Measurements (left), differences (middle), and percent differences (right) reported by the dry gas meter (DGM) and two Systems B 

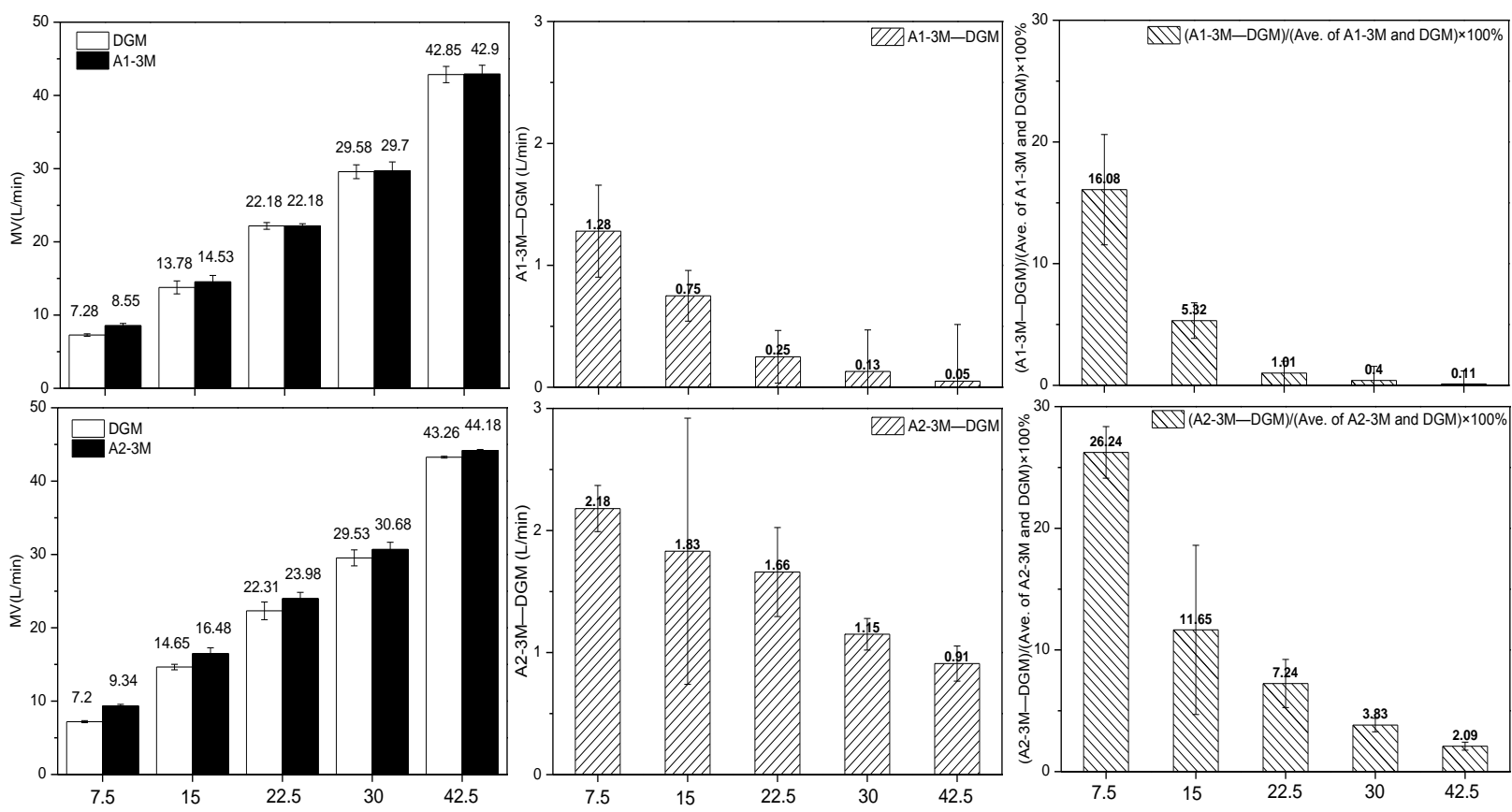

Fig. 2. 6. Measurements (left), differences (middle), and percent differences (right) reported by the dry gas meter (DGM) and two Systems A-3M 


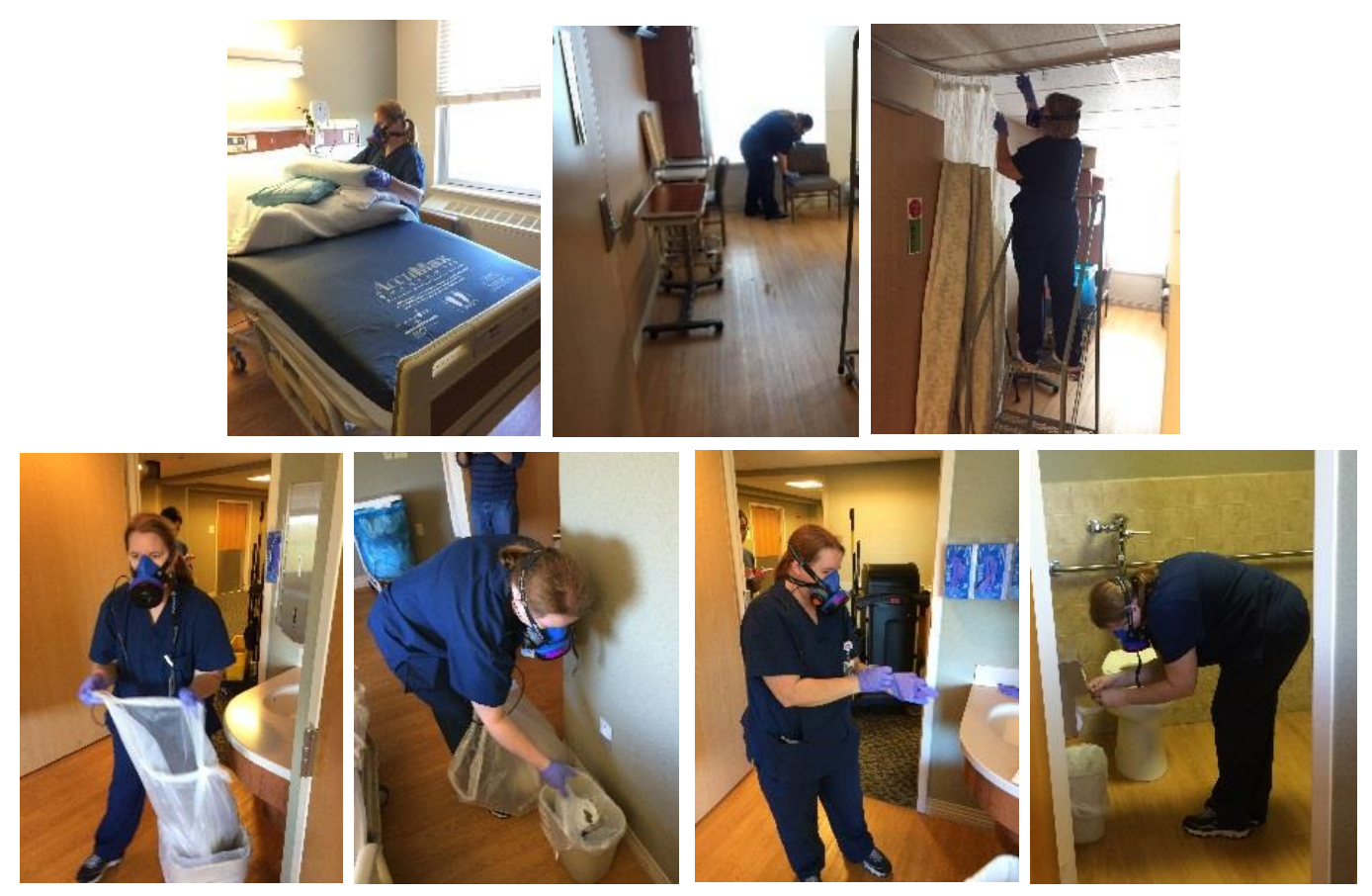

Fig. 3. 1. Subject worn respiratory flow recording device while performing isolation unit work 

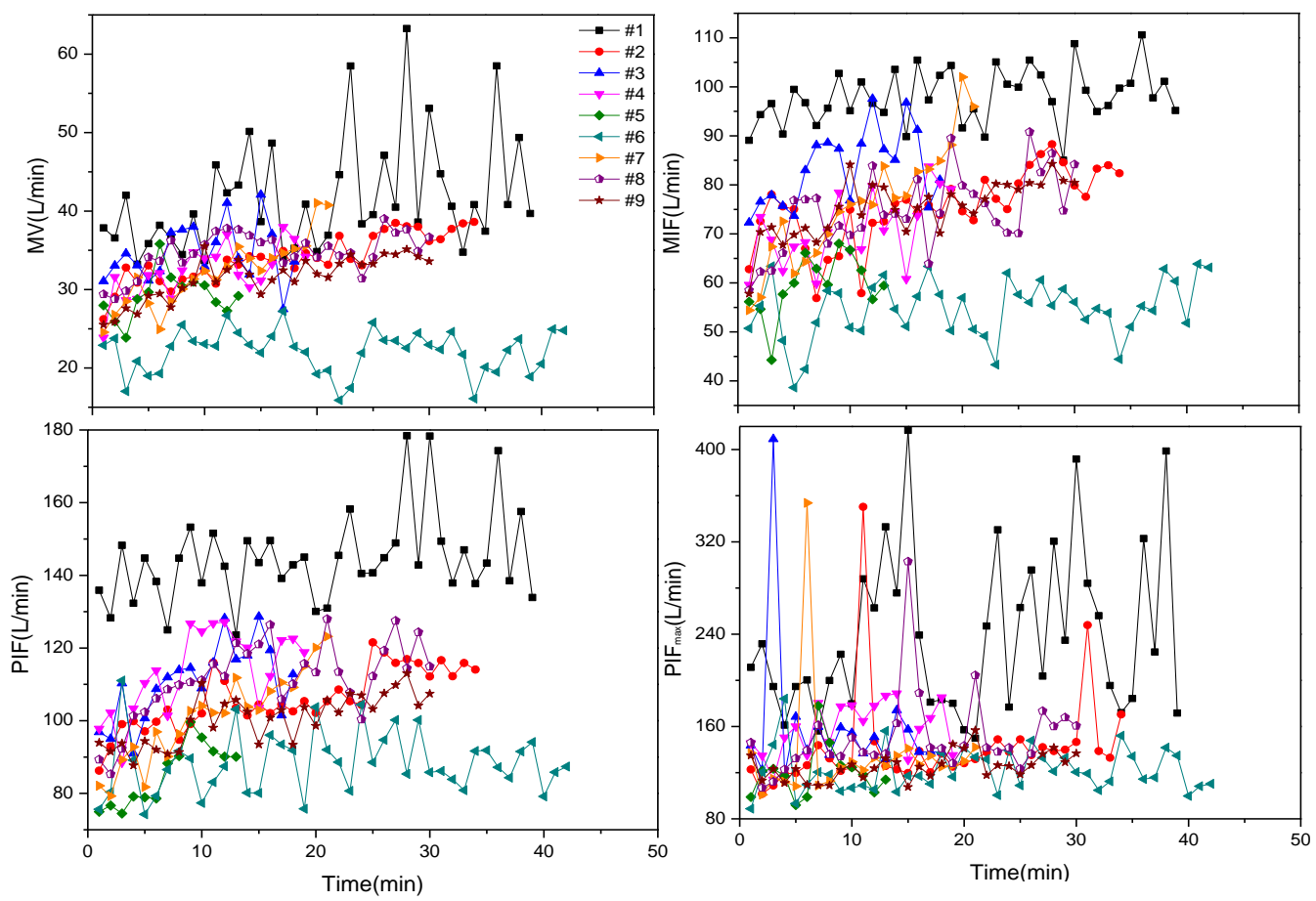

Fig. 3. 2. Fluctuations of MV, MIF, PIF, and $\mathrm{PIF}_{\max }$ along with time 

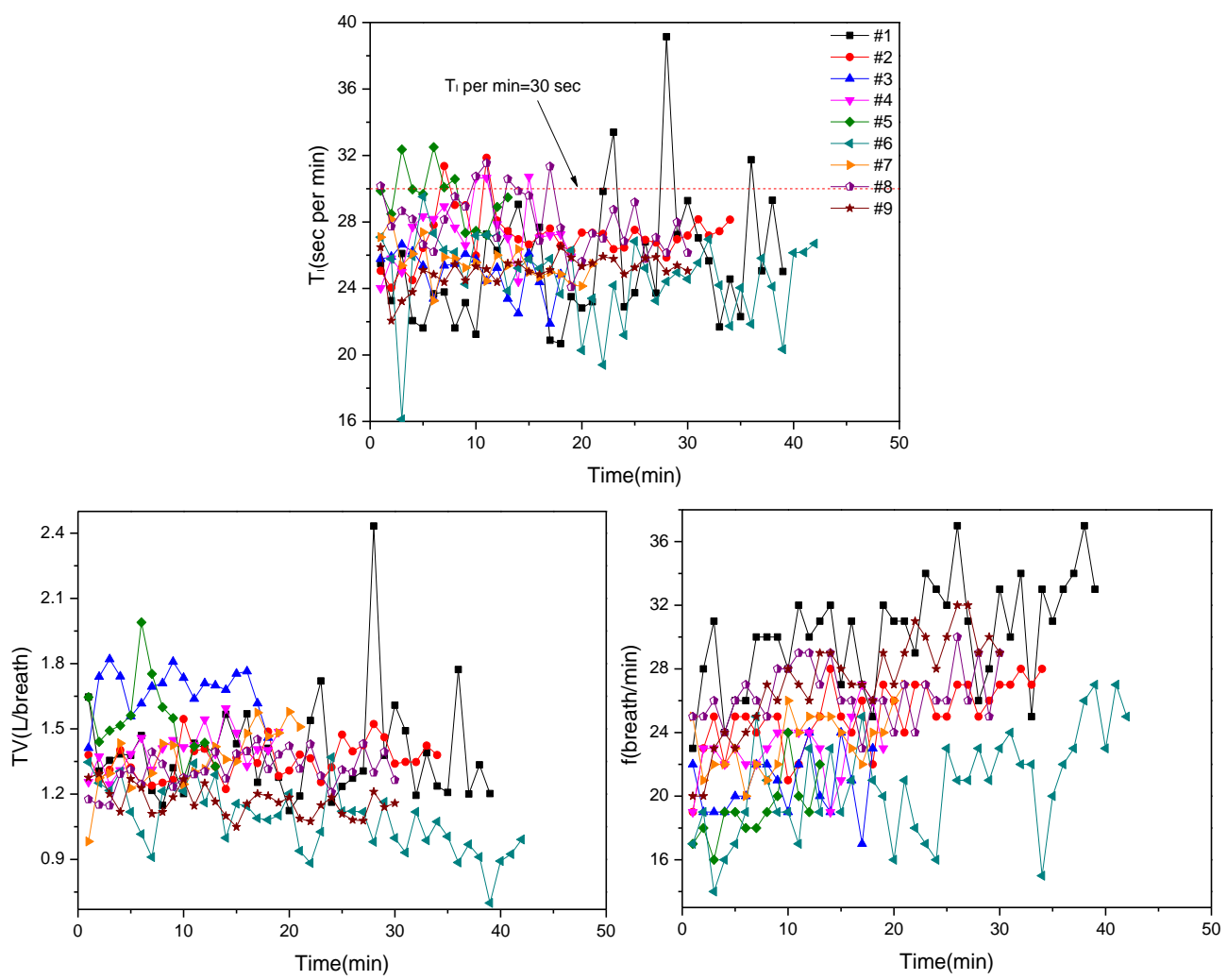

Fig. 3. 3. Changes of $T_{I}, f$, and $T V$ as time elapses 

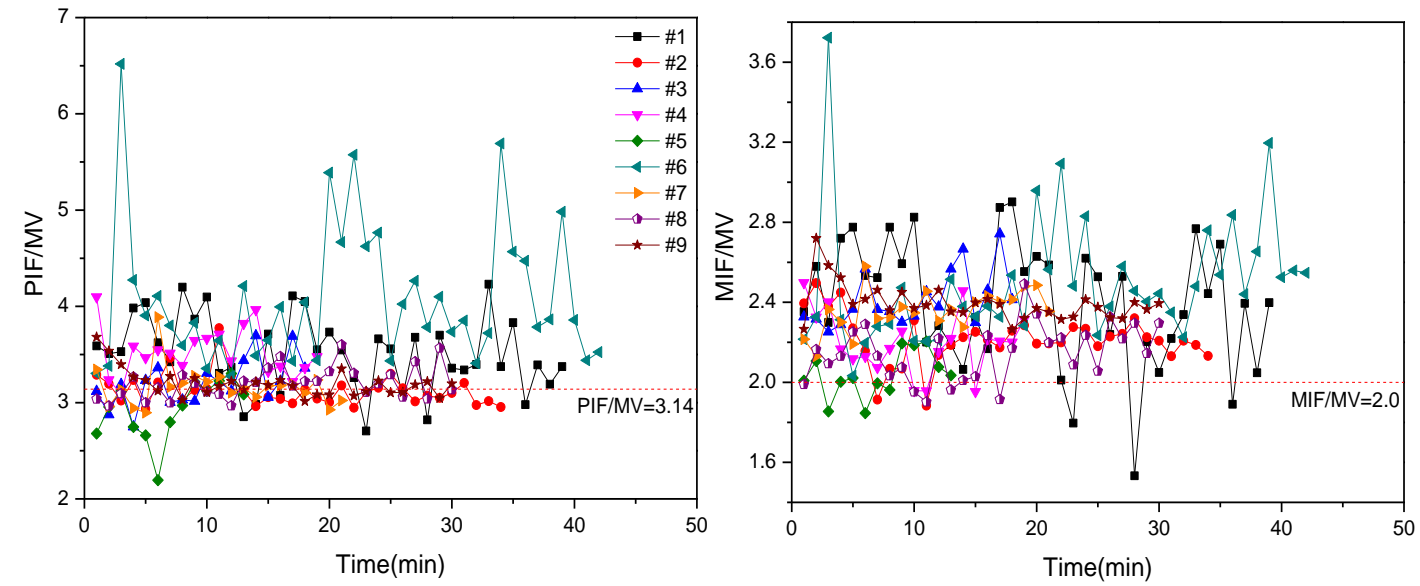

Fig. 3. 4. Fluctuations of $P I F / M V$ and $M I F / M V$ ratios along with time 

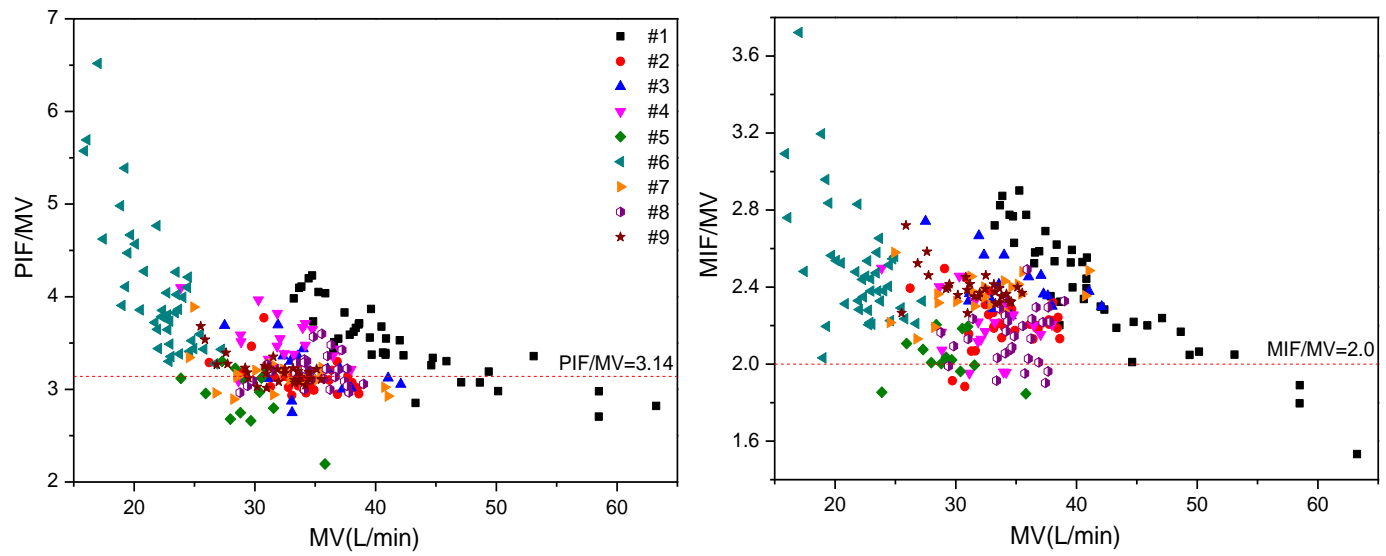

Fig. 3. 5. Changes of PIF/MV and MIF/MV ratios along with $M V$ 


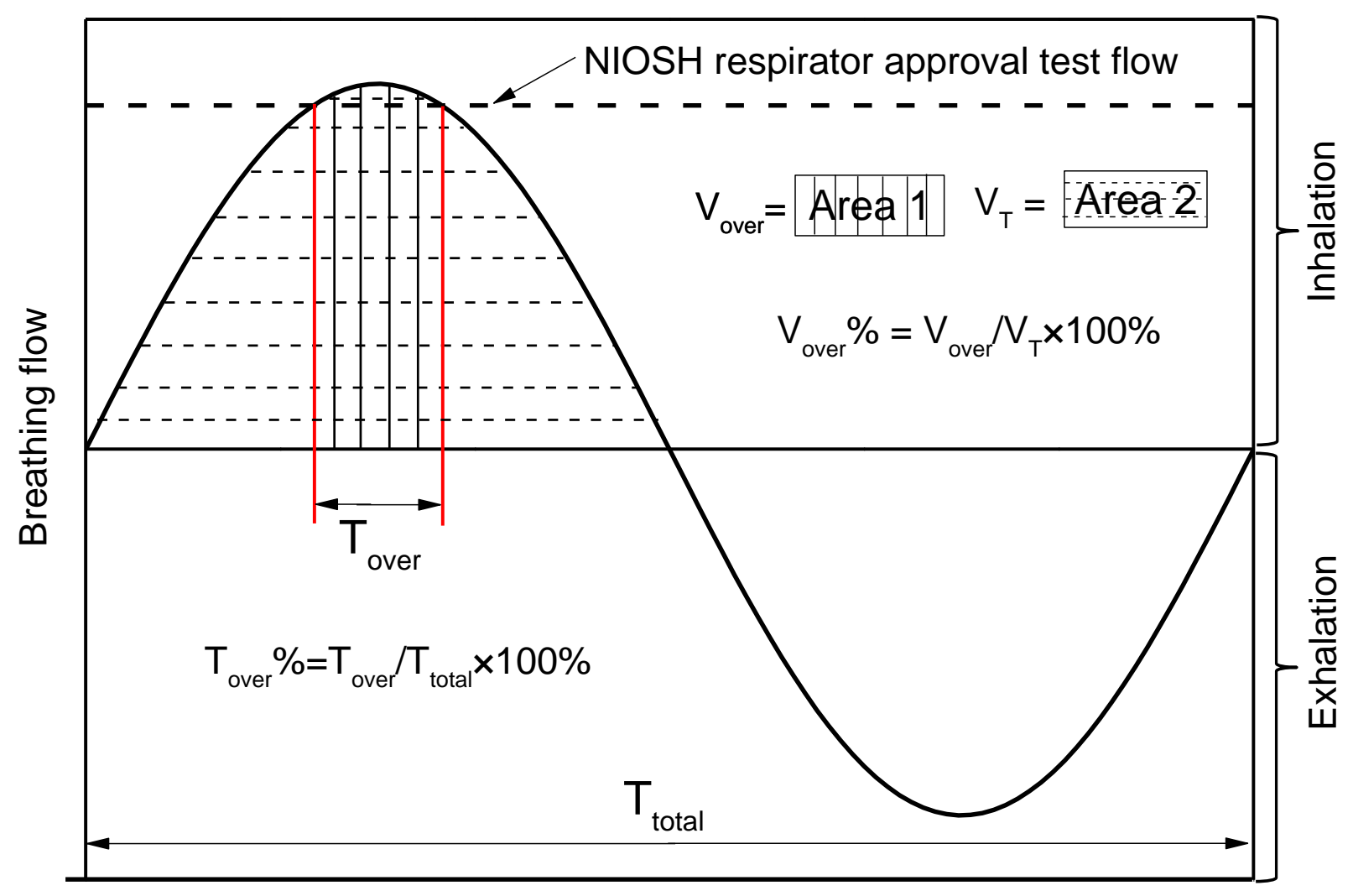

Fig.4. 1. Illustration of $\mathrm{V}_{\mathrm{T}}, \mathrm{V}_{\text {over }} \%$, and $\mathrm{T}_{\text {over }} \%$ by representative sinusoidal breathing pattern 


\section{TABLES}


Table 1. 1. Specifications of breathing recording devices A and B

\begin{tabular}{lcc}
\hline Categories & Device A & Device B \\
\hline Maximum measurement (L/min) & $400-500$ & 220 \\
Sampling interval (s) & 0.02 & 0.1 \\
Sampling duration & $8 \mathrm{hr}$ & $13 \mathrm{~min}$ \\
Data storage capacity & $1.44 \times 10^{6}$ & 8000 \\
Coupled respirators & Three sizes (S/M, M/L, L/XL) & One size \\
Weight (g) & $<450$ & $<540$ \\
\hline
\end{tabular}


Table 1. 2. Summary of experimental conditions

\begin{tabular}{l|l}
\hline Variable & \multicolumn{1}{l}{ Levels } \\
\hline Device & 2 units of device A (A1 and A2), 2 units of device B (B1 and B2) \\
\hline Subject & 15 human subjects \\
& $\begin{array}{l}\text { 1. Patient Assessment_asking questions (PA) } \\
\text { 2. Vitals - measuring blood pressure and heart rate (V) }\end{array}$ \\
Exercise & $\begin{array}{l}\text { 3. IV Treatment_administering IV care using a manikin (IV) } \\
\text { 4. Changing linen (CL) } \\
\text { 5. Carrying a 5 lb weight while walking (CW) } \\
\text { 6. Normal breathing while standing (NB) }\end{array}$ \\
\hline Replicate & \multicolumn{1}{c}{2} \\
\hline Total runs & \multicolumn{1}{c}{$4 \times 15 \times 6 \times 2=720$} \\
\hline
\end{tabular}


Table 1. 3. Definitions of inhalation parameters

\begin{tabular}{l|l}
\hline Parameter & Description \\
\hline MV $(\mathrm{L} / \mathrm{min})$ & Air volume inhaled in one minute \\
MIF $(\mathrm{L} / \mathrm{min})$ & Mean flow rate during inhalation phase \\
$\mathrm{PIF}(\mathrm{L} / \mathrm{min})$ & Average of peak inhalation flow rates of a series of breaths \\
$\mathrm{PIF}_{\max }(\mathrm{L} / \mathrm{min})$ & Maximum of peak inhalation flow rates of a series of breaths \\
$\mathrm{PIF} / \mathrm{MV}$ & Ratio of PIF to MV \\
MIF/MV & Ratio of MIF to MV \\
$\mathrm{f}(\mathrm{breaths} / \mathrm{min})$ & Number of breath cycles in one minute \\
$\mathrm{TV}(\mathrm{L} / \mathrm{breath})$ & Air volume inspired during each breath \\
$\mathrm{T}_{\mathrm{I}}(\mathrm{sec}$ per min $)$ & Time spent for inhalation during one minute \\
$\mathrm{DC}(\%)$ & Ratio of inhalation time $\left(\mathrm{T}_{\mathrm{I}}\right)$ to total breath time $\left(\mathrm{T}_{\mathrm{tot}}\right)$ \\
\hline
\end{tabular}


Table 1. 4. Measurements of breathing responses to exercises by devices A1 and A2

\begin{tabular}{|c|c|c|c|c|c|c|c|}
\hline Parameter & Device & $\mathbf{P A}$ & $\mathbf{V}$ & IV & $\mathbf{C L}$ & $\mathbf{C W}$ & NB \\
\hline \multirow{2}{*}{$\begin{array}{c}\mathrm{MV} \\
(\mathrm{L} / \mathrm{min})\end{array}$} & A1 & $16.5 \pm 3.2$ & $22.4 \pm 4.0$ & $23.7 \pm 2.9$ & $27.9 \pm 4.2$ & $26.8 \pm 3.1$ & $20.7 \pm 3.2$ \\
\hline & $\mathrm{A} 2$ & $16.4 \pm 5.2$ & $20.6 \pm 4.7$ & $22.5 \pm 4.3$ & $26.9 \pm 4.6$ & $26.3 \pm 4.6$ & $19.3 \pm 4.0$ \\
\hline \multirow{2}{*}{$\begin{array}{c}\text { MIF } \\
(\mathrm{L} / \mathrm{min})\end{array}$} & A1 & $51.4 \pm 12.3$ & $53.1 \pm 8.5$ & $55.3 \pm 7.8$ & $62.3 \pm 10.5$ & $59.4 \pm 8.0$ & $46.2 \pm 7.1$ \\
\hline & $\mathrm{A} 2$ & $52.4 \pm 10.1$ & $50.0 \pm 12.5$ & $53.6 \pm 11.8$ & $61.3 \pm 11.7$ & $58.1 \pm 10.4$ & $44.1 \pm 9.6$ \\
\hline \multirow{4}{*}{$\begin{array}{c}\text { PIF } \\
(\mathrm{L} / \mathrm{min})\end{array}$} & A1 & $96.8 \pm 17.2$ & $76.8 \pm 18.7$ & $78.8 \pm 13.4$ & $92.7 \pm 23.8$ & $86.6 \pm 18.2$ & $69.0 \pm 12.7$ \\
\hline & $\mathrm{A} 2$ & $95.1 \pm 19.5$ & $72.2 \pm 18.9$ & $76.7 \pm 15.9$ & $89.3 \pm 18.8$ & $87.8 \pm 24.5$ & $63.2 \pm 13.2$ \\
\hline & $\mathrm{A} 1^{*}$ & 105.5 & 86.2 & 85.6 & 104.8 & 95.8 & 75.4 \\
\hline & $\mathrm{A} 2^{*}$ & 100.1 & 77.0 & 80.8 & 94.2 & 94.1 & 66.6 \\
\hline \multirow{2}{*}{$\begin{array}{l}\mathrm{PIF}_{\max } \\
(\mathrm{L} / \mathrm{min})\end{array}$} & A1 & $139.1 \pm 31.1$ & $102.1 \pm 29.0$ & $100.8 \pm 17.3$ & $114.2 \pm 26.1$ & $106.3 \pm 19.0$ & $86.6 \pm 20.5$ \\
\hline & $\mathrm{A} 2$ & $129.9 \pm 24.0$ & $101.0 \pm 30.5$ & $95.5 \pm 16.4$ & $108.7 \pm 16.7$ & $101.0 \pm 19.2$ & $79.2 \pm 20.5$ \\
\hline \multirow{2}{*}{ PIF/MV } & A1 & $5.97 \pm 0.93$ & $3.44 \pm 0.65$ & $3.34 \pm 0.64$ & $3.33 \pm 0.78$ & $3.22 \pm 0.54$ & $3.36 \pm 0.60$ \\
\hline & $\mathrm{A} 2$ & $6.07 \pm 1.51$ & $3.49 \pm 0.44$ & $3.44 \pm 0.53$ & $3.33 \pm 0.39$ & $3.34 \pm 0.66$ & $3.30 \pm 0.37$ \\
\hline \multirow{2}{*}{ MIF/MV } & A1 & $3.17 \pm 0.65$ & $2.38 \pm 0.16$ & $2.33 \pm 0.20$ & $2.23 \pm 0.17$ & $2.21 \pm 0.12$ & $2.25 \pm 0.21$ \\
\hline & $\mathrm{A} 2$ & $3.37 \pm 0.84$ & $2.40 \pm 0.24$ & $2.39 \pm 0.32$ & $2.28 \pm 0.14$ & $2.22 \pm 0.16$ & $2.30 \pm 0.35$ \\
\hline \multirow{2}{*}{$\begin{array}{c}\mathrm{f} \\
\text { (Breaths/min) }\end{array}$} & A1 & $17 \pm 2$ & $23 \pm 3$ & $23 \pm 4$ & $25 \pm 4$ & $25 \pm 4$ & $20 \pm 3$ \\
\hline & $\mathrm{A} 2$ & $16 \pm 2$ & $23 \pm 3$ & $22 \pm 3$ & $26 \pm 5$ & $25 \pm 4$ & $20 \pm 3$ \\
\hline \multirow{2}{*}{$\begin{array}{c}\text { TV } \\
\text { (L/breath) }\end{array}$} & A1 & $1.00 \pm 0.18$ & $0.99 \pm 0.19$ & $1.07 \pm 0.15$ & $1.13 \pm 0.23$ & $1.11 \pm 0.17$ & $1.04 \pm 0.18$ \\
\hline & $\mathrm{A} 2$ & $1.06 \pm 0.37$ & $0.94 \pm 0.24$ & $1.03 \pm 0.22$ & $1.06 \pm 0.24$ & $1.09 \pm 0.25$ & $0.99 \pm 0.26$ \\
\hline \multirow{2}{*}{$\begin{array}{c}\mathrm{T}_{\mathrm{I}} \\
\text { (sec per min) }\end{array}$} & A1 & $19.9 \pm 4.7$ & $25.3 \pm 1.8$ & $26.0 \pm 2.6$ & $27.1 \pm 2.2$ & $27.2 \pm 1.6$ & $26.9 \pm 2.6$ \\
\hline & $\mathrm{A} 2$ & $19.8 \pm 8.6$ & $25.2 \pm 3.1$ & $25.7 \pm 4.4$ & $26.2 \pm 1.9$ & $27.1 \pm 2.3$ & $27.6 \pm 6.5$ \\
\hline \multirow{2}{*}{ DC (100\%) } & A1 & $33 \pm 8$ & $42 \pm 3$ & $43 \pm 4$ & $45 \pm 4$ & $45 \pm 3$ & $45 \pm 4$ \\
\hline & $\mathrm{A} 2$ & $33 \pm 14$ & $42 \pm 5$ & $43 \pm 7$ & $44 \pm 3$ & $45 \pm 4$ & $46 \pm 11$ \\
\hline
\end{tabular}

Note: *Indicates the upper 95\% confidence interval (CI) for PIF. 
Table 1. 5. Duncan's grouping of MV, MIF, and PIF for devices A1 and A2

\begin{tabular}{ccccccc}
\hline \multirow{2}{*}{ Exercise } & \multicolumn{2}{c}{ MV } & \multicolumn{2}{c}{ MIF } & \multicolumn{2}{c}{ PIF } \\
\cline { 2 - 7 } & A1 & A2 & A1 & A2 & A1 & A2 \\
\hline PA & E & E & C & C & A & A \\
V & C & C & BC & C & D & C \\
IV & B & B & B & C & D & C \\
CL & A & A & A & A & B & B \\
CW & A & A & A & B & C & B \\
NB & D & D & D & D & E & D \\
\hline
\end{tabular}

Note: Inspiratory flows during exercises with the same letter are not significantly different $(\mathrm{P}>0.05)$. 
Table 1. 6. Measurement of breathing responses to exercises by devices B1 and B2

\begin{tabular}{|c|c|c|c|c|c|c|c|}
\hline Parameter & Device & $\overline{\mathbf{P A}}$ & $\bar{V}$ & IV & $\overline{C L}$ & $\overline{C W}$ & $\overline{\text { NB }}$ \\
\hline \multirow{2}{*}{$\begin{array}{c}\text { MV } \\
(\mathrm{L} / \mathrm{min}) \\
\end{array}$} & B1 & $38.6 \pm 26.7$ & $27.6 \pm 18.9$ & $28.9 \pm 17.2$ & $39.0 \pm 24.6$ & $38.9 \pm 21.3$ & $23.4 \pm 13.7$ \\
\hline & B2 & $23.0 \pm 14.7$ & $20.7 \pm 12.0$ & $23.3 \pm 12.0$ & $32.6 \pm 17.7$ & $32.5 \pm 18.7$ & $18.7 \pm 11.2$ \\
\hline \multirow{2}{*}{$\begin{array}{c}\mathrm{MIF} \\
(\mathrm{L} / \mathrm{min})\end{array}$} & B1 & $119.0 \pm 99.6$ & $64.7 \pm 41.9$ & $69.5 \pm 46.6$ & $89.6 \pm 60.6$ & $86.8 \pm 51.0$ & $56.0 \pm 35.5$ \\
\hline & B2 & $97.9 \pm 71.8$ & $54.3 \pm 32.1$ & $57.8 \pm 29.3$ & $81.1 \pm 45.7$ & $77.6 \pm 46.0$ & $48.7 \pm 29.5$ \\
\hline \multirow{4}{*}{$\begin{array}{c}\text { PIF } \\
(\mathrm{L} / \mathrm{min})\end{array}$} & B1 & $221.5 \pm 202.4$ & $110.0 \pm 79.5$ & $106.4 \pm 67.8$ & $143.4 \pm 97.4$ & $141.0 \pm 81.8$ & $87.6 \pm 55.7$ \\
\hline & B2 & $177.7 \pm 146.7$ & $84.9 \pm 51.7$ & $89.5 \pm 49.7$ & $123.5 \pm 68.5$ & $117.4 \pm 66.9$ & $73.2 \pm 48.1$ \\
\hline & $\mathrm{B} 1^{*}$ & 323.9 & 150.2 & 140.7 & 192.7 & 182.4 & 115.8 \\
\hline & $\mathrm{B} 2^{*}$ & 215.6 & 98.3 & 102.3 & 141.2 & 134.7 & 85.6 \\
\hline \multirow{2}{*}{$\begin{array}{l}\mathrm{PIF}_{\max } \\
(\mathrm{L} / \mathrm{min})\end{array}$} & B1 & $864.9 \pm 1748.4$ & $254.2 \pm 207.7$ & $197.7 \pm 120.2$ & $275.4 \pm 211.0$ & $241.4 \pm 154.2$ & $146.2 \pm 98.2$ \\
\hline & B2 & $467.2 \pm 709.4$ & $172.3 \pm 181.5$ & $143.5 \pm 87.7$ & $231.4 \pm 144.3$ & $204.2 \pm 150.2$ & $110.1 \pm 96.2$ \\
\hline \multirow{2}{*}{ PIF/MV } & B1 & $5.71 \pm 1.82$ & $4.44 \pm 1.61$ & $3.57 \pm 0.41$ & $3.56 \pm 0.45$ & $3.63 \pm 0.44$ & $4.00 \pm 1.42$ \\
\hline & B2 & $7.91 \pm 2.47$ & $4.42 \pm 1.47$ & $3.91 \pm 0.75$ & $3.96 \pm 0.86$ & $3.78 \pm 0.80$ & $4.10 \pm 1.08$ \\
\hline \multirow{2}{*}{ MIF/MV } & B1 & $3.18 \pm 1.08$ & $2.55 \pm 0.61$ & $2.31 \pm 0.41$ & $2.22 \pm 0.34$ & $2.19 \pm 0.27$ & $2.43 \pm 0.48$ \\
\hline & $\mathrm{B} 2$ & $4.71 \pm 2.17$ & $2.98 \pm 1.21$ & $2.73 \pm 0.69$ & $2.73 \pm 0.88$ & $2.65 \pm 1.00$ & $2.88 \pm 0.86$ \\
\hline \multirow{2}{*}{$\begin{array}{c}\mathrm{f} \\
\text { (breaths/min) }\end{array}$} & B1 & $16 \pm 2$ & $21 \pm 4$ & $20 \pm 4$ & $23 \pm 5$ & $22 \pm 5$ & $19 \pm 4$ \\
\hline & B2 & $15 \pm 1$ & $22 \pm 3$ & $21 \pm 3$ & $24 \pm 5$ & $23 \pm 4$ & $20 \pm 4$ \\
\hline \multirow{2}{*}{$\begin{array}{c}\text { TV } \\
\text { (L/breath) } \\
\end{array}$} & B1 & $2.47 \pm 1.62$ & $1.38 \pm 0.93$ & $1.48 \pm 0.66$ & $1.69 \pm 0.86$ & $1.76 \pm 0.76$ & $1.31 \pm 0.64$ \\
\hline & B2 & $1.58 \pm 1.05$ & $1.02 \pm 0.65$ & $1.13 \pm 0.59$ & $1.45 \pm 0.80$ & $1.48 \pm 0.84$ & $1.01 \pm 0.58$ \\
\hline \multirow{2}{*}{$\begin{array}{c}\mathrm{T}_{\mathrm{I}} \\
(\mathrm{sec} \text { per min) }\end{array}$} & B1 & $22.7 \pm 12.3$ & $24.6 \pm 4.6$ & $26.2 \pm 5.1$ & $27.6 \pm 4.8$ & $27.8 \pm 3.9$ & $25.2 \pm 5.0$ \\
\hline & $\mathrm{B} 2$ & $14.5 \pm 3.2$ & $22.3 \pm 3.4$ & $23.7 \pm 2.7$ & $23.9 \pm 2.7$ & $25.0 \pm 2.9$ & $22.1 \pm 2.3$ \\
\hline \multirow{2}{*}{ DC (100\%) } & $\mathrm{B} 1$ & $38 \pm 20$ & $41 \pm 8$ & $44 \pm 8$ & $46 \pm 8$ & $47 \pm 6$ & $42 \pm 8$ \\
\hline & $\mathrm{B} 2$ & $24 \pm 5$ & $37 \pm 6$ & $39 \pm 5$ & $40 \pm 5$ & $42 \pm 4$ & $37 \pm 5$ \\
\hline
\end{tabular}

Note: "Indicates the upper 95\% confidence interval (CI) for PIF. 
Table 1. 7. Duncan's grouping of MV, MIF, and PIF for B1 and B2

\begin{tabular}{ccccccc}
\hline \multirow{2}{*}{ Exercise } & \multicolumn{2}{c}{ MV } & \multicolumn{2}{c}{ MIF } & \multicolumn{2}{c}{ PIF } \\
\cline { 2 - 7 } & B1 & B2 & B1 & B2 & B1 & B2 \\
\hline PA & A & BC & A & A & A & A \\
V & B & BC & C & C & C & D \\
IV & B & B & C & C & C & CD \\
CL & A & A & B & B & B & B \\
CW & A & A & B & B & B & BC \\
NB & B & C & C & C & C & D \\
\hline
\end{tabular}

Note: Inspiratory flows during exercises with the same letter are not significantly different $(\mathrm{P}>0.05)$. 
Table 2. 1. Summary of experimental conditions

\begin{tabular}{lll}
\hline Categorizes & Accuracy & Compatibility \\
\hline & A1-S/M, A1-M/L, A1-L/XL & A1-3M \\
Test systems & A2-S/M, A2-M/L, A2-L/XL & A2-3M \\
& B1, B2 & N/A \\
Test flow (MV, L/min) & $7.5,15,22.5,30$, and 42.5 & $7.5,15,22.5,30$, and 42.5 \\
Replicates & 4 & 4 \\
\hline Total runs & $8 \times 5 \times 4=160$ & $2 \times 5 \times 4=40$ \\
\hline
\end{tabular}


Table 2. 2. Mean differences, $95 \%$ LoAs, and ICCs between the dry gas meter and different Systems A

\begin{tabular}{lcccc}
\hline Systems A & Mean difference & 95\% Lower LoA & 95\% Upper LoA & ICC \\
\hline A1-S/M & 0.97 & -1.06 & 3.00 & 0.997 \\
A1-M/L & 0.85 & -0.79 & 2.49 & 0.998 \\
A1-L/XL & 1.12 & -0.17 & 2.42 & 0.997 \\
A2-S/M & 2.00 & -0.22 & 4.22 & 0.992 \\
A2-M/L & -0.35 & -2.80 & 2.09 & 0.998 \\
A2-L/XL & 1.99 & -0.15 & 4.13 & 0.992 \\
\hline
\end{tabular}


Table 2. 3. Grouping of the difference between the dry gas meter and different flow recording systems

\begin{tabular}{cccl}
\hline Grouping & Mean Difference (L/min) & Run & Test Systems \\
\hline A & 29.42 & 20 & B2 \\
A & 28.14 & 20 & B1 \\
B & 2.00 & 20 & A2-S/M \\
B & 1.99 & 20 & A2-L/LX \\
B & 1.55 & 20 & A2-3M \\
B & 1.12 & 20 & A1-L/XL \\
B & 0.97 & 20 & A1-S/M \\
B & 0.85 & 20 & A1-M/L \\
B & 0.44 & 20 & A1-3M \\
B & -0.35 & 20 & A2-M/L \\
\hline
\end{tabular}


Table 3. 1. Physical measurements of the subjects

\begin{tabular}{ccccccc}
\hline Subject & Gender & Age & Weight $(\mathbf{k g})$ & Height $(\mathbf{m})$ & $\mathbf{A}_{\text {Du }}\left(\mathbf{m}^{2}\right)$ & $\mathbf{B M I}\left(\mathbf{k g} / \mathbf{m}^{2}\right)$ \\
\hline$\# 1$ & M & 43 & 117.93 & 1.65 & 2.21 & $43.27^{* *}$ \\
$\# 2$ & $\mathrm{~F}$ & 39 & 86.18 & 1.63 & 1.91 & $32.61^{* *}$ \\
$\# 3$ & $\mathrm{~F}$ & 21 & 113.4 & 1.65 & 2.17 & $41.60^{* *}$ \\
$\# 4$ & $\mathrm{~F}$ & 44 & 65.77 & 1.50 & 1.60 & $29.29^{*}$ \\
$\# 5$ & $\mathrm{~F}$ & 45 & 56.70 & 1.65 & 1.62 & 20.80 \\
$\# 6$ & $\mathrm{M}$ & 43 & 61.24 & 1.60 & 1.63 & 23.91 \\
$\# 7$ & $\mathrm{~F}$ & 28 & 58.97 & 1.60 & 1.61 & 23.03 \\
$\# 8$ & $\mathrm{~F}$ & 49 & 60.33 & 1.60 & 1.62 & 23.56 \\
$\# 9$ & $\mathrm{~F}$ & 22 & 68.04 & 1.65 & 1.75 & 24.96 \\
\hline
\end{tabular}

Note: "Indicates a subject is overweight; ${ }^{* *}$ suggests a subject is obese. 
Table 3. 2. Summary of experimental conditions

\begin{tabular}{c|l}
\hline Variable & \multicolumn{1}{c}{ Level } \\
\hline Device & A portable respiratory flow recording device \\
\hline Subject & 9 cleaners from Monongalia General Hospital \\
& 1. Empty waste-empty waste and change trash bags \\
& 2. High dust-use a duster to clean the dust in high places \\
& 3. Sanitize- sanitize everywhere of the unit \\
Isolation Unit Work & 4. Spot clean-clean bed, chair, wall, window, door, etc. \\
(around 30-min) & 5. Clean restroom-clean stool, washbasin, bathtub, etc. \\
& 6. Dust mop-use a dry mop to clean the floor \\
& 7. Inspect work-inspect if anywhere need re-clean \\
& 8. Damp mop-use a wet mop to clean the floor \\
\hline
\end{tabular}


Table 3. 3. Average inhalation parameters in the field and lab based study

\begin{tabular}{lcccc}
\hline \multirow{2}{*}{ Parameter } & \multicolumn{2}{c}{ Average } & \multicolumn{2}{c}{ 95\% CI } \\
\cline { 2 - 5 } & Field data & Lab data & Field data & Lab data \\
\hline MV (L/min) & 32.5 & 22.5 & $(29.1,35.9)$ & $(21.0,24.0)$ \\
MIF (L/min) & 74.2 & 53.9 & $(66.0,82.4)$ & $(50.0,57.9)$ \\
PIF (L/min) & 106.8 & 82.1 & $(95.6,118.1)$ & $(74.2,90.0)$ \\
PIF $\max (\mathrm{L} / \mathrm{min})$ & 150.2 & 105.4 & $(126.6,173.9)$ & $(96.6,114.1)$ \\
PIF/MV & 3.33 & 3.80 & $(3.11,3.54)$ & $(3.54,4.07)$ \\
MIF/MV & 2.30 & 2.46 & $(2.20,2.39)$ & $(2.37,2.55)$ \\
f (breath/min) & 24 & 22 & $(22,26)$ & $(21,23)$ \\
TV (L/breath) & 1.37 & 1.04 & $(1.25,1.48)$ & $(0.94,1.14)$ \\
T (sec per min) & 26.4 & 25.3 & $(25.3,27.5)$ & $(24.2,26.5)$ \\
DC (100\%) & 44 & 42 & $(42,46)$ & $(40,44)$ \\
\hline
\end{tabular}


Table 3. 4. Theoretical MV, PIF, and PIF/MV under Speech and Non-speech Conditions

\begin{tabular}{cccc}
\hline Speech Condition & Parameter & Mean \pm SD & 95\% CI \\
\hline \multirow{3}{*}{ Non-speech } & MV & $35.1 \pm 4.6$ & $(32.1,38.1)$ \\
& PIF & $108.3 \pm 11.6$ & $(100.7,115.9)$ \\
& PIF/MV & $3.09 \pm 0.06$ & $(3.05,3.13)$ \\
\hline \multirow{3}{*}{ Speech } & MV & $28.1 \pm 3.6$ & $(25.7,30.5)$ \\
& PIF & $211.5 \pm 14.1$ & $(202.3,220.7)$ \\
& PIF/MV & $7.59 \pm 0.43$ & $(7.30,7.78)$ \\
\hline
\end{tabular}


Table 3. 5. Correlations of MV, MIF, and PIF with Age, Weight, Height, $A_{D u}$ and BMI

\begin{tabular}{lccc}
\hline \multirow{2}{*}{ Parameter } & \multicolumn{3}{c}{ Coefficient of correlation } \\
\cline { 2 - 4 } & MV & MIF & PIF \\
\hline Age (years) & -0.05 & -0.27 & -0.08 \\
Weight $(\mathrm{kg})$ & $0.69 *$ & $0.80^{*}$ & $0.74 *$ \\
Height $(\mathrm{m})$ & 0.21 & 0.28 & 0.00 \\
$\mathrm{~A}_{\mathrm{Du}}\left(\mathrm{m}^{2}\right)$ & $0.67 *$ & $0.79 *$ & $0.68^{*}$ \\
$\mathrm{BMI}\left(\mathrm{kg} / \mathrm{m}^{2}\right)$ & $0.69 *$ & $0.79 *$ & $0.78^{*}$ \\
\hline
\end{tabular}

Note: *Suggests coefficient of correlation is significant $(\mathrm{P}<0.05)$. 
Table 3. 6. Expression of inspiratory flow by age, weight, height, $A_{D u}$ and BMI

\begin{tabular}{clcc}
\hline Response & \multicolumn{1}{c}{ Equation } & R-Sq(adj) & P-value \\
\hline MV & $19.79+0.43 * \mathrm{BMI}$ & 40.32 & 0.039 \\
MIF & $41.94+0.42 *$ Weight & 58.84 & 0.010 \\
PIF & $59.45+1.62 *$ BMI & 55.36 & 0.013 \\
\hline
\end{tabular}


Table 3. 7. Different PIF percentiles measured in field and lab-based study

\begin{tabular}{ccc}
\hline Percentile & Field data & Lab data \\
\hline 95th & 156.6 & 117.2 \\
90th & 143.4 & 106.7 \\
80th & 129.2 & 94.3 \\
75th & 124.0 & 90.5 \\
70th & 120.3 & 87.0 \\
60th & 113.1 & 81.6 \\
50th & 107.6 & 77.3 \\
40th & 101.6 & 72.6 \\
30th & 96.2 & 67.7 \\
25th & 93.2 & 65.2 \\
20th & 89.5 & 62.4 \\
10th & 80.4 & 56.0 \\
\hline
\end{tabular}

Note: The percentiles come from 6031 breath cycles. 
Table 4. 1. $\mathrm{V}_{\mathrm{T}}$ for different exercises performed in both lab-based and field studies

\begin{tabular}{lc}
\hline Exercise & $\mathbf{V}_{\mathrm{T}}, \mathbf{L}(\mathbf{M e a n} \pm \mathbf{S D})$ \\
\hline Patient assessment & $1.03 \pm 0.29$ \\
Vitals & $0.96 \pm 0.21$ \\
IV treatment & $1.05 \pm 0.19$ \\
Changing linen & $1.10 \pm 0.24$ \\
Carrying weight & $1.10 \pm 0.21$ \\
Normal breathing & $1.01 \pm 0.22$ \\
Isolation unit work & $1.32 \pm 0.21$ \\
\hline
\end{tabular}


Table 4. 2. $\mathrm{V}_{\text {over }} \%$ for different exercises performed in both lab-based and field studies

\begin{tabular}{lccc}
\hline \multirow{2}{*}{\multicolumn{1}{c}{ Exercise }} & \multicolumn{3}{c}{$\mathbf{V}_{\text {over, \% }(\text { Mean } \pm \mathbf{S D})}$} \\
\cline { 2 - 4 } & $\mathbf{> 8 5} \mathbf{~ L / m i n}$ & $\mathbf{> 1 1 5} \mathbf{~ L / m i n}$ & $\mathbf{> 1 7 0 ~ \mathbf { ~ } / \mathbf { m i n }}$ \\
\hline Patient assessment & $36.66 \pm 5.28$ & $9.77 \pm 3.32$ & $0.56 \pm 0.16$ \\
Vitals & $11.01 \pm 3.58$ & $1.15 \pm 0.71$ & $0.00 \pm 0.00$ \\
IV treatment & $11.51 \pm 4.41$ & $0.69 \pm 0.41$ & $0.00 \pm 0.00$ \\
Changing linen & $26.28 \pm 6.18$ & $2.76 \pm 1.49$ & $0.00 \pm 0.00$ \\
Carrying weight & $18.59 \pm 5.79$ & $1.70 \pm 1.24$ & $0.00 \pm 0.00$ \\
Normal breathing & $4.67 \pm 2.66$ & $0.31 \pm 0.25$ & $0.00 \pm 0.00$ \\
Isolation unit work & $57.43 \pm 6.85$ & $15.67 \pm 6.09$ & $0.33 \pm 0.09$ \\
\hline
\end{tabular}


Table 4. 3. $\mathrm{T}_{\text {over }} \%$ for different exercises performed in both lab-based and field studies

\begin{tabular}{|c|c|c|c|}
\hline \multirow{2}{*}{ Exercise } & \multicolumn{3}{|c|}{$\mathbf{T}_{\text {over }} \%($ Mean \pm SD $)$} \\
\hline & $>85 \mathrm{~L} / \mathrm{min}$ & $>115 \mathrm{~L} / \mathrm{min}$ & $>170 \mathrm{~L} / \mathrm{min}$ \\
\hline Patient assessment & $5.83 \pm 0.99$ & $1.24 \pm 0.62$ & $0.05 \pm 0.02$ \\
\hline Vitals & $3.07 \pm 1.29$ & $0.32 \pm 0.14$ & $0.00 \pm 0.00$ \\
\hline IV treatment & $3.24 \pm 1.32$ & $0.15 \pm 0.11$ & $0.00 \pm 0.00$ \\
\hline Changing linen & $8.27 \pm 2.21$ & $0.75 \pm 0.58$ & $0.00 \pm 0.00$ \\
\hline Carrying weight & $5.80 \pm 1.88$ & $0.46 \pm 0.36$ & $0.00 \pm 0.00$ \\
\hline Normal breathing & $1.22 \pm 0.98$ & $0.05 \pm 0.05$ & $0.00 \pm 0.00$ \\
\hline Isolation unit work & $18.33 \pm 2.46$ & $4.33 \pm 1.82$ & $0.03 \pm 0.01$ \\
\hline
\end{tabular}


Table 4. 4. Estimated fifth percentile $\mathrm{PF}_{\text {over }}$ for loose-fitting PAPRs during different exercises

\begin{tabular}{lcc}
\hline \multicolumn{1}{c}{ Exercise } & $\mathbf{V}_{\text {dead }}=\mathbf{0}$ & $\mathbf{V}_{\text {dead }}=\mathbf{1 . 4} \mathbf{~ L}$ \\
\hline Patient assessment & 156 & $\infty$ \\
Vitals & $\infty$ & $\infty$ \\
IV treatment & $\infty$ & $\infty$ \\
Changing linen & $\infty$ & $\infty$ \\
Carrying weight & $\infty$ & $\infty$ \\
Normal breathing & $\infty$ & $\infty$ \\
Isolation unit work & 257 & $\infty$ \\
\hline
\end{tabular}

